Review paper

\title{
X-ray sources: 125 years of developments of this intriguing technology
}

\author{
Rolf Behling \\ XtraininX Technical Consulting, Norderstedt, Germany
}

\section{A B S T R A C T}

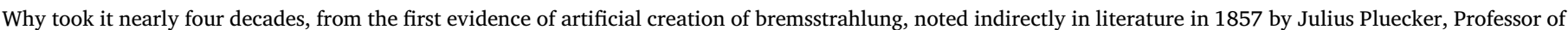

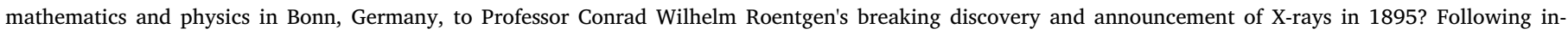

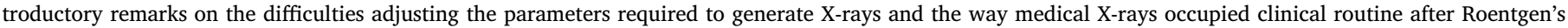

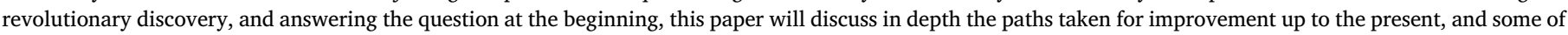
the culs-de-sac.

\section{Introduction}

Pluecker, working in Bonn, Germany, had studied and published magnetically deflectable light effects in the partial vacuum of Geissler discharge tubes as early as in the summer of 1857 , see $[45,13]^{1}$. He noticed and reported in his 1858 publication a greenish fluorescence on the glass wall. This is characteristic evidence of electrons hitting the wall and X-ray generation by cathode rays. Johann Wilhelm Hittorf, who Pluecker had mentored as a PhD student in Bonn, continued ten years later, investigating shadowing of the fluorescence by objects. Philip Eduard Anton von Lenard released cathode rays from partial vacuum into free air, see [1], chapter 1 . When repeating such experiments with great perseverance in Wuerzburg, Germany, Roentgen went to the extremes of the parameter space available at the time. A large Ruhmkorff inductor and flexible vacuum pumps allowed him to raise tube voltages and fine-tune the gas pressure. He could reduce the gas pressure to at least an order of magnitude below Geissler's, which is essential. So, he shifted the point of operation much further to the lowpressure branch of the so-called Paschen curve. A comparatively narrow banded combination of low residual gas pressure and voltage turned out essential to generate X-rays in detectable quantities. 125 years ago, Roentgen succeeded in weeks of tireless investigation, and, for the first time, correctly identified the physical background of X-rays. Eyewitnesses later confirmed the great difficulty of the task, see the Epilog. Others had experienced similar effects before, e.g. Philips Lenard, fogging photo plates, see [39], Arthur Goodspeed and William Jennings at the University of Pennsylvania, USA, in 1890, but were unable to elucidate them, see [50]. A single year after Roentgen sparking it, scientific, medical, and industrial development had exploded.

\section{Enabling technologies and physics in the 19th century}

The history of medical and industrial X-rays and the evolution of the technology of its sources has fascinated now for about 125 years, see e.g. $[2,5-10,12,26,29,30,41,43,48]$. Although alternative sources exist and despite of their deficiencies, see [6], vacuum electronics in the form of sealed-off X-ray tubes will remain the affordable sources of medical diagnostic X-rays also in the future, see $[3,5]$. This paper will track the various branches of the development of the technology, and briefly honor a few of those many scientists, developers, craftsmen, business leaders, and artisans, who have pushed innovation.

Repeating Pluecker's, Hittorf's and later Lenard's experiments on cathode rays, Roentgen recognized X-rays on Friday, November 8th, 1895 in the Physical Institute of the University of Würzburg, Germany, see Fig. 1. Pluecker had begun reporting his findings in 1857, see footnote 1and [45], pg. 89. The British Professor of Physics at the University of Cambridge, UK Joseph John Thomson qualified cathode rays in 1896 as magnetically deflectable beams of "electrons". As Roentgen discovered in 1895, X-rays were something different. Hard scattering of electrons impacting on the atomic nuclei of, first, glass targets turned out essential to generate those highly energetic X-ray photons which are capable of transitioning portions of a human body

\footnotetext{
${ }^{1}$ Extract from a report of the session of July 9th, 1857 of the Lower Rhine Society for Natural and Medicinal Studies in Bonn, published in the supplement to the Kölnische Zeitung, no. 201, July 22nd, 1857 (translated by the author): “...The tubes and balls, which the lecturer used for his experiments, were made by Mr. Geissler [remark: in Bonn, Germany] himself and contain various gases and vapors, through which, by means of sealed-in platinum wires, the discharge takes place. One of these tubes shows in a length of 16" at equal distances from each other about 400 black stripes, up to two lines wide. When the electric luminous flux with its dark stripes enters from a narrow tube into another sphere, it widens into a bright light mist in which one often sees dark layers, often not. If such a sphere, merging to both sides into narrower tubes, is placed on the approached anchors of an electromagnet, the electric light is either attracted or repelled, depending on the direction of the current and the polarity of the magnet. In the first case, the luminous flux entering the sphere runs out into a brightly shining peak, which descends to the poles, while from the other side the light flickers erratically...".
} 


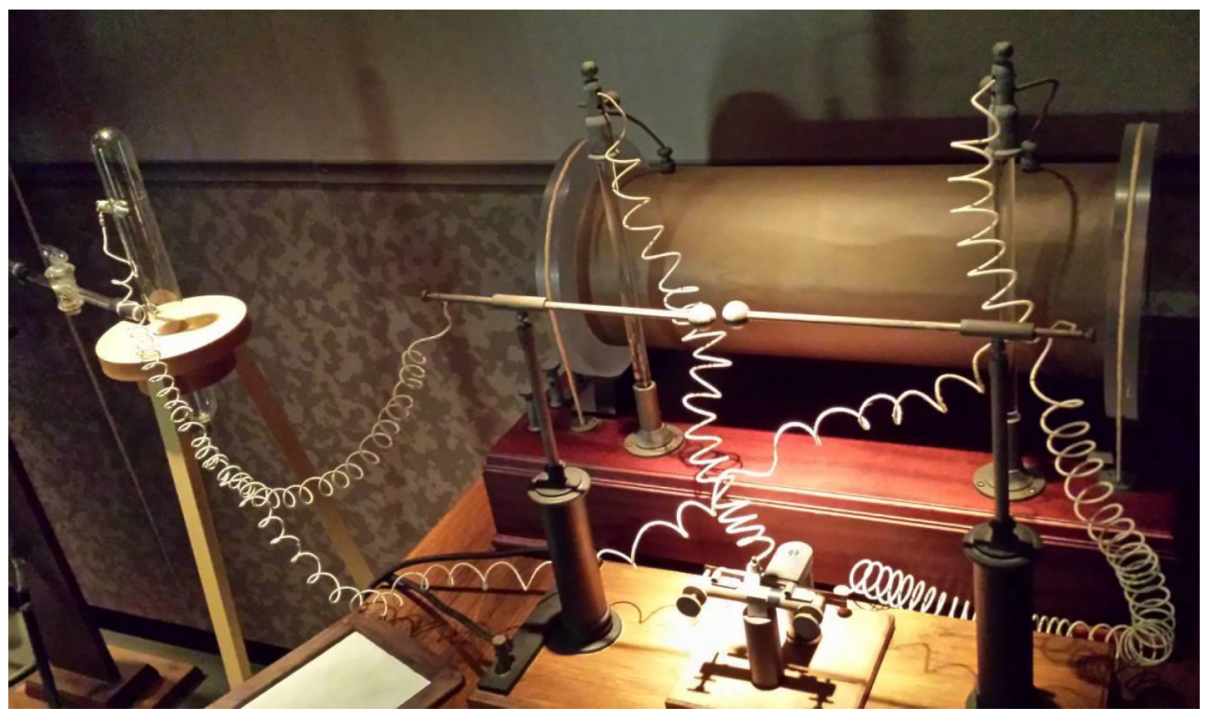

Fig. 1. Replica of C. W. Roentgen's first experimental equipment in his laboratory in Würzburg, Germany. It shows an actively pumped simple Crookes tube and a "large" Ruehmkorff inductor. Roentgen discovered X-rays at dawn of Friday November 8th, 1895. (Photo taken at the German Roentgen Museum, Remscheid-Lennep, Germany.) and taking up information, see e.g. $[5,15,44]$. Required ingredients are fast moving free electrons and a target material with highly charged atomic nuclei.

Ancient Egyptians had already studied high voltage associated with the electric eel, as early as 2750BCE By 1644, Evangelista Torricelli evacuated glass tubes with falling mercury. In 1657, Otto von Guericke attempted to separate large evacuated "Magdeburger" half spheres with horses and failed. In 1705 Francis Hauksbee, the elder, discovered sparks of light through partly evacuated vessels. William Morgan might well have generated X-rays already in 1785 when experimenting with vacuum insulation. Since the mid of the nineteenth century, voltages of tens of kilovolts at powers of tens of watts have become available. As said before, Julius Pluecker generated free electrons in partial vacuum ("cathode rays") from 1857. Johann Wilhelm Hittorf extended these experiments from 1869. Also, Sir William Crookes deflected electrons magnetically. Philip Lenard released them through extremely thin foils of metal into free air.

\section{Roentgen's discovery}

Roentgen used Crooke's or Hittorf's or Lenard's tubes, charged by a "large" Ruhmkorff inductor, see [46]. Under comparatively high vacuum in the tube and high peak voltage, he began noticing a glow of a remote scintillator screen, see $[15,37,44]$. Already five years earlier A. W. Goodspeed and his assistant W. N. Jennings Philadelphia, USA, had destroyed photo plates. They did not know at that time: It was by Xrays. Roentgen eventually identified the cause of the damage. He varied the tube voltage and - this was the key to success - the vacuum conditions in his tubes to the extremes at that time. Sealed Geissler tubes, which Pluecker had once purchased in Bonn, where he also worked, were suited to generate colorful discharge patterns of the Paschen type. To generate well visual effects, Pluecker operated in the high pressure regime of the so-called Paschen curves, typically called the "right" branch, where $\mathrm{p} \cdot \mathrm{d}$, the product of gap distance $\mathrm{d}$ and pressure $\mathrm{p}$, exceeds ca. $3 \cdot 10^{2} \mathrm{~Pa} \cdot \mathrm{cm}$. Depending on the size of the tubes and the gap between electrodes, the pressure varied by multiple orders of magnitude. High voltage was typically limited to a few thousand volts. Pluecker saw that the pattern of light emission depended on the strength and direction of external magnetic fields. It may be important in view of history of science that he reported greenish fluorescence of the glass wall, when the cathode rays hit, see [45], paragraph 35 . The summer of 1857 seems the first time that bremsstrahlung was generated artificially. High voltage was comparatively low, though. The glass will have absorbed almost all photons. Roentgen had better equipment, notably a more powerful high voltage source. He could vary the gas pressure with mercury pumps attached to the tubes he tried. He was able to fine-tune the pressure in a narrow span of a factor of three only and match high voltage with the different pressure levels. Fortunately, he used cardboard as a shield against ultra-violet light and possible cathode rays, which might emerge. The peak of the pulsing tube voltage from the large "Ruhmkorff" inductor was high enough to ignite the discharge even at rather low gas pressure of $1 \mathrm{~Pa}$. Before backscattering, electrons hit the glass with energies of a few dozen kilo electron volts. $\mathrm{X}$-rays emerged, for the first time clearly recognized.

$\mathrm{X}$-rays penetrated objects downstream of their obvious origin. Roentgen optimized detection technology and identified key characteristics of the newly discovered radiation in a period of weeks. Although he speculated and, in part, misinterpreted, he laid the firm ground for early diagnostic and therapeutic application of X-rays. Many of the effects, which he studied for the first time under controlled conditions, are still being employed.

Visual effects in discharges helped identifying and optimizing the parameters for X-ray production. Fig. 2 (a) shows the greenish glowing glass wall of a Crooke's tube with Maltese cross, evacuated, and operated to generate cathode rays and X-rays. Fig. 2 (b) and (c) are historic pictures of X-radiating tubes in operation, published in [23]. According to Professor Herrmann Gocht, they operate in good condition as indicated by the clear visual split between the tube halves. Tube design and electrical equipment resemble vacuum tubes and high voltage generators which Roentgen had used before. The oscillogram in Fig. 8 (d) shows that unconditioned high voltage from an inductor is alternating. Tubes discharged in both directions. The reverse current grew with the primary voltage from the batteries, raised on purpose to accelerate the magnetic charging of the inductor and to speed up imaging by enhancing the interrupter frequency. At higher reverse voltage, though, tubes aged faster by sputtering from the anode during the reverse phase and gas gettering effects. The fluorescence pattern changed. An area of false light (German terminology used by [23]: Gegenlicht, reverse light) appeared on the glass wall, caused by the reverse current (German: Schließungsstrom, closure current), as depicted in Fig. 2 (d). Fig. 7 depicts a valve, one of the many countermeasures taken. Instead, the greenish color, visible in Fig. 2 (e), signaled X-ray generation in a well-controlled fashion. Strikingly, current glass X-ray tubes fluoresce weakly blueish, see Fig. 46. Since many years, the yellow or green color has disappeared from modern tubes. In a private communication with Dr. Sándor Jeszenszky, retired director of the Hungarian Electrotechnical Museum, Budapest, Mr. Arno Preßler (1905-1990), son of the glassblower and owner of the Preßler glass instruments manufacturing 
a) Electron impact

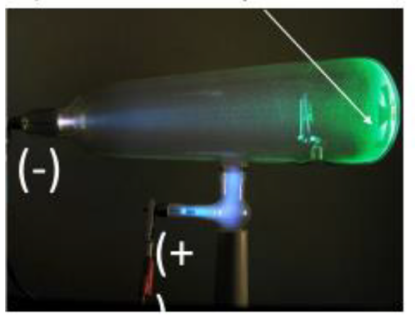

d)

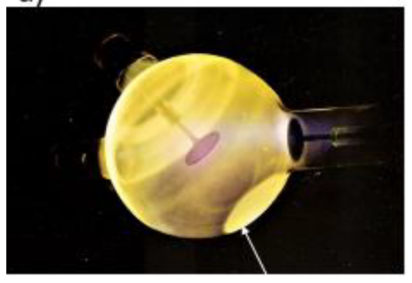

False light ("Gegenlicht") b)

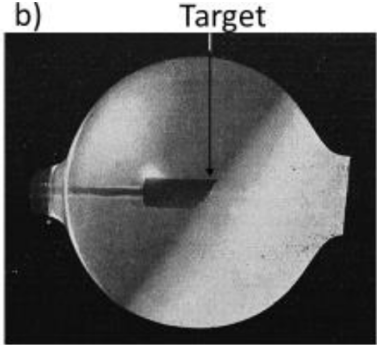

e)

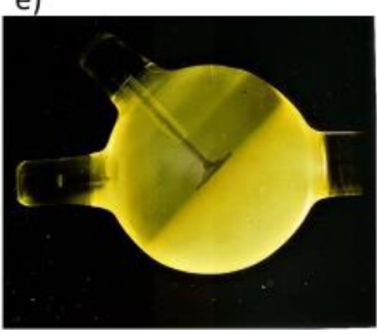

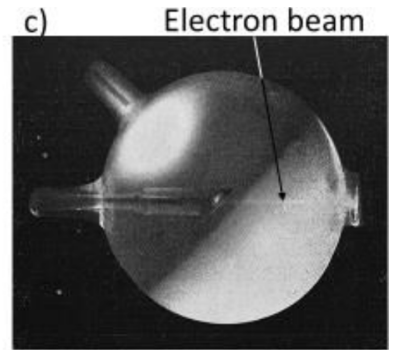

f)

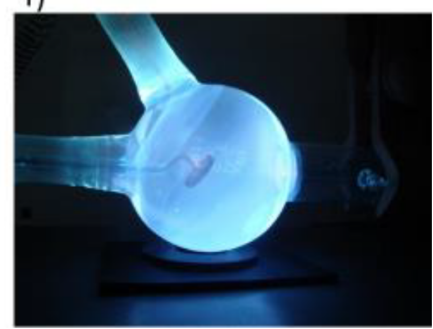

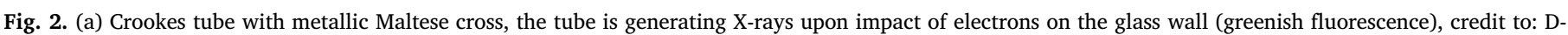

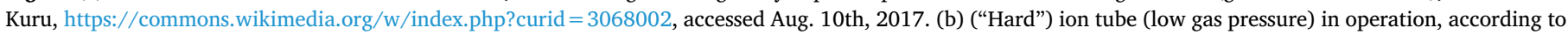

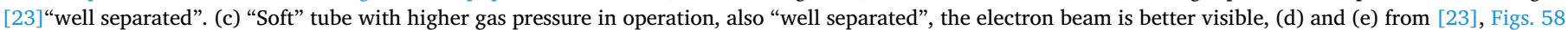

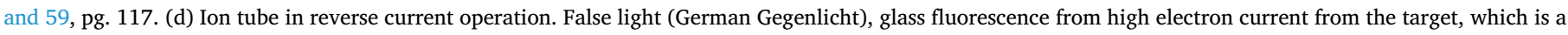

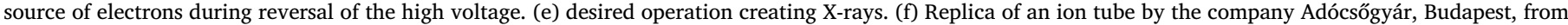

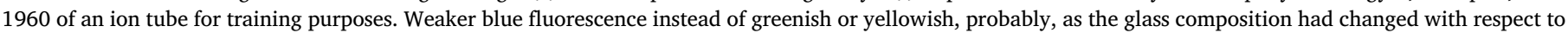
the older tubes. (d) to (f) Private communication with respectively by courtesy of Dr. Sándor Jeszenszky, Budapest, Hungary.

plant in Thuringia, Germany, Rudolf Preßler (1875-1935), reported that the green fluorescence disappeared unexpectedly in the $1930 \mathrm{~s}$ and changed into a weak blueish. Before, the green color of glass from iron oxides, was compensated by manganese oxide admixture. $\mathrm{Mn}^{2+}$ ions generated green fluorescence. Later, in industrial glass manufacturing, selenium compounds have been added instead for modern boron silicate glasses for X-ray tubes. This is said to have caused the change, as can be seen in Fig. 2 (f).

\section{Early clinical use and industrialization from 1896}

Within a first single year after the discovery, more than one thousand articles on X-rays were published worldwide. [42] reports that on January 12th, 1896 the first X-ray image were intentionally produced on the American continent at the Davidson College, North Carolina. This date has been questioned, however, see [25], who assigns the first radiograph of human anatomy to the Scotsman Swinton Campbell on January 13, 1896 . By February 3rd, 1896, a diagnostic X-ray of the broken wrist was taken at Dartmouth College, Hannover, NH, USA.

Upon initiative of the head of the first surgical department, Prof. Dr. Hermann Kuemmell, the earliest sustained installation of X-ray equipment globally in a public clinic was put in operation on March 20th, 1896 in the "New General Hospital" in Hamburg-Eppendorf, Germany (now UKE, see $[18,24,37,48]$ and Fig. 3). This story is characteristic for the enthusiasm of surgeons, scientists and industry leaders in those days. Kuemmell had sent his assistants Hermann Gocht and Gustav Opitz, see Fig. 3 (b) and (c), to downtown Hamburg, to see the glass blower C.H.F. Mueller, whose company was later acquired by Philips, The Netherlands. Gocht, Optiz and Mueller enthusiastically experimented with the new radiation and its sources and installed the first clinical equipment in a preparation room of the new operation theatre ${ }^{2}$.

\footnotetext{
${ }^{2}$ Translation from [24], page 779. Herman Gocht, recalling in 1914 the events, which happened eighteen years before: Meanwhile, March 20th, 1896, had arrived; on this day the first X-ray apparatus was put into service in the surgical department of Kümmell at the Eppendorf Hospital. Kümmell had acquired the
}

The building still exists; see Fig. 3 (e). In those days, key users had to master medical physics, plasma physics, high voltage electronics, and radiology. Gocht became a leading radiologist. Unfortunately, all three and many of their coworkers and staff died from radiation-induced illness.

Work in physics laboratories accelerated, as well. Less than a week after the first clinical installation in Hamburg, Siemens and Halske, Germany, filed the first X-ray tube patent, DE91028 on March 26th, 1896, see [41]. Fig. 4 shows an overview in the catalog from about 1900 and two samples of ion tubes from C.H.F. Mueller. Many other companies and began producing X-ray tubes, as well, see e.g. [34].

Reiniger, Gebbert and Schall AG, Erlangen, later Siemens, Munich, Germany, delivered tubes and scientific equipment to Prof. Roentgen as early as 1896 and contributed important innovations. The company of E. Gundelach in Thuringia, Germany, another competitor, claimed to have produced 45,000 tubes by April 1905, C. H. F. Mueller, Hamburg, Germany, 50.000. Machlett New York, NY, established in 1897, which became a division of Varian in 1989, now Varex, Salt Lake City, UT, USA, was probably the first producer in the United States, see [28]. Toshiba, Japan, began producing X-ray tubes in 1915, see Fig. 5. This Giba tube was the predecessor of a large variety of products from the company.

The number of concepts of different X-ray tube types exploded already in the very early days. Among these is the first concept for moving the target for heat dissipation. Fig. 6 is from a catalog of ideas from the year 1896, see [11]. Concept no. 4 depicts "Wood's" tube. Actual it sketches a rotating frame tube. Concept no. 4 has a concave cathode dangling from a flexible diabolo-type pulley, fixed in space by

\section{(footnote continued)}

Ruhmkorff apparatus (inductor) from the company Keiser and Schmidt in Berlin (Germany). It generated $25 \mathrm{~cm}$ long sparks (remark: this corresponds to a peak tube voltage of about $120 \mathrm{kVp}$, see [33], Fig. 1) with the help of a Deprez platinum circuit breaker. We used two existing accumulator batteries from Reiniger, Gebbert and Schall, Erlangen, (Germany), which were otherwise used for light and cauterization in surgical manipulations. Florence Mueller delivered the tubes to us. 
(d)

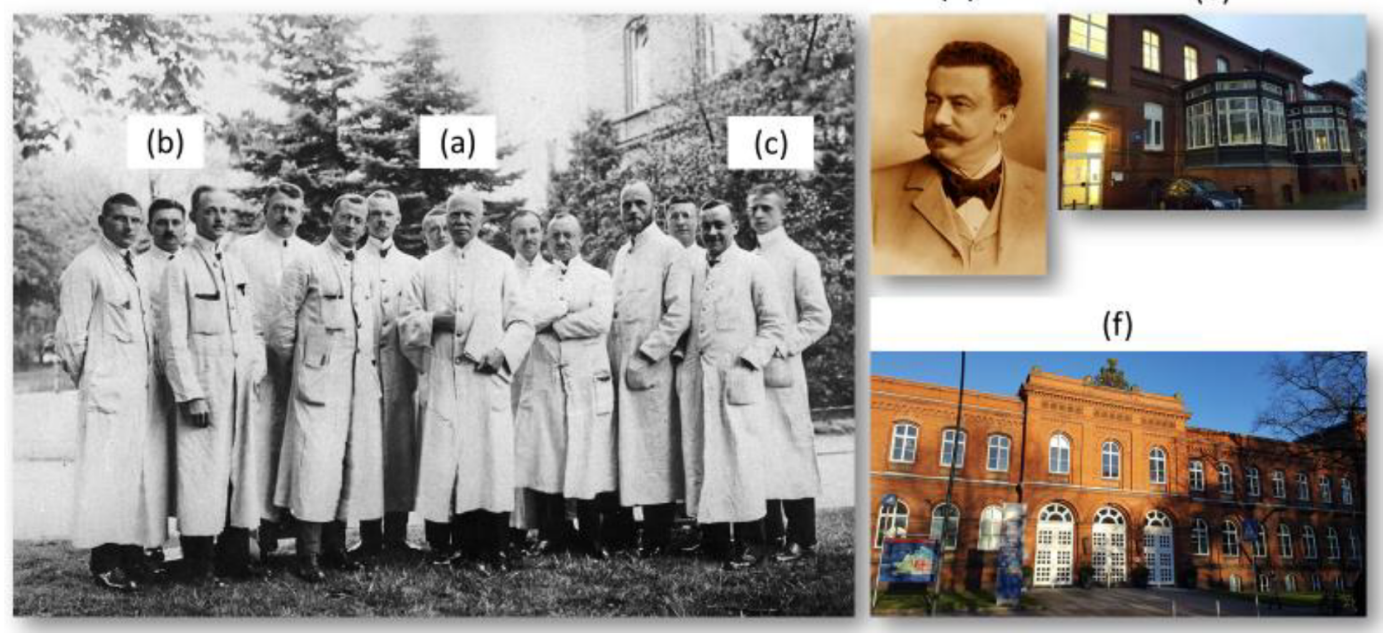

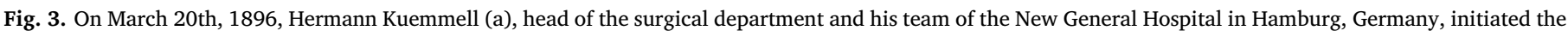

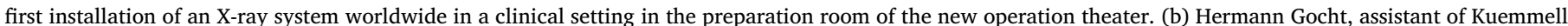

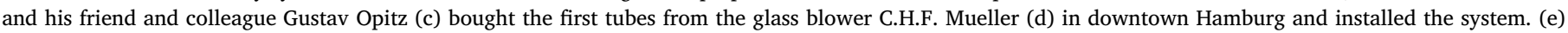

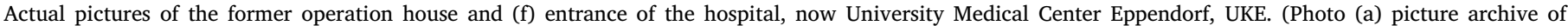
Medizinhistorisches Museum Hamburg, Germany, UKE).

a)

\section{C.H.F. Mueller catalog, around 1898}

$\int_{1} \int_{2}^{\infty} \underbrace{\infty}_{3}$

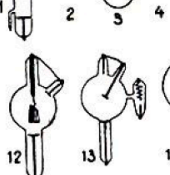
5

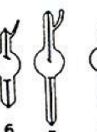<smiles>c1ccccc1</smiles><smiles>c1ccsc1</smiles>

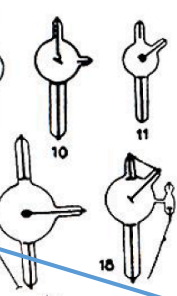

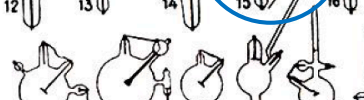
$\rightarrow(4)$

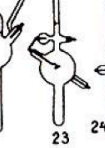

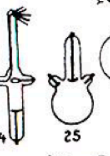<smiles>c1ccc2ccccc2c1</smiles>
Sis 19l ${ }_{20} / 21 / 22$<smiles>c1ccc(N(C23CC4CC(CC(C4)C2)C3)C23CC4CC(CC(C4)C2)C3)cc1</smiles>

28 22

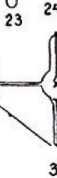

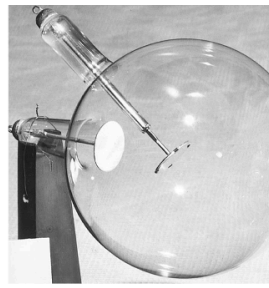

b) Gold metal tube,

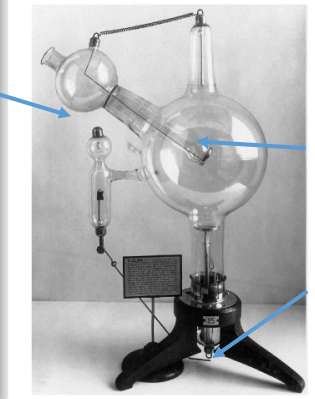
London 1901

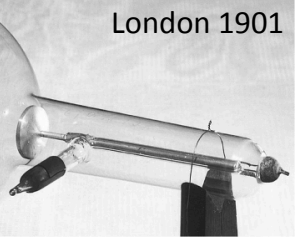

c) Water cooled Nr. 151898

Boiler

Spark-gap for automatic gas regulation
Fig. 4. Ion tubes produced by the C.H.F. Mueller AG, Hamburg, Germany (later Philips), about 1900. (a) Catalog from about 1900. (b) Mueller ion tube, which won the gold medal for the best tube out of 28 in the London Roentgen Society competition 1901. The tube is on exhibit in the Science Museum, London, UK. (c) First water cooled tube after Prof Dr. B. Walter (physicist, Hamburg Germany). The automatic gas regulator is activated with an adjustable spark gap when the tube voltage rises due to falling gas pressure inside the glass envelope.

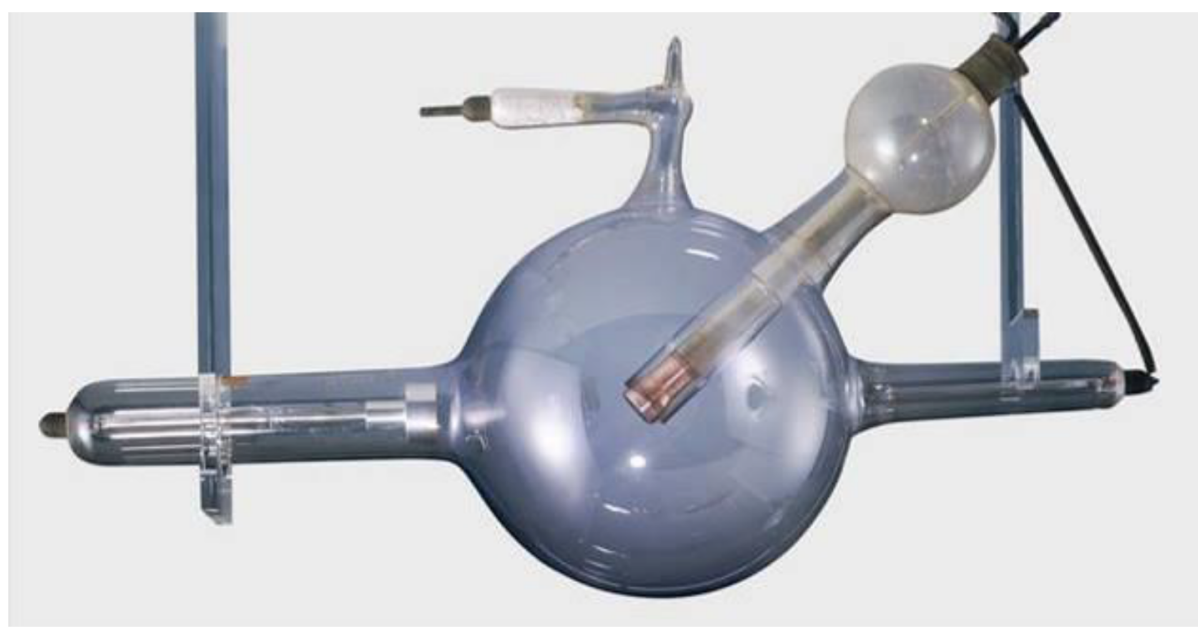

Fig. 5. Toshiba "Giba" x-ray tube, the first Japanese domestic x-ray tube, developed and commercialized in 1915 by Toshiba Denki, later Toshiba Electron tubes \& Device Co., Ltd (TETD, now Canon, Japan, group). Many types of $\mathrm{x}$-ray tubes have been developed originating from this "Giba X-ray tube". (Courtesy of Toshiba Science Museum.) 


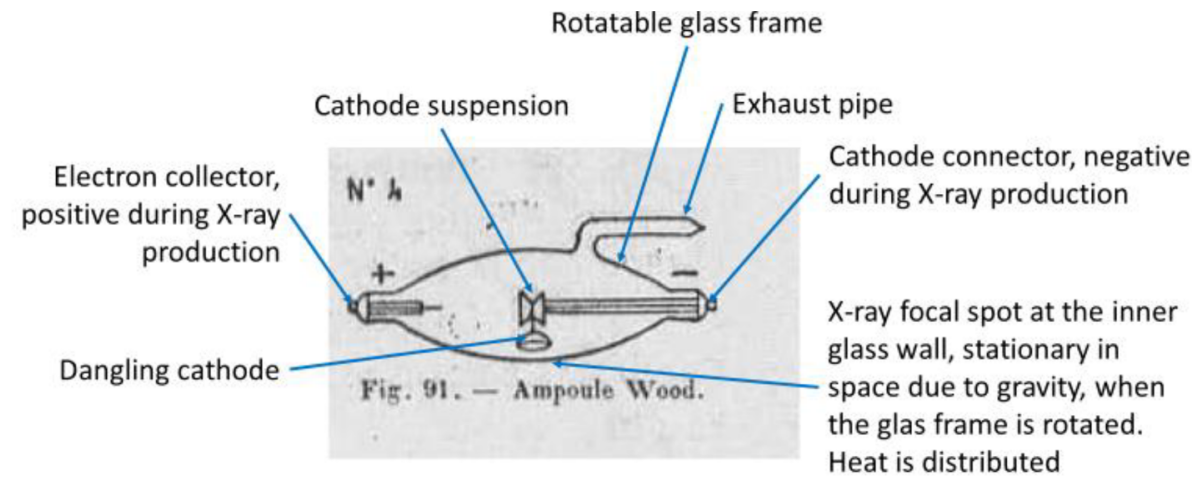

Fig. 6. Wood's tube concept, predecessor of rotating frame and rotating anode tubes, see also the concept comparison in Fig. 18, adapted from Breton(1896).

gravity. While rotating the tube about its longitudinal axis, the heat from electron impact is spread across a large portion of the glass wall.

The first glass vessels had a cylindrical shape, they were "tubes", as shown in the replica to the left of Fig. 1.

It was soon recognized that electrons, backscattered from the anode, hitting the glass at large flux density, tend to locally overheat the material and cause surface discharges. The diameter of the glass was blown up around the anode. The center portions of X-ray tubes became balls.

The high voltage source had to be capable to deliver at least $20 \mathrm{kV}$. Roentgen used a large "Ruhmkorff" inductor, as shown in Fig. 7, which produced a spark length of about up to $25 \mathrm{~cm}$ corresponding to about $120 \mathrm{kV}$. Driven by lead batteries and interrupters, these inductors generated pulsing voltage of positive and negative polarity, as can be seen in Fig. 8. It was soon recognized, that "reverse" voltage and current, during the phase when no X-rays were created, caused sputtering of anode material and early tube failure. A valve shown in the upper right corner of the figure solved this problem. Reverse voltage dropped across the valve instead of the X-ray tube, while highly conductive in the "right" phase. Such valves became obsolete with the invention of "gas free" tubes with thermionic cathodes, as they are nearly perfect diodes themselves, see Chapter 4.

DC influence machines became a competing alternative to inductors and interrupters, as depicted in Fig. 9. High voltage generators developed in parallel to X-ray tubes.

Fig. 10 illustrates some of the pitfalls, which surfaced. Excessive electron current density in an ion tube nearly destroyed the anode by surface melting. The original C.F.H. Mueller tube shown in Fig. 10 (a), serial number 82456, was produced around 1910, and had been in use. During the phase of negative charging of the cathode by the inductor, residual gas was ionized by electrons moving through the thin gas in the direction of the positive electrode. Upon ionization, the number of electrons grew exponentially along the way, characterized by the first Townsend coefficient. Massive positive ions were left behind, while electrons escaped fast. Ions were drawn to the cathode and released more electrons upon impact, a process characterized by the second Townsend coefficient. While processes in Geissler tubes of the $1850 \mathrm{~s}$ were well described by the first Townsend coefficient, the second became the dominating parameter for X-ray production. Low enough gas pressure was required to allow electrons to gain sufficient speed before the next collision with a gas molecule and high-energy impact on the target. For proper working, a characteristic dark space had to extend throughout most of the tube. Ions impacting on the cathode cup at the right in Fig. 10 (d) released up to a dozen electrons, depending on the surface condition. The electrostatic field defined by a concave cathode cup accelerated the electrons between cathode and anode at the left in Fig. 10 (d) and focused them into the focal spot on the copper target which may be coated by platinum (not known). (b) The melting pattern of an overheated focal spot is clearly visible. As the metal evaporated and chemically reacted with residual gas, and as ions were implanted in the cathode, the gas pressure inside the sealed vessel dropped over

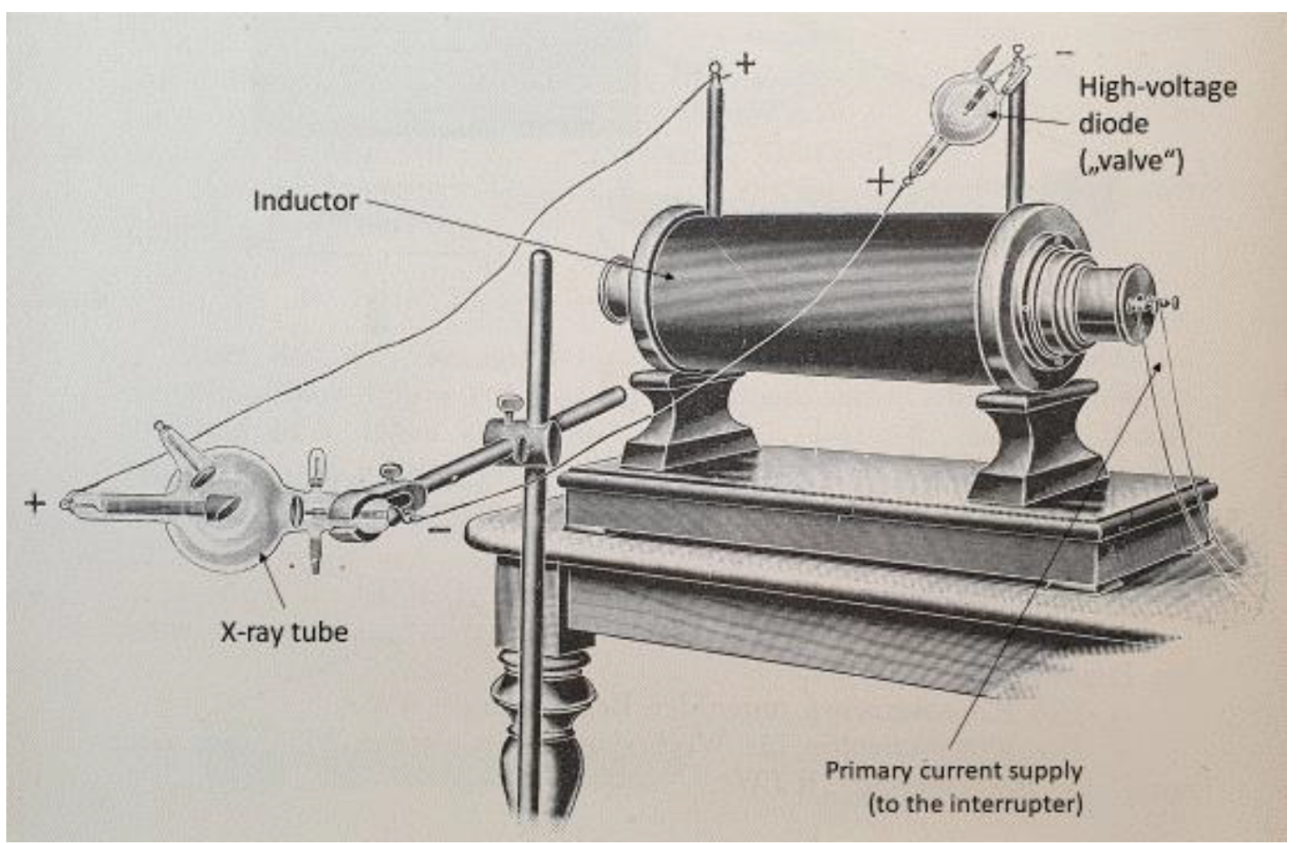

Fig. 7. High voltage inductor with a "valve" attached in series with the X-ray tube. The ion cathode X-ray tube resembles a diode. If that characteristic of an individual tube is insufficient to suppress reverse currents, it is advised to connect a suitable valve tube series, in which reverse voltage cannot ignite an ionic discharge. Taken from [1], fig. 97. 
a)

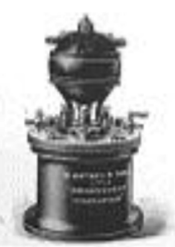

b) Primary

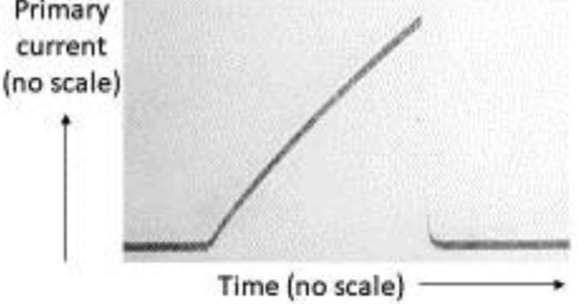

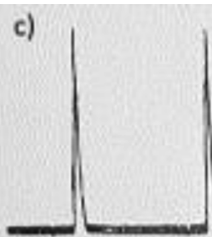

d)

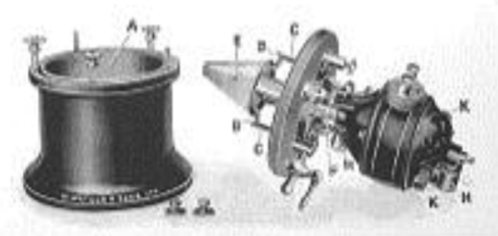

$\sim+60 k$
Current.

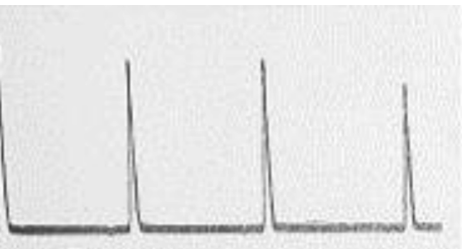

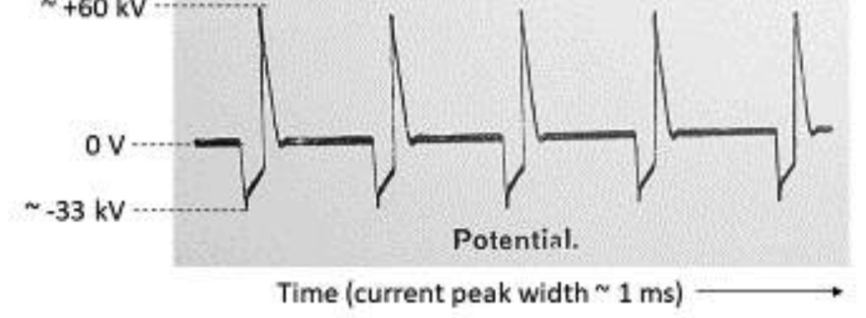

Fig. 8. Typical voltage and current waveforms at an inductor. (a) "Dreadnought" Hg interrupter from the price list of (W. Watson and Sons. Watson \& Sons, Ltd, 1916) (b) Primary current (no scale given) of a 13 in. coil able to deliver a 10 in. spark (120 to $140 \mathrm{kVp}$, see [33] Fig. 1), operated with a Hg-oil breaker (taken from Salomonson, Journal of the Roentgen Society, 1911, cited after [31], Fig. 32. (c) Secondary current (no current scale given, peak width about 1 ms) through a medium vacuum tube. (d) High voltage. Observe the narrow peak of about $60 \mathrm{kV}$ (at this point X-rays are produced with current flowing) and the broad peak of reverse voltage.

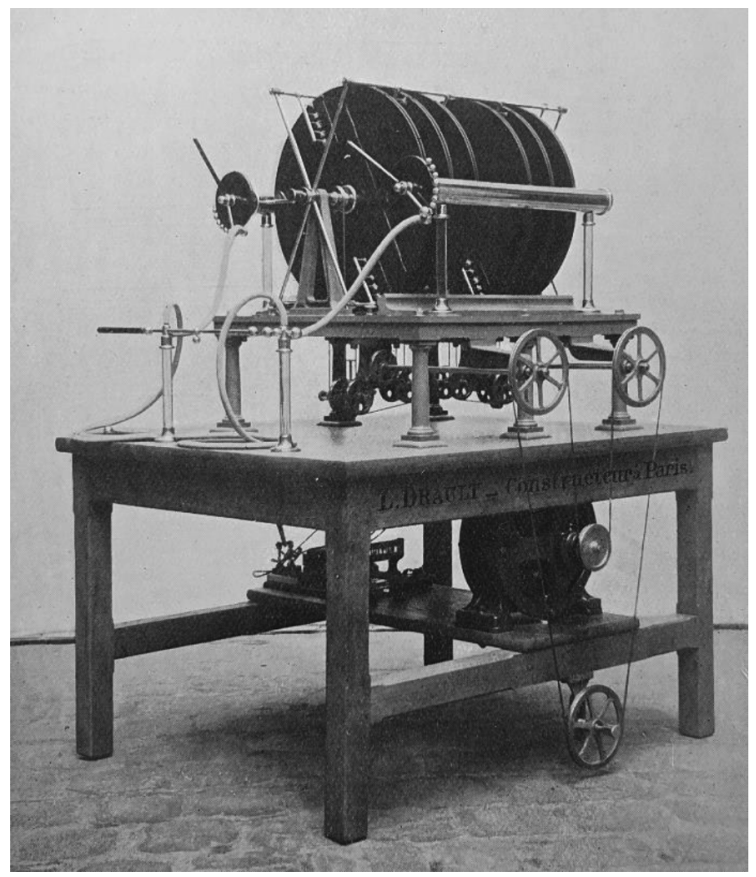

Fig. 9. Influence machine - L. Drault Paris, ca. 1916, from [49]

time. A sealed "soft" tube turned "hard". The high voltage required to maintain the discharge had to grow. The intensity peak of the X-ray spectrum shifted to higher energies. Due to higher transparency, soft tissue did not deliver good contrast anymore. It turned out, that for a given tube geometry the entire medical X-ray spectrum was covered by a change in gas pressure by only a factor of three. This is rather narrow a band in vacuum physics, which typically deals with orders of magnitude. Manufacturers devised sophisticated countermeasures to finetune the gas pressure. Gas releasing material in a remote appendix of the tube, see Fig. 10 (c) was heated to re-fill the mobile tube such that it was "softened" again. The tube was then able to spark discharges at reduced high voltage and deliver photons with lower energy.

Radiographers added clinical aspects. Fig. 11 demonstrates the ingenuity at the time, an ion tube for stereoscopic viewing. Fig. 12 depicts the viewing geometry (left) and an early attempt of augmented reality, using images like the ones in Fig. 13. The first 3D images were made, the predecessor to today's computed tomography (CT), although their operating principle is completely different. Stereoscopy is based on two images taken with traditional central projection, while CT reconstructs 3D images numerically from hundreds of projections, a whole new way of imaging. CT was suggested by Gabriel Frank in Budapest, Hungary, in 1938, and first patented by the company C.H.F Mueller, which we know as producer of X-ray tubes and systems, under DE693374C as "Verfahren zur Herstellung von Koerperschnittbildern mittels Roentgenstrahlen" (method to produce volume slice images by X-rays). After the German occupation, Gabriel Frank died in 1944 in a labor camp at the front line. The patent was forgotten.

Radiation quality was another aspect. Soft radiation was asked for in skin therapy and for imaging of small objects with low contrast. Lindemann brothers in Berlin delivered highly transparent glass. Elements of high atomic number (in brackets), in the mostly used Thueringer Waldglas" (wood glass from Thuringia, where many glass blowers originated), see [38], pg. 181, sodium (11) silicon (14), potassium (19) and calcium (20), were replaced by bohrium (5), lithium (3) and beryllium (4). Fig. 14 from a Mueller catalog shows a Lindemann glass insert as X-ray window, the predecessor of modern beryllium metal windows. However, radiation with high intensity of lowenergy photons can be extremely harmful. While the glass wall of a small size ion tube had a thickness of about $0.6 \mathrm{~mm}$, which corresponded to about the same X-ray filtration as aluminum, modern standards for general radiography require X-ray filters of at least $2.5 \mathrm{~mm}$ aluminum equivalent.

\section{Victims of X-rays and safety measures}

The low power rating and low duty factors of short X-ray pulses from ion tubes, see Fig. 8, tempted physicians to use all photons they could get to speed up the acquisition. The current minimum required filter of $2.5 \mathrm{~mm}$ aluminum for general radiography reduces the hazardous skin dose by between one and two orders of magnitude. Today's high-power tubes allow to image at even much less patient dose with filters of up to $0.9 \mathrm{~mm}$ copper for angiography, e.g. $1.2 \mathrm{~mm}$ titanium or relatively thick tin or gold filters for computed tomography. Ironically, high tube power is a prerequisite for low patient X-ray dose. According to [33], skin dose for pelvic examinations could be reduced 400 times over the years.

Biological harm soon became obvious, see [42]. Many of the 

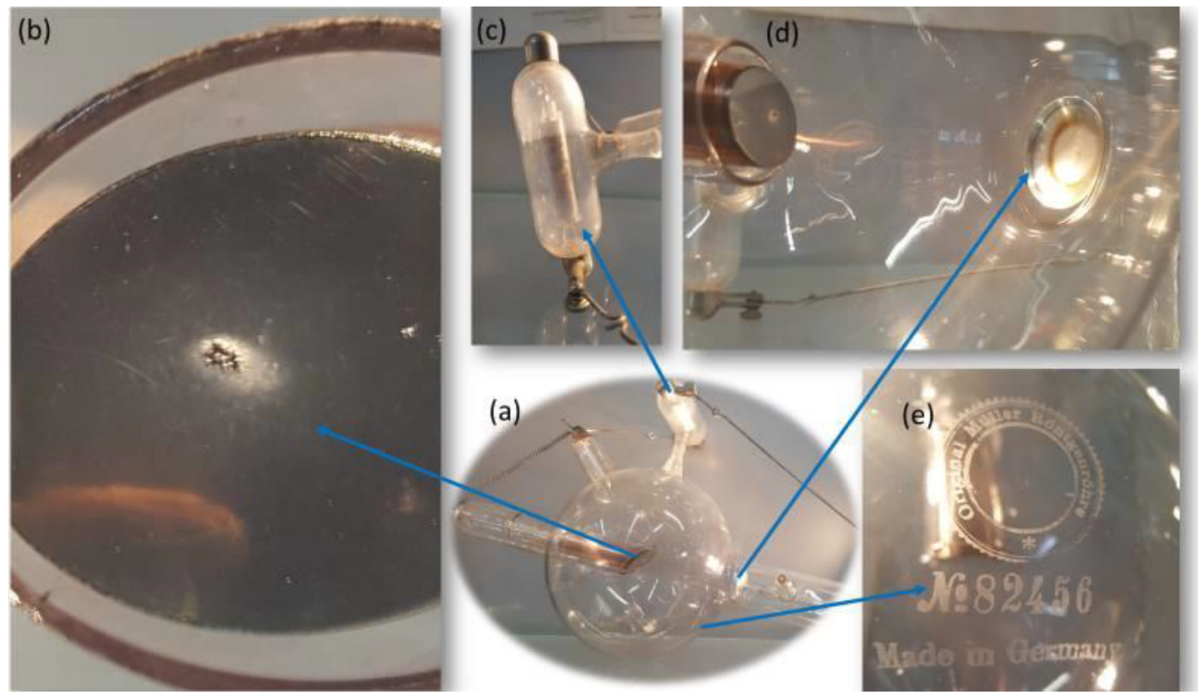

Fig. 10. (a) Ion tube akin the one depicted in Fig. 4. (b) Close-up view of the target. Repeated heavy electron impact overloaded the ellipsoidal focal spot. Melting and re-solidification led to cracking of the surface. (c) Regulator for gas production from heated potassium hydroxide, which engaged automatically when the discharge between anode and cathode ceased at insufficient gas pressure and the inductor voltage exceeded a predefined level. (d) The concave cathode cup shows signs of oxidation and areas cleaned by ion impact. (e) Production label and serial number 82,456 of the C.H.F. Mueller AG, Hamburg, Germany (later Philips).

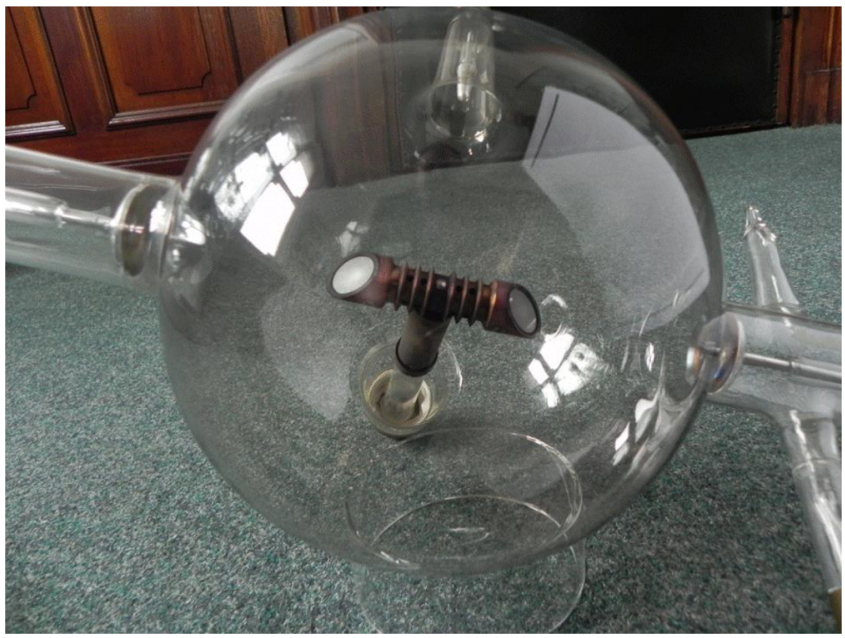

Fig. 11. Ion tube for stereoscopic imaging from 1912 after Dr. Fürstenau produced by the H. Bauer GmbH, Jena, Germany or Radiologie GmbH, Berlin, Germany. (Picture taken at the Siemens X-ray tube museum Rudolstadt, Germany.) pioneering individuals suffered and died from cancer. 404 victims and casualties have been reported by 1992, see Molineus W, Holthusen H, Meyer H (1992), Ehrenbuch der Radiologen aller Nationen, cited after [32]. X-ray imaging with ion tubes was artistry. Some radiographers sacrificed their health when adjusting the equipment by imaging their hands before exposing patients. The exhibit of the cancerous hand of a radiographer can be seen at the German Roentgen Museum in Remscheid-Lennep, Germany. Electrical shock was another cause of injury. The increasing quest for reduction of the dose of ionizing radiation resulted in improvements of the X-ray beam quality by X-ray filters and radiation shields against primary radiation. X-ray sources were encapsulated, measures against scattered radiation taken. High voltage supply was shielded. Improved safety standards were stipulated. Over the years, X-radiation became increasingly monochromatic. Powerful angiography tubes, like the Philips MRC 2000508 from 1990, shown in Fig. 43, with liquid bearing cooling and a large anode disk of $200 \mathrm{~mm}$ diameter allowed for enhancing the thickness of the X-ray filter, see [27], while the workflow has been even improved. For a comparison of spectra and intensities see [5], Figure 3.5.

\section{High vacuum vs. semi-vacuum}

The electrical X-ray conversion factor for bremsstrahlung (X-ray a)

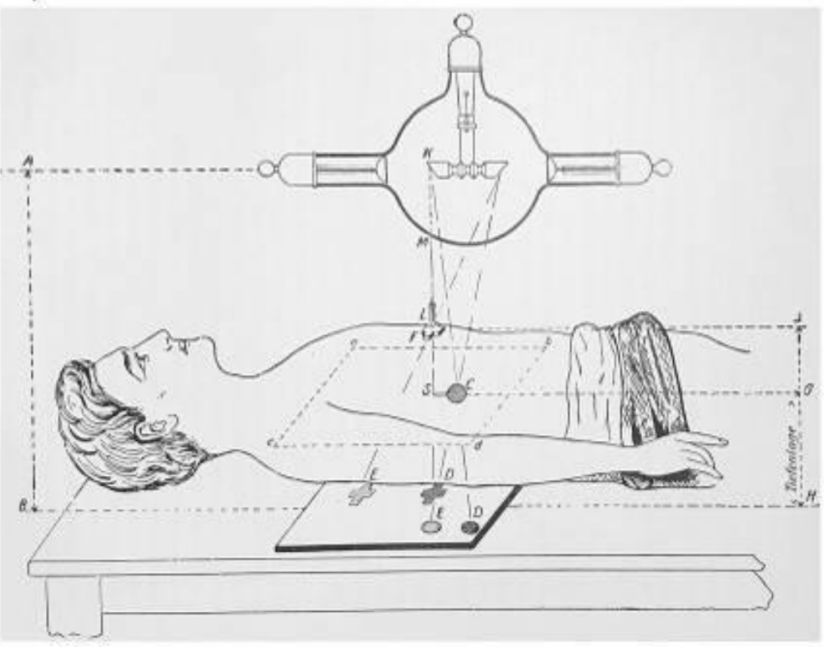

b)

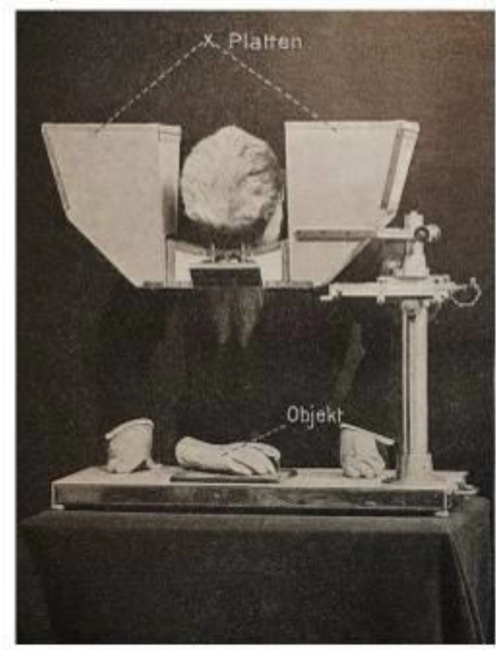

Fig. 12. (a) Stereoscopic viewing and (b) augmented reality in 2013, from [1], figs. 331 and 303. The object view in (b) is superimposed to stereoscopic X-ray images. 


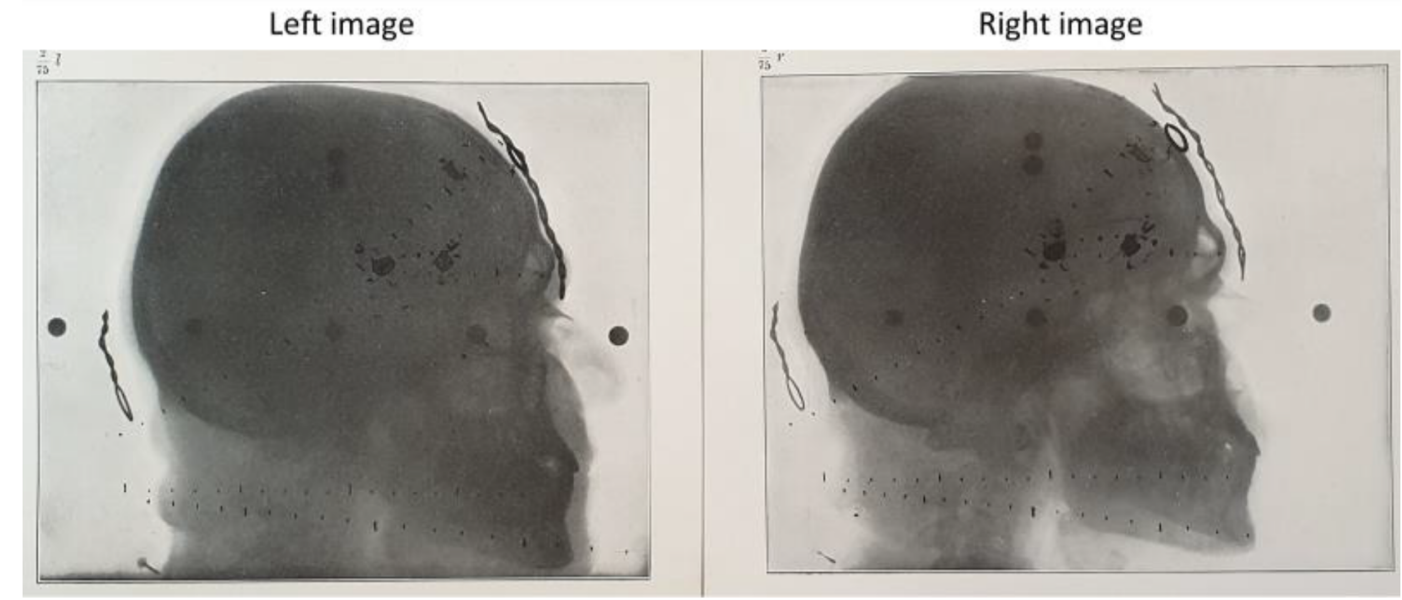

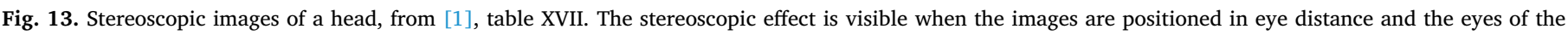
viewer are aligned in parallel.

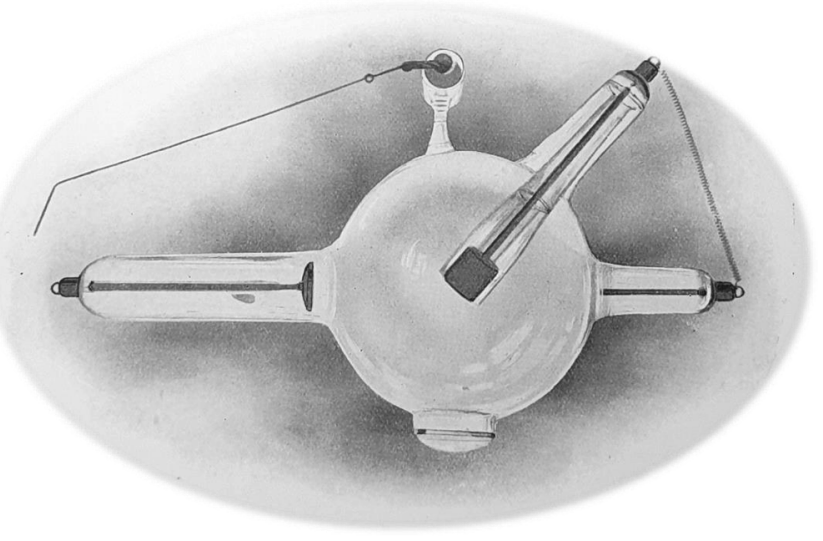

Fig. 14. Mueller tube, series, 13a, with Lindemann low-z glass window (bottom), ca. 1916, copied from[49]

intensity versus electrical power) grows with the square of the tube voltage. In addition, when operating an ion tube at low-pressure, its current rises steeply with high voltage. Both factors combined, X-ray intensity and penetration were related in a very unfavorite manner ${ }^{3}$. Ideal would have been a kind of anti-correlation to optimally employ the thermal capacity of the focal spot area. Higher tube voltage, which causes a harder photon spectrum with better penetration of the object, would allow for lowering the current.

Already by 1882 , the German physicist Eugen Goldstein had successfully maintained gas discharges for the production of electron beams at comparatively low gas pressure by heating the cathode, see [14]. But, given the required temperatures of at least $1000^{\circ} \mathrm{C}$ to provide for full electron current, stable emitter material was missing. Instead, most electrons from the cathode were released by ion impact to bear the main discharge. As many others, Julius Edgar Lilienfeld and William David Coolidge aimed at "softening" the X-ray tubes. Lilienfeld attached an incandescent lamp to an ion tube. Fig. 15 depicts one of the many Lilienfeld tubes produced. A comparatively weak thermionic cathode, shown in Fig. 15 (b), comprised a heated filament and sent a

\footnotetext{
${ }^{3}$ See [23] , page 114, translated from German: "Of course, the evacuation of the tube can now be pushed ever higher, so that currents of the greatest energy are ultimately required to pass and excite the tubes. The resulting $X$-rays become more and more intense, the penetration becomes so strong that the bones hardly cast a shadow, so that we cannot speak of an impressive differentiation of the bones and soft tissues anymore."
}

small electron current through an auxiliary anode ring through a hollow cathode to pre-ionize the residual gas in the tube. This process ignited and controlled the main gas discharge between cathode and anode inside the pink colored glass envelope shown at the bottom of Fig. 15 (a). The amplified electron bombardment out of the main discharge on the tungsten inlay in copper generated high X-ray flux at low voltages. For the first time, Lilienfeld decoupled tube voltage, the X-ray spectrum and image contrast, and tube current, the X-ray intensity, far better than the gas regulator.

Since 1905 William David Coolidge, who had before studied at the same institution as Lilienfeld, the University of Leipzig, Germany, had been working at the GE Research Laboratory in Schenectady, NY, USA, primarily on incandescent lamps. Employing his invention of light emitting ductile tungsten wires, he demonstrated a simplified X-ray tube publicly on December 27, 1913 for the first time in New York City at a dinner party given in his honor by Dr. Lewis Cole. Cole was the first physician to have his office equipped with the new tube. The full tube current was generated by a heated tungsten wire even at low tube voltage. A gas discharge became obsolete. Instead, the tube was highly evacuated. The tungsten wire withstood the required temperatures of about $2000{ }^{\circ} \mathrm{C}$, see [5]. Coolidge cooperated with Irving Langmuir (Nobel Prize for Chemistry 1932) at GE, who had graduated from the University of Göttingen, Germany in 1906. Coolidge was able to reduce the gap between anode and cathode to avoid electronic space charge. Xray imaging became far better controllable. Fig. 16 shows an ancient exhibit in the GE X-ray tube museum in Schenectady, NY, USA. Fig. 17 portrays Langmuir, Thomson visiting, and Coolidge at GE Research in 1923.

Ion tubes were still improved too. In 1916, the Victor X-ray Company of Chicago, IL (later to be acquired by General Electric, USA), produced ion tubes filled with hydrogen to reduce sputtering from electrodes, see Fig. 33, and claimed to improve durability, high voltage stability and shrink the parallel spark gap. Reportedly there were instances of cold cathode tubes being employed as late as the $1960 \mathrm{~s}$. In the meantime, thermionic cathodes have taken over. There have been many attempts to lower the temperature of the electron emitter by material with lower work function. The work function characterizes the energy supply required for the electrons to leave the metal. Barium and thorium and their oxides were tried. These and materials with similar effect are in use for vacuum electronic devices as klystrons, switching and amplifier tubes etc., see [19-20,21]. But tungsten has remained the electron emitter material of choice in the chemically and physically harsh environment of an encapsulated X-ray tube. (In the meantime, field emission cathodes have captured some niche space for stationary anode diagnostic X-ray tubes.) The new technical simplification of the 


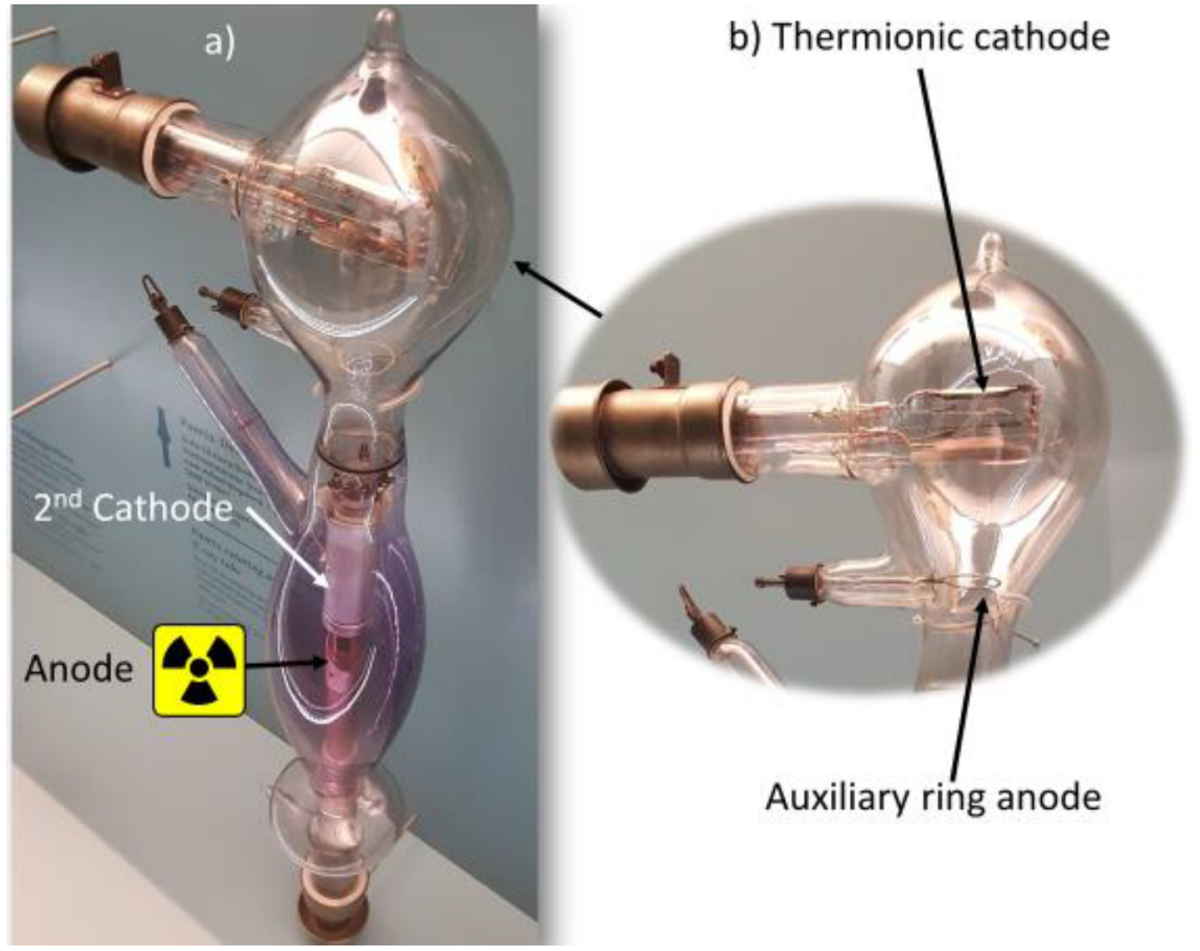

Fig. 15. (a) Lilienfeld ion X-ray tube with thermionic electron production to pre-ionize residual gas. (b) Thermionic electron X-ray "softener", an electron source with auxiliary anode to pre-ionize the residual gas. This model marks the transition between ion tubes and high vacuum tubes. (Photo taken at the German Röntgen Museum, RemscheidLennep, Germany.)

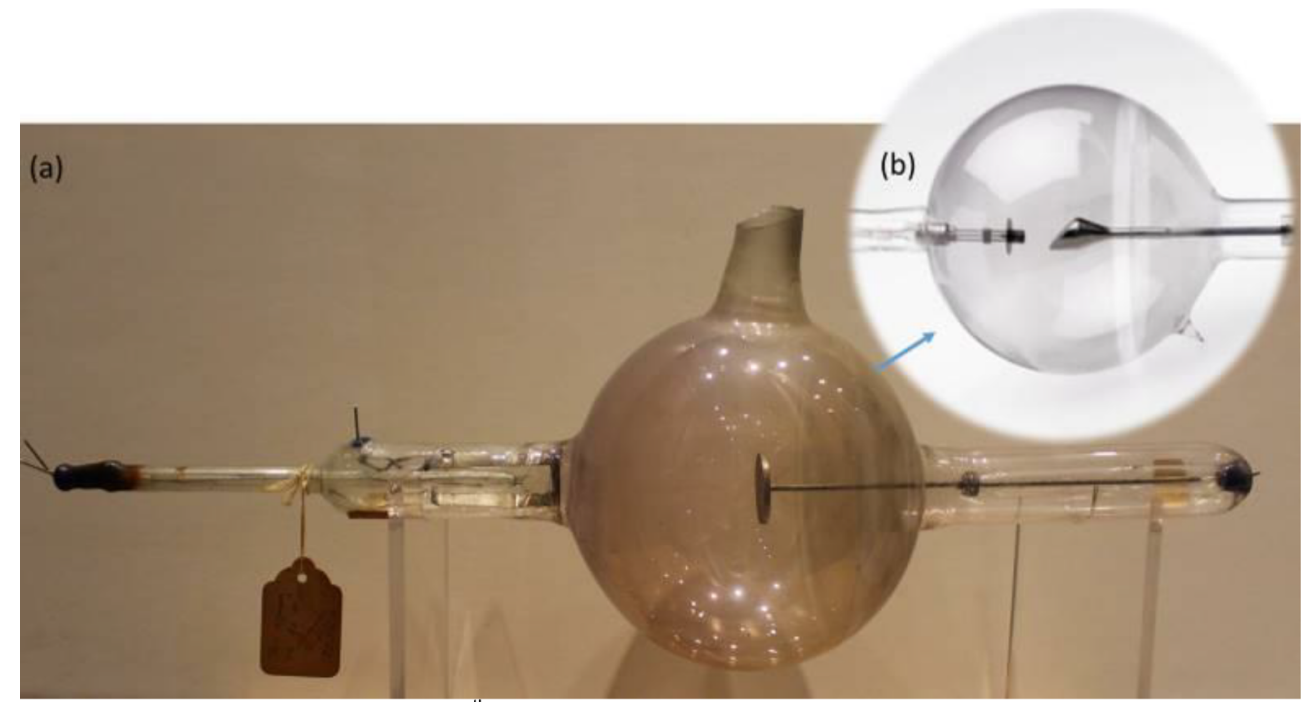

Fig. 16. Photo of one of the original experimental X-ray tubes from April 1913 used by W.D. Coolidge at the GE Research laboratory (Schenectady, NY, USA). It comprised a tungsten thermionic emitter inside a highly evacuated sealed glass envelope. This concept allowed for very stable operation and repeatable results during imaging. For the first time, X-ray production was easily controllable by setting tube current independently from penetrating power and image contrast, which are a function of the tube voltage across the anode-cathode gap. As other manufacturers did before, tungsten was used as target material. (b) Close-up photo of a series production unit delivered from 1914. (Pictures courtesy of GE).

workflow revolutionized the profession of radiographers. Before, the selection of the right ion tubes and adjustment of the technique factors required high technical skills. Radiographers had to be both surgeons and physicists in medicine. The inventions of Lilienfeld and Coolidge marked the split between radiologists, medical physicists, and engineers.

\section{Goetze's line focus}

The typical imaging geometry comprises a detector in about a meter distance from the X-ray source. Thus, the X-ray fan beam is only in the order of $10^{\circ}$ to ca. $20^{\circ}$ wide in axial direction. The surgeon O. Goetze concluded from the nearly isotropic polar distribution of X-ray intensity from the anode and the fact, that we use only a small portion of the generated X-rays, that it would be beneficial to take them off under a grazing angle. He proposed an axially elongated physical line focal spot, which maintains its (apparent) optical shortness when seen from the patient perspective. Fig. 36 shows a mapping of a rectangular Goetze focus on the damaged target of a rotating anode tube. Goetze's invention from 1918 was a great advantage for the Mueller company, who produced line focal spots from 1922. Compared with a conventional elliptical focal spot the thermal capacity of the anode and the space charge limited electron current grew by nearly an order of magnitude. Line foci have become standard. The anode angle is always minimized to maximize power rating and electron emission capability. Roentgen's first anode was the X-ray transparent end portion of a glass tube with an "anode angle" of about $90^{\circ}$. He took X-rays off normal to the glass wall. As the available tube current grew, the distance between tube and detector could be enhanced. This allowed for taking the X-ray off more closely to the anode shadow. The line-focus concept finds its limit by the so called "heel effect". X-rays emerge from 2 to $3 \mu \mathrm{m}$ below the surface and pass a few tens of micrometers of target material, typically tungsten. Thus, a few degrees close to the anode shadow, the X-ray intensity drops by intrinsic attenuation. The decrease of intensity, 


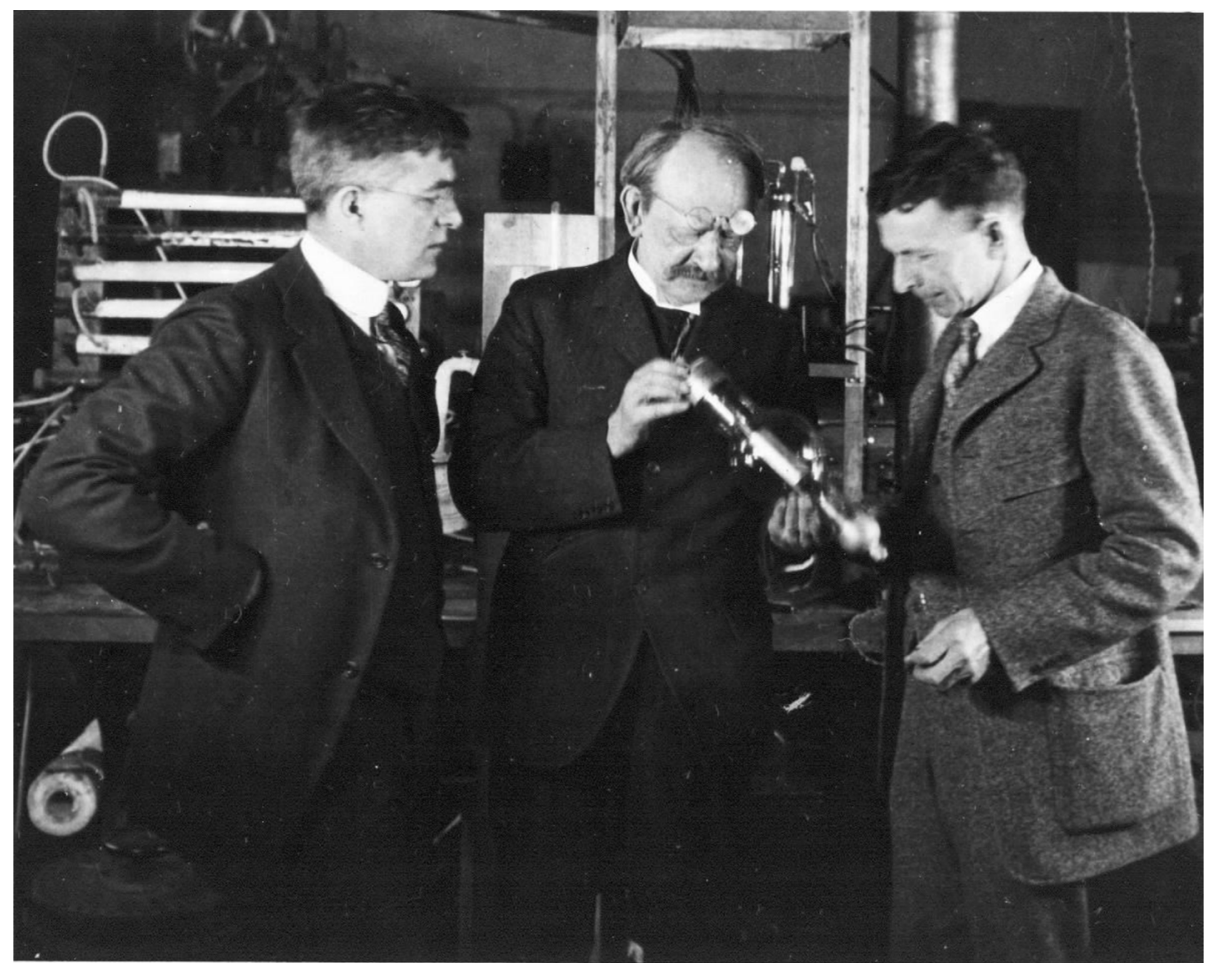

Fig. 17. I. Langmuir (left), W.D. Coolidge (right) from GE Research, Schenectady, NY, USA in 1923. J.J. Thomson (middle), who discovered the electron, visiting. (Picture courtesy of GE).

\section{Rotating frame}

a) 1896 Wood's tube

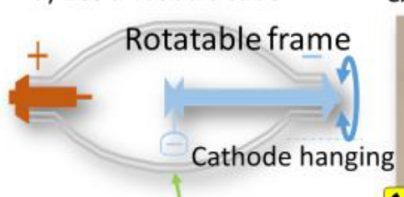

- Focal spot

b) Siemens, from 2003

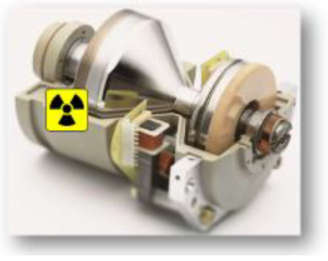

(c) 1930 Siemens experimental

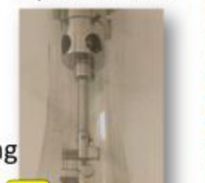

d) Philips from 1929

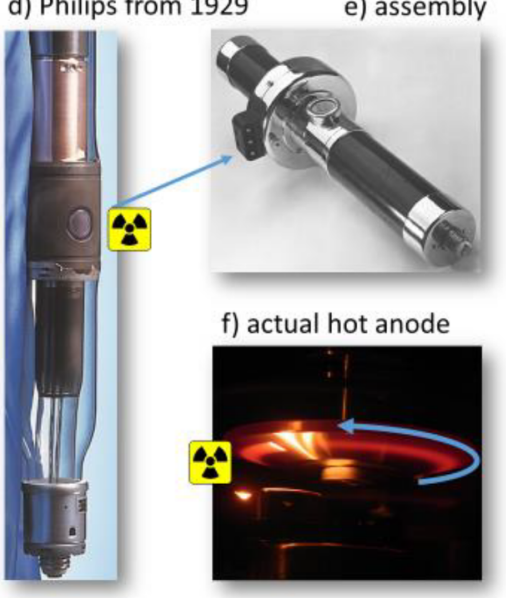

Fig. 18. Competing concepts: Left: rotating frame, right rotating anode tubes: (a) First idea of a movable target by R.W. Wood (before Nov. 1st, 1896): The cathode hangs from a pulley while the area of electron impact on the glass frame and may oscillate. (b) Siemens rotating frame tube of the traton ${ }^{\mathrm{TM}}$ series for CT with magnetic fixation of the electron beam. (c) Experimental rotating frame tube, with magnetic fixation of the cathode (1930), Phönix AG, Rudolstadt, Germany, and later Siemens. (d) 1st commercialized rotating target tube Rotalix ${ }^{\mathrm{TM}}$ (1929) from Philips, (e) tube housing assembly for this tube. (f) Close-up view of a current rotating anode glass tube in operation. (Figure (a) adapted from [22],Fig. 91), (b) courtesy of Siemens, (c) taken in the Siemens X-ray tube museum Rudolstadt, Germany, (d) and (e) courtesy of Philips). depicted in an angular polar diagram, resembles a human heel. A spectrum change with take-off angle is associated with this intrinsic attenuation, too. Tungsten imprints its spectral characteristic, most importantly its k-edge. Above the k-edge photon energy of about $69 \mathrm{keV}$, which is close to the mean energy in many CT examinations, photons are sufficiently energetic to ionize the deepest shells of tungsten atoms and are partially lost from the beam by this photoelectric effect. Radiation generated with tube voltage beyond $69 \mathrm{kV}$ softens by this filter. In summary, the anode angle of a tube is an essential parameter.

In 1923, in reaction to Goetzes invention and the competitive situation with the Mueller company, Siemens patented a dual focal spot tube, which allowed optimizing the spatial resolution in the image. With the Biangulix ${ }^{\mathrm{TM}}$ tube, the company further introduced an target with two radially separated focal spot tracks with different angles in a rotating anode tube, which allowed to fine-tune the trade-off between width of the X-ray fan beam, the desired spatial resolution and the power rating. Such a tube is depicted further below in Fig. 24. As, unfortunately, the image projection of "in-line focal spots" jumps when focal spots are switched, most modern tubes comprise superimposed focal spots with identical anode angle, typically between $6^{\circ}$ and $15^{\circ}$.

Due to relativistic effects, X-ray intensity from a thin target is enhanced in forward direction. This benefit is employed extensively for radiation therapy with linear accelerators and tube voltages in the megavolt range. But, for imaging with less than $150 \mathrm{kV}$, the relativistic effect is less pronounced, and the small anode angle allows for a greater gain of X-ray flux than employment of the relativistic forward enhancement. Thus, shortly after Roentgen's discovery, reflection targets have become standard for diagnostic imaging. X-rays are taken off at the side of the anode where the electrons impinge, see e.g. Fig. 18 (f). 


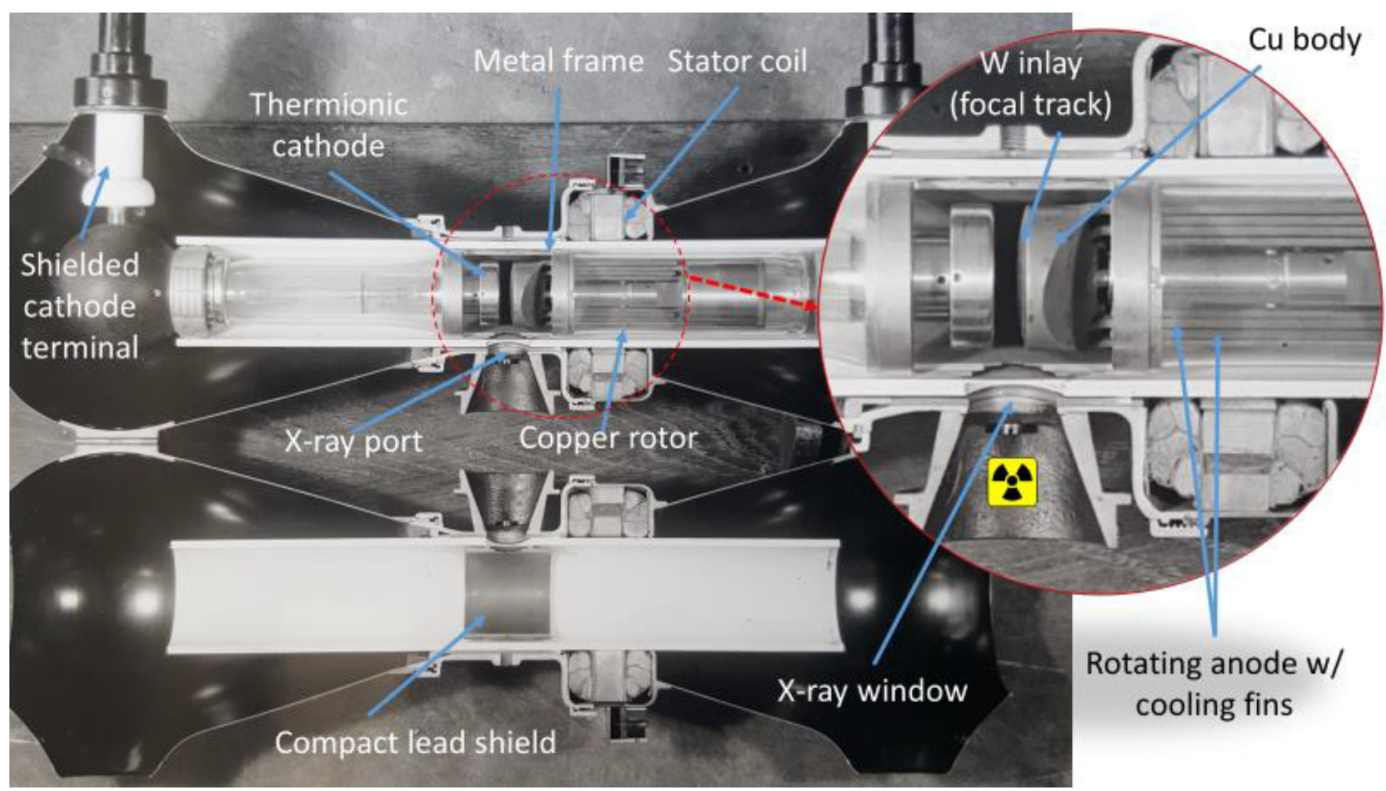

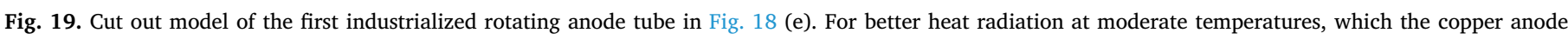

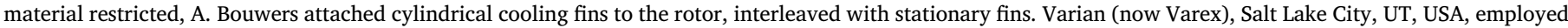

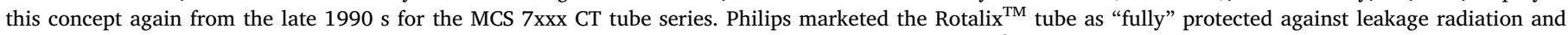

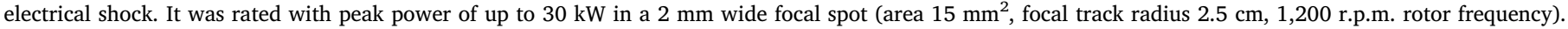

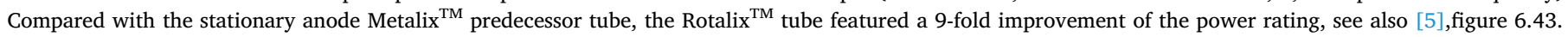

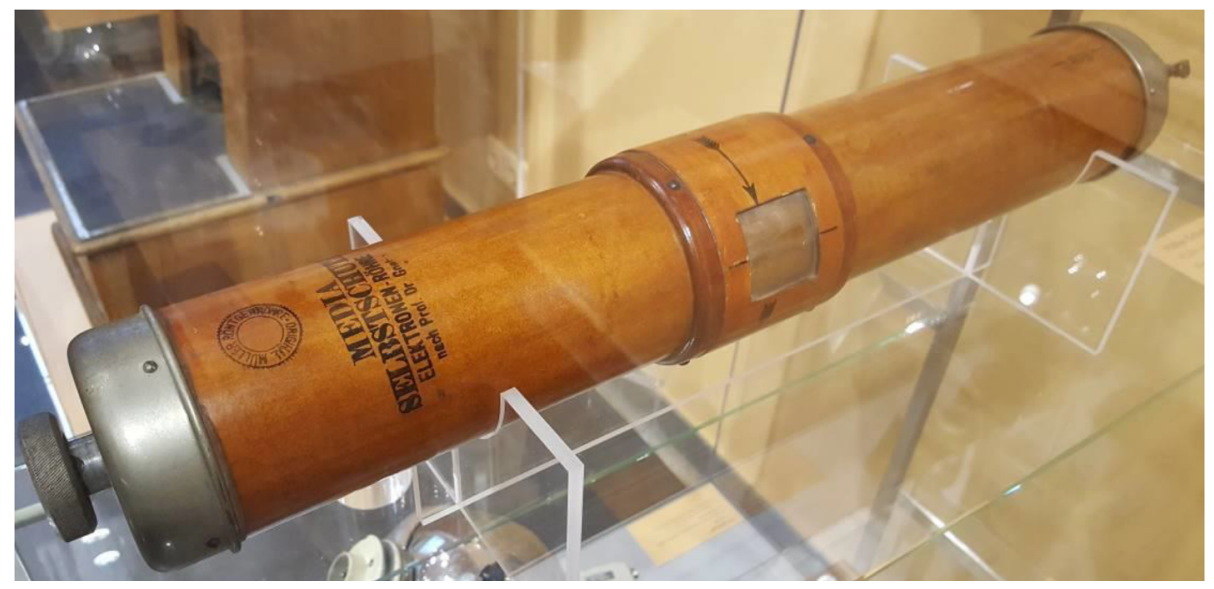

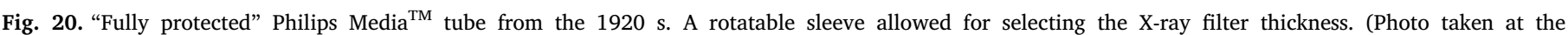
Medizinhistorisches Museum Hamburg, Germany, UKE).

Figs. 18 to 20 show Philips' "fully protected" MediaTM and RotalixTM tubes of the $1920 \mathrm{~s}$. The MediaTM tube had an X-ray filter changer in a rotatable sleeve. Beam limiting devices as in Fig. 21 were introduced.

\section{Rotating targets}

As aforementioned in Chapter 2, the concept of the rotating target probably originated with Robert Williams Wood, see [11] and Fig. 6. Coolidge from GE, too, suggested a rotating tube frame and filed an application in 1915 for US patent 1,215,116. The focal spot should be kept stationary in space through deflection of the electron beam. Fig. 18 compares various concepts. Wood's (Fig. 18 (a)) anticipates Siemens' Straton ${ }^{\mathrm{TM}}$ rotating frame tube for computed tomography, see [47] and Fig. 18 (b). Siemens and Dunlee, Aurora, IL, USA (later Philips) experimented with other rotating frame tube concepts, using a magnetically fixed cathode and cathode suspension by ball bearings, but never commercialized it. A Siemens version of these experimental tubes is shown in Fig. 18 (c). Another suggestion, rotating only the anode in the vacuum space inside the X-ray tube instead, originates reportedly from Eliuh Thompson at GE in 1896. But, it was not realized in practice until 1915 by Coolidge, who rotated the anode with a speed of 750 r.p.mand a focal track radius of $19 \mathrm{~mm}$. The tube was not put on the market, however.

After E. Pohl had publicly demonstrated a rotating anode tube in Stockholm, Sweden in 1928, Albert Bouwers of the newly established Philips "Natuurkundig Laboratorium" (NatLab) in Eindhoven, The Netherlands, commercialized it for Philips under the name Rotalix ${ }^{\mathrm{TM}}$ in 1929. This marked the broad commercial availability of rotating anode tubes. Compared with stationary anodes, exposure times can be reduced by up to two orders of magnitude by introducing convection cooling in addition to heat conduction, see [5], figure 6.43. Bouwers used a cylindrical rotating copper anode with tungsten inlay, see Fig. 18 (d), (e), and Fig. 19. A squirrel-cage motor transferred mechanical torque, see [10]. Uncoated and clean ball bearings quickly cold-weld in vacuum after a few rotations. Bouwers used highly refined grease for 


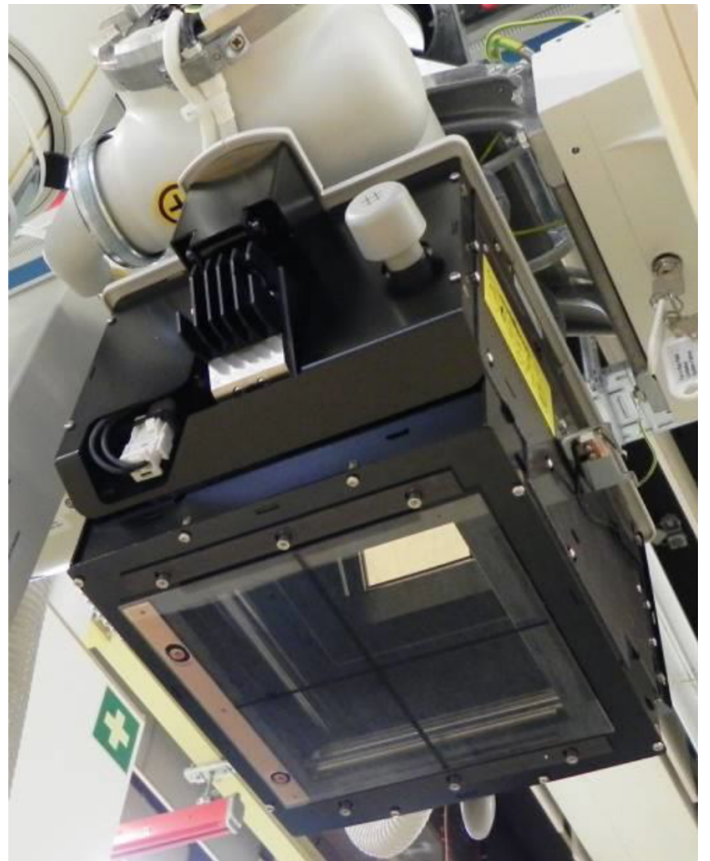

Fig. 21. Modern beam limiting device from Philips, with beam limiting apertures which adds X-ray filtration. The cover was removed. different path. Instead of a bulky large area radiator at moderate temperature, Alfred Ungelenk, the founder of the Siemens factory in Rudolstadt, Germany, tried rotating high temperature tungsten disks to exploit the special characteristics of the Stephan-Boltzmann law: The rate of heat dissipation is proportional to about $\mathrm{T}_{\text {anode }}{ }^{4}-\mathrm{T}_{\text {ambient }}{ }^{4}$, where $T_{\text {anode }}$ is the anode surface temperature and $T_{\text {ambient }}$ the temperature of the environment. The first attempt with a rotating tungsten foil failed, see Fig. 22. Instead, from 1933 on, the Siemens Pantix ${ }^{\mathrm{TM}}$ tube shown in Fig. 23 was delivered with a thicker and more stable all tungsten anode. GE introduced a similar tube RT 1-2 in 1936, when Coolidge served as the director of the Research Laboratory.

The benefit of this high temperature concept is high heat dissipation when the anode is at its thermal limit, see Fig. 25. Philips used the high temperature concept with the Super Rotalix Ceramics ${ }^{\mathrm{TM}}$ tube series, see below in Fig. 59, delivered from 1980 onwards primarily for angiography and cardiology work, and avoided graphite backing of the allmetal anode, as shown with the Siemens Opti 150 tube in Fig. 26. Given the limitation of the focal spot temperature by the melting point of tungsten, the allowable temperature difference between focal spot and bulk anode of Ungelenk's high temperature tube is lower than with Bouwer's. This reduces the permitted thermal pulse power for comparable focal track speed and focal spot size. To mitigate, Siemens enhanced the rotor speed to more than 5,400 r.p.m in 1934 . 9,000 or 10,800 r.p.m. rotor frequency has become industry standard since the late 1950 s. Fig. 27 depicts a typical X-ray tube assembly of current production and marks its major components. The highest rotor speed

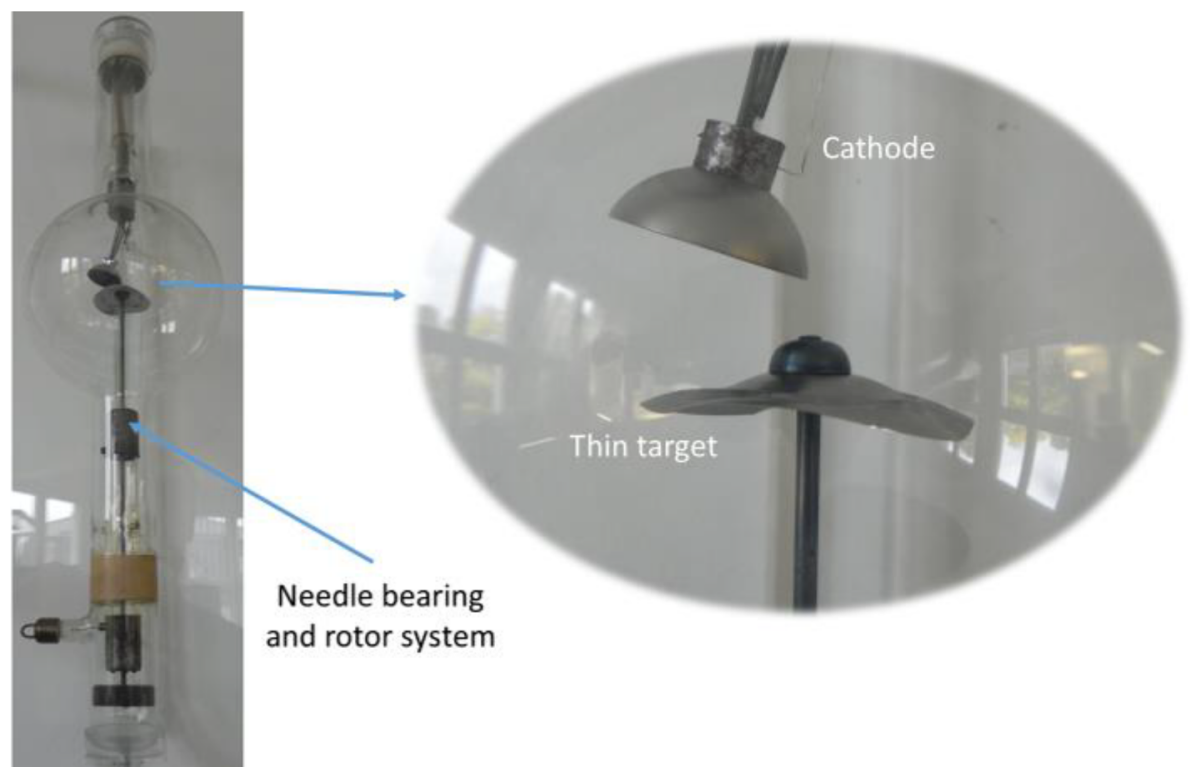

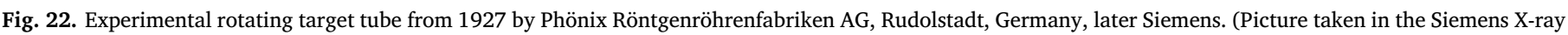
tube museum Rudolstadt, Germany).

lubrication. But, this is challenging for the quality of the vacuum, electrical stability against discharges through vacuum and electrical conductivity. On top, ball bearings practically cut the heat conduction from anode to ambient. Using copper for the anode limited the allowable temperature to below ca. $400{ }^{\circ} \mathrm{C}$. This relatively low temperature (the target shown in Fig. 18 (f) reaches up to $1500{ }^{\circ} \mathrm{C}$ ) hampers heat dissipation by thermal radiation. Bouwers anode was a stationary anode, put on ball bearings. Though extremely innovative, technical problems mounted. For improvement, he introduced a finned anode structure, with interleaved stationary fins to maximize the surface area. This concept saw a revival in the 1980 s by Varian (now Varex, Salt Lake City, UT, USA) for their high-end CT tubes with graphite-backed grooved anodes, see [5]. Four years after Philips, facing the commercial threat, see [34], Siemens launched rotating anodes, taking a slightly has been available from 1982. Siemens produced the Opti 110/12/50 tube with even 16,800 r.p.m. rotor frequency for magnification imaging, which employs small focal spots. However, this high speed is a severe challenge for ball bearing systems. Fig. 28 illustrates the effect of rotor drive or bearing failure.

\section{Stationary anode tubes}

Since the late $1920 \mathrm{~s}$, the concept of rotating anodes, either spinning in vacuum or as part of the tube frame, has become the basis for all modern high-performance X-ray tubes. Before, the stationary focal spot limited the power rating by limited heat conduction and heat capacity of tungsten. The industry devised a multitude of sophisticated cooling means at the back of the target, tungsten-in-copper brazed structures, 


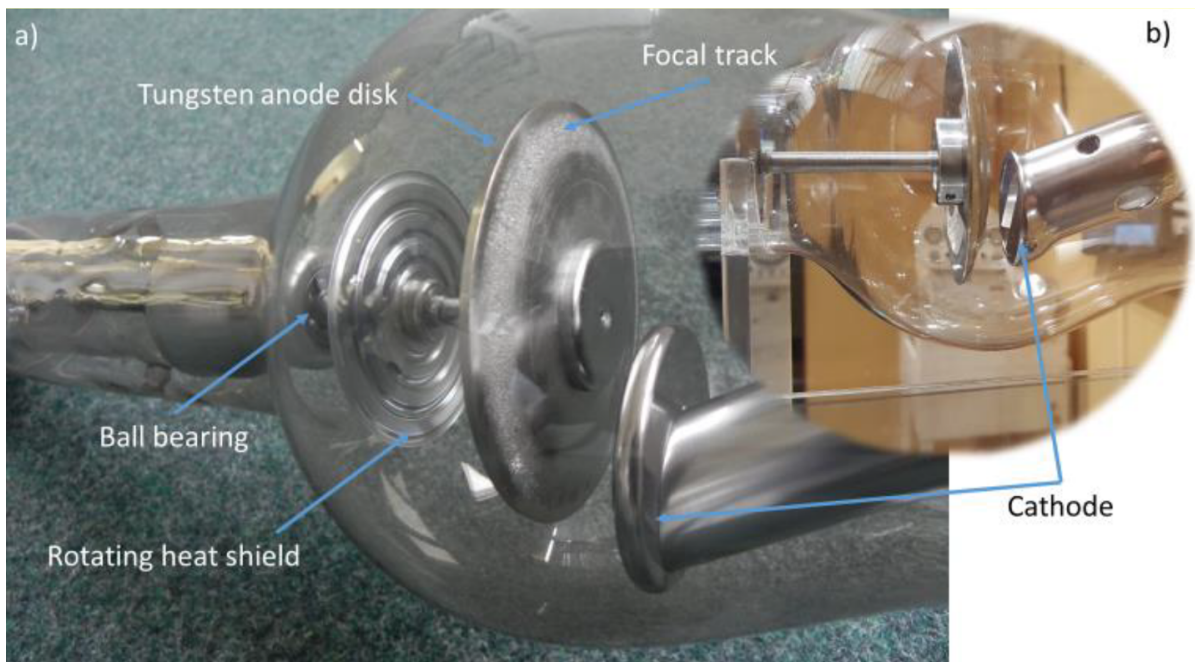

Fig. 23. (a) Rotating anode system of a Siemens Pantix $^{\mathrm{TM}}$ tube, equipped with an all tungsten high temperature anode disk and produced from 1933 by Siemens-Reiniger-Werke AG, Rudolstadt, Germany. This tube was Siemens' answer to the prior Philips Rotalix $^{\mathrm{TM}}$ rotating anode tube from 1929, see Figs. 12 and 13. While the Rotalix ${ }^{\mathrm{TM}}$ tube primarily stored enthalpy at moderate temperatures in the finned copper / tungsten anode and radiated heat from a large surface area, the Pantix ${ }^{\mathrm{TM}}$ design aimed at employing the Stephan-Boltzmann ("T $\mathrm{T}^{4}$ ") law to achieve high heat radiation from a hot disk. (b) Earlier version without a heat shield at the rotating anode. (Picture (a) taken in the Siemens X-ray tube museum Rudolstadt, Germany, (b) taken at the Medizinhistorisches Museum Hamburg, UKE, Germany).

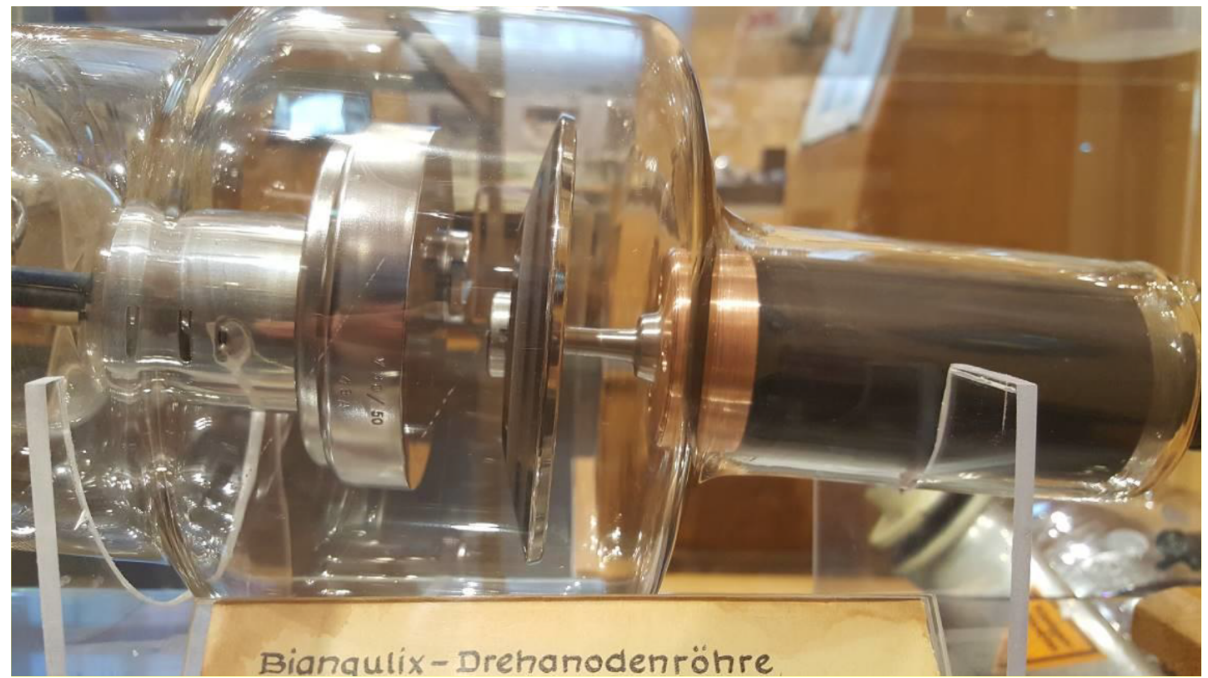

Fig. 24. Siemens Biangulix ${ }^{\mathrm{TM}}$ tube. Its anode has two separated focal spot tracks with different anode angles. (Picture taken at the Medizinhistorisches Museum Hamburg, Germany, UKE).

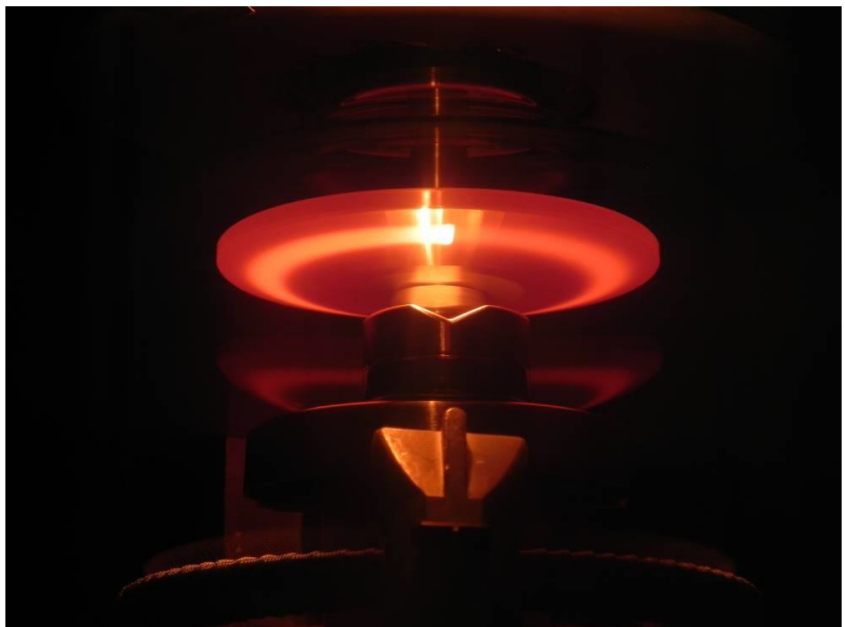

Fig. 25. Thermal radiation of a rotating anode tube during the exhaust process. The rectangular thermal focal spot and the hot trail of the focal track are visible on top of the light from the filament of the cathode at the bottom, reflected from the anode.

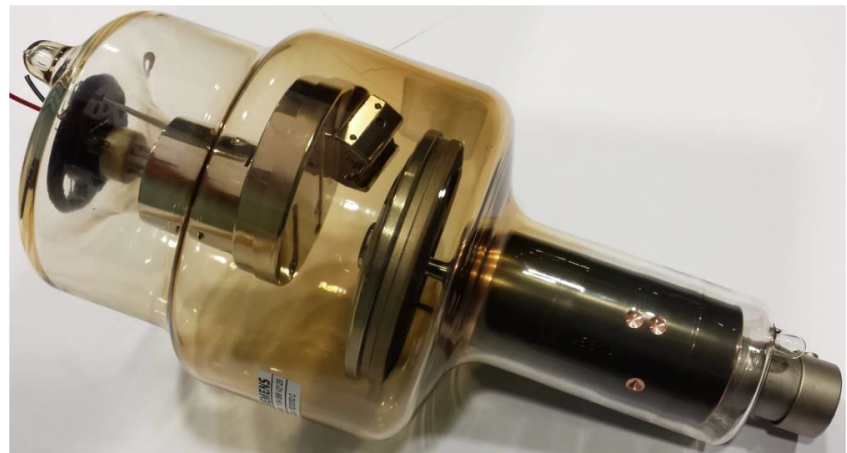

Fig. 26. Brazed graphite backed RW/TZM compound anode in a Siemens Opti 1503050 radiographic tube.

phase-change heat storage and water coolers. In any case, an about 1millimeter thick layer of tungsten turned out necessary as first layer heat spreader. The gain of performance of stationary anode tubes leveled off over time. Stationary anode tubes are still important elements, though, of the tube portfolio for surgery C-arm and dental application, where either low and steady long-term photon flux is required, or the system geometry is short. Fig. 29 shows the Siemens ERG 80 ö 


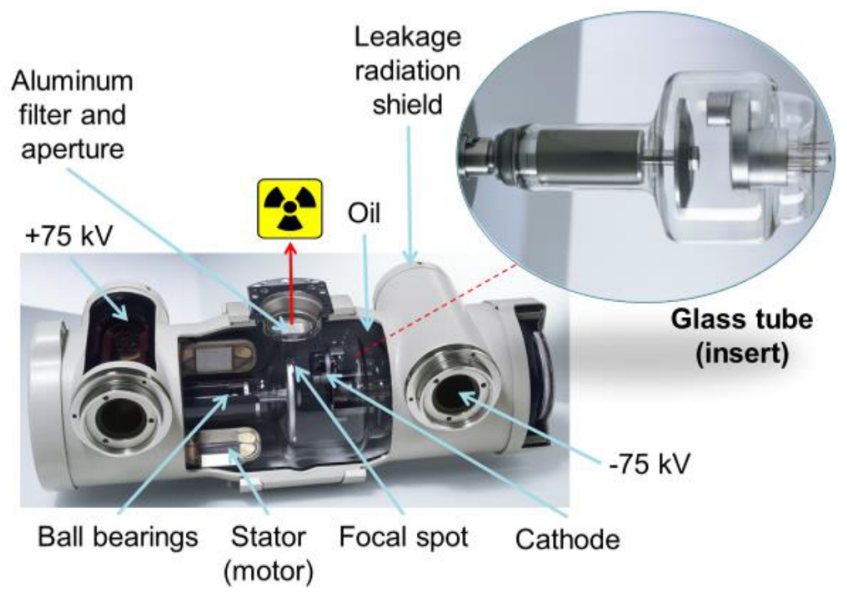

Fig. 27. Function and major components of a conventional radiographic X-ray tube assembly from Philips, which has been in production in similar form since the 1950 s.

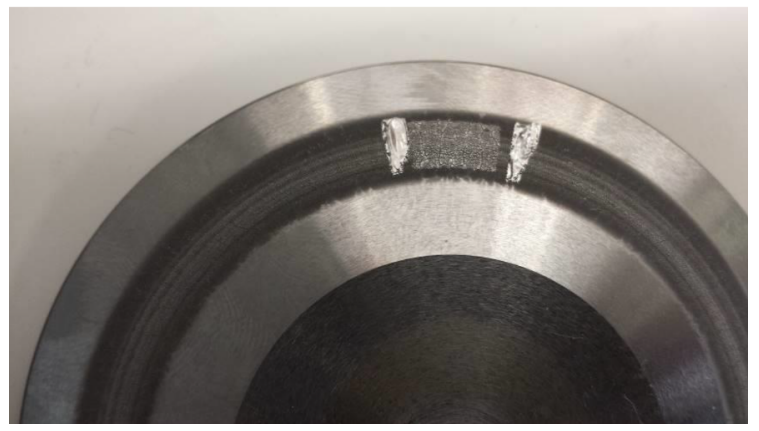

Fig. 28. Eroded focal track of a rotating anode. Malfunction of the rotor during two subsequent trials to rotate caused two marks of molten target material, which map the shape of the rectangular electronic focal spot.

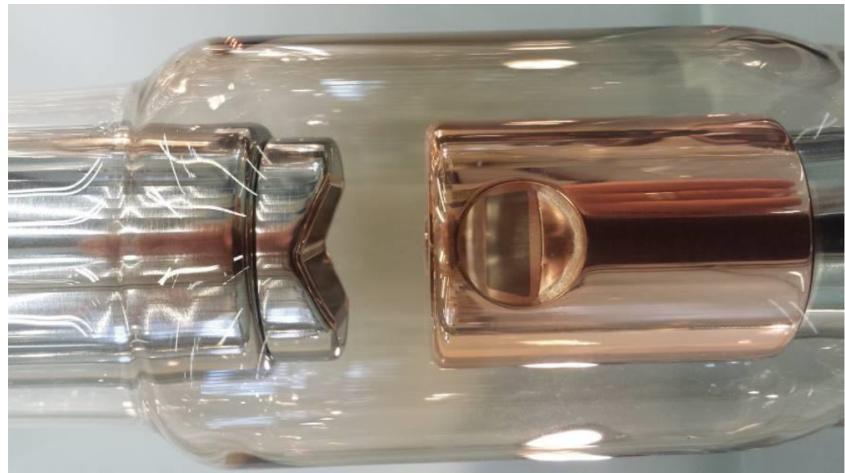

Fig. 30. Close-up photo of the Philips superimposed dual focal spot stationary anode tube FO 17 for surgical C-arm systems.

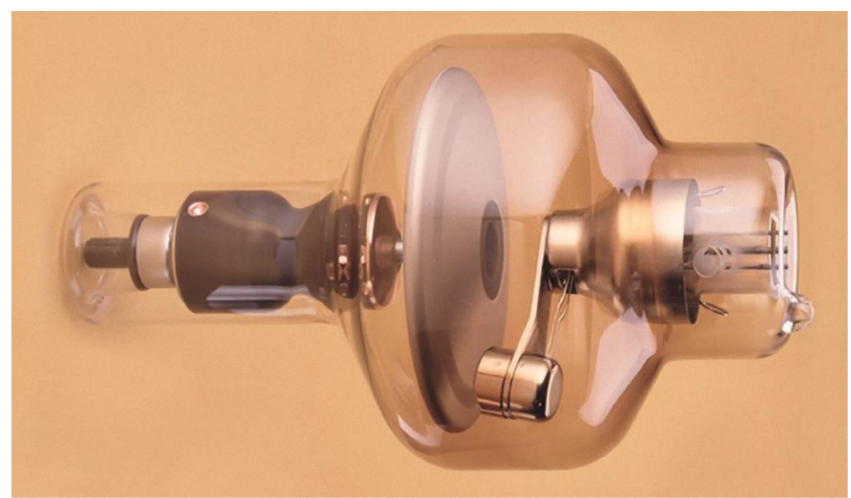

Fig. 31. GE-CGR vascular tube with graphite target, coated with tungsten and rhenium. (Photo courtesy of GE).

of inertia is disadvantageous, when the tube rotor, equipped with ball bearings, must get started before an exposure. On the other hand, such

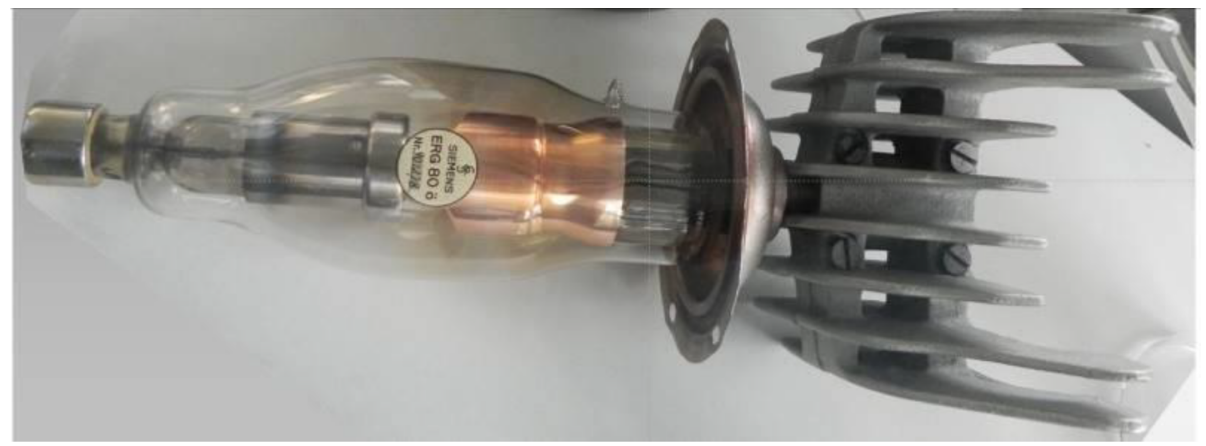

Fig. 29. Siemens stationary anode tube ERG 80 ö with cooling fins from 1942. (Photo taken in the Siemens X-ray tube museum Rudolstadt, Germany).

stationary anode tube from 1942, featuring heat dissipation through cooling fins. Fig. 30 is a picture of the Philips tube FO 17 with superimposed dual focal spots for surgery C-arm systems. A scattered electron trap improves electrical stability. Fig. 53, below, depicts a small dental tube, Oralix 12 from Philips, for $50 \mathrm{kV}$ tube voltage, which operates well without such an electron trap.

\section{Component development}

\subsection{Anodes}

Tungsten is a rather brittle material with high density. All-tungsten rotating anodes, first introduced with Siemens' Pantix tube in 1934, tended to break in cool condition. The high mass and large momentum anodes permit heating to temperatures beyond $2000{ }^{\circ} \mathrm{C}$, and radiate heat well. But, pre-heating to prevent rupture from thermo-mechanical stress is advised prior to operation. The introduction of specifically lighter molybdenum backed rhenium-tungsten compound anodes in the $1960 \mathrm{~s}$ improved the situation. Since then, a 1-millimeter thick top layer of rhenium-tungsten (RT) alloy, backed by a several millimeter thick powder sintered titanium-zirconium-molybdenum (TZM) body, has become the basic technology for most rotating anode tubes.

From the $1960 \mathrm{~s}$, Thomson-CGR, France, later GE, produced a vascular tube with an extremely light weight target, depicted in Fig. 31. The anode of this tube was made of metal-coated graphite. Mass reduction helped improving bearing life and anode diameter. The great thermal emissivity of graphite adds. The anode comprised a coating of tungsten directly onto a graphite substrate using an electrochemical 

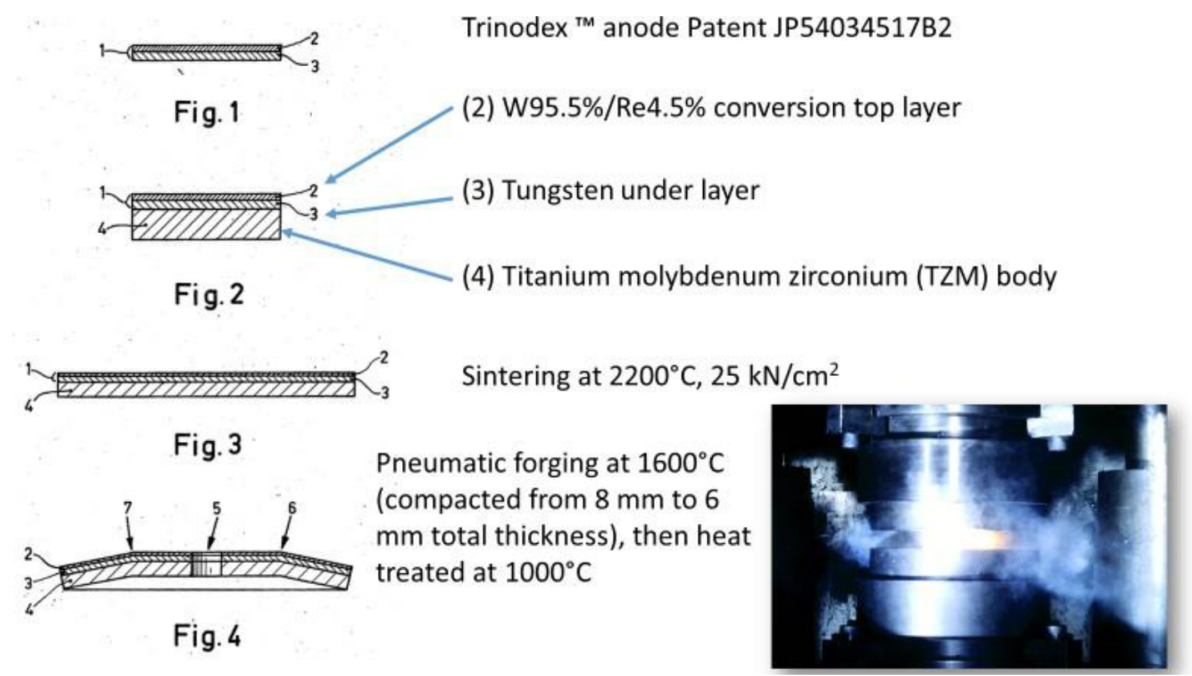

Fig. 32. Philips Trinodex ${ }^{\mathrm{TM}}$ anode, in production from 1973, hot forged from three metal slabs.

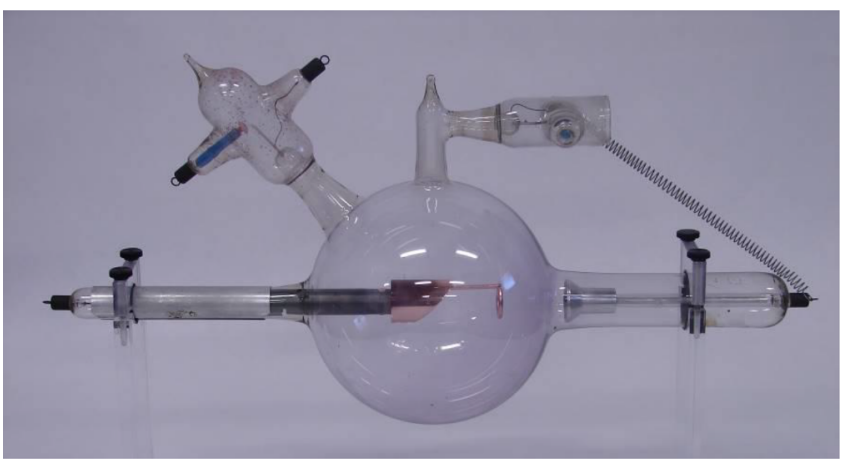

Fig. 33. Hydrogen ion X-ray tube with field enhancing pull ring on anode potential, introduced in 1916 by the Victor X-Ray Company of Chicago, IL, later to be acquired by General Electric to become GEXCO, the forerunner of today's GE Healthcare. (Photo courtesy of GE). material, see Fig. 32. Anode life was improved by extreme mechanical strength, very low porosity in the top layer and, thus, excellent focal track durability. The focal track of rotating anode tubes is subject to thermo-mechanical erosion from millions of heat-cool cycles during tube life, which results in loss of X-ray output.

For heavy-duty application in angiography, Siemens first and later Varian introduced graphite-backed RT-TZM, material as depicted in Fig. 26 in a Siemens tube. Based on statistics of technique factors in practice and due to other emerging technology, Philips first refrained from entering this path. As with the stationary anode tube shown in Fig. 30, rotating anode metal center section tubes enable trapping of backscattered electrons on stationary structures. About $48 \%$ of the primary electrons is backscattered from a tungsten target. These electrons carry about $40 \%$ of the primary power. Preventing them, at least partially, from "falling" back on the anode is therefore an effective means of keeping the anode cool. Scattered electron traps can be the

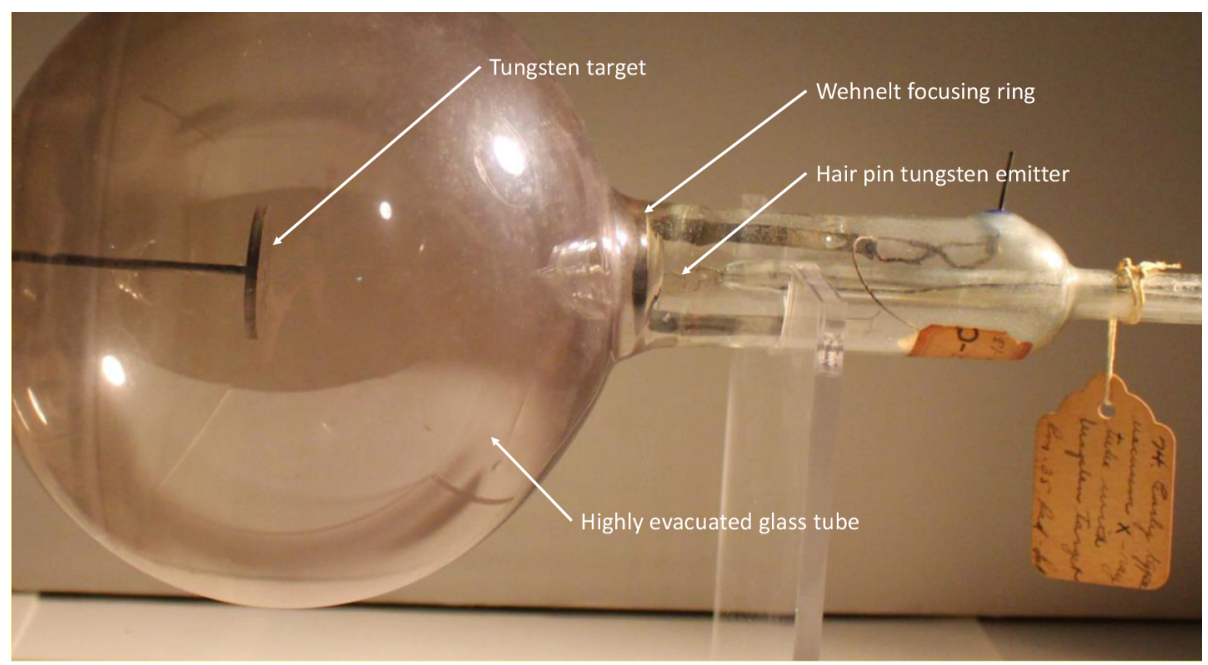

Fig. 34. Photo of an original laboratory Coolidge tube, taken on April 30th, 1913, showing a Wehnelt type focusing ring about the thermionic tungsten emitter. (Photo courtesy of GE).

salt-bath process, with a thin interposed rhenium layer; later designs were produced through chemical vapor deposition of tungsten from tungsten and rhenium hexafluoride gas.

Philips took a side path utilizing its high-pressure forging facility in Eindhoven, The Netherlands, to produce the compound Trinodex ${ }^{\mathrm{TM}}$ grounded metal center section in bipolar tubes, see Fig. 18 (d), Fig. 19, Fig. 43 and Fig. 59 or liquid cooled devices in anode grounded tubes. Liquid-bearing- technology, see Fig. 42 and Fig. 43, which revolutionized tube technology in 1990 , helped as well to efficiently dissipate heat instead of storing enthalpy in the anode, see below. 


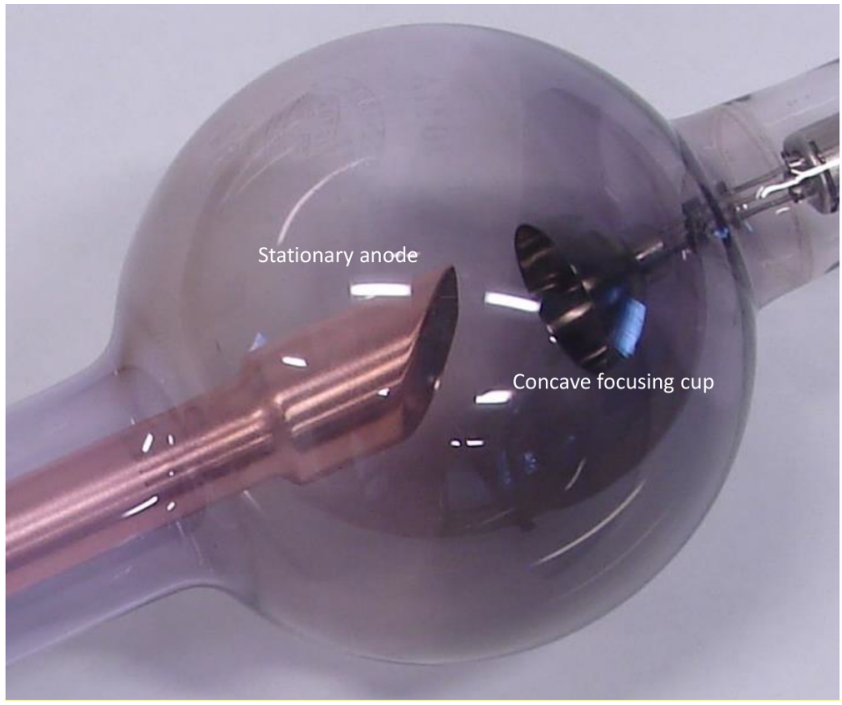

Fig. 35. Bell-shaped focusing elements of a stationary anode of a Coolidge tube. (Photo courtesy of GE).

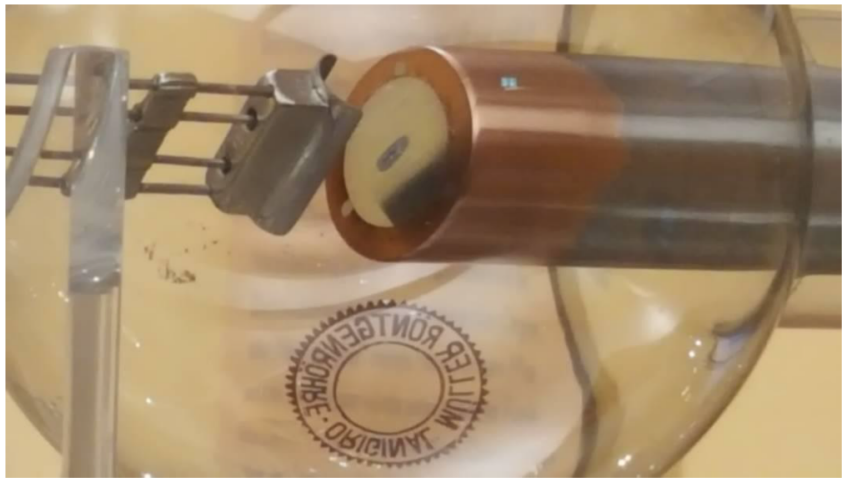

Fig. 36. Focusing elements of a stationary anode tube with line focus from C.H.F. Mueller, Hamburg, Germany, later Philips. The line focus is mapped in the melting structure on the anode.

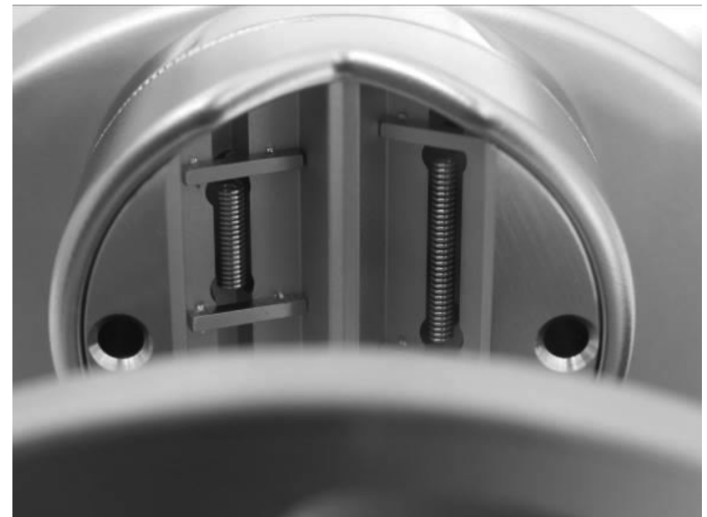

Fig. 38. Close-up view of the thermionic cathode for superimposed focal spots of a Philips SRO ${ }^{\mathrm{TM}} 33100$ tube.

\subsection{Cathodes and electron focusing}

Switching back in time, improvements of the anode demanded improved cathodes from the very beginning. Based on a prior concept of Crookes, Mueller in Hamburg, Germany, improved the spatial image resolution soon after Roentgen's discovery by producing the "FocusTube", like the one depicted in Fig. 10. The cathode plate, which ejects electrons normal to the surface upon ion impact, was given a concave form. The Victor X-ray Company of Chicago, Il (later to be acquired by General Electric to become GEXCO, the forerunner of today's GE Healthcare) used hydrogen as the gaseous species inside the tube to reduce sputtering effects, an applied a ring-shaped pull electrode in connection with the anode, which enhanced the electron current, see Fig. 33.

After introducing thermionic electron emission, Coolidge first encapsulated the tungsten thermionic emitter coil by a small metallic cylinder, as can be seen in Fig. 16 (b). He also experimented with a focusing ring, as in Fig. 34. In later versions a bell-shaped cathode focused the electrons, see Fig. 35. Siemens used such a form as well for their first laboratory model of a rotating anode tube, see Fig. 22.

The introduction of line focal spots resulted in a rectangular shape

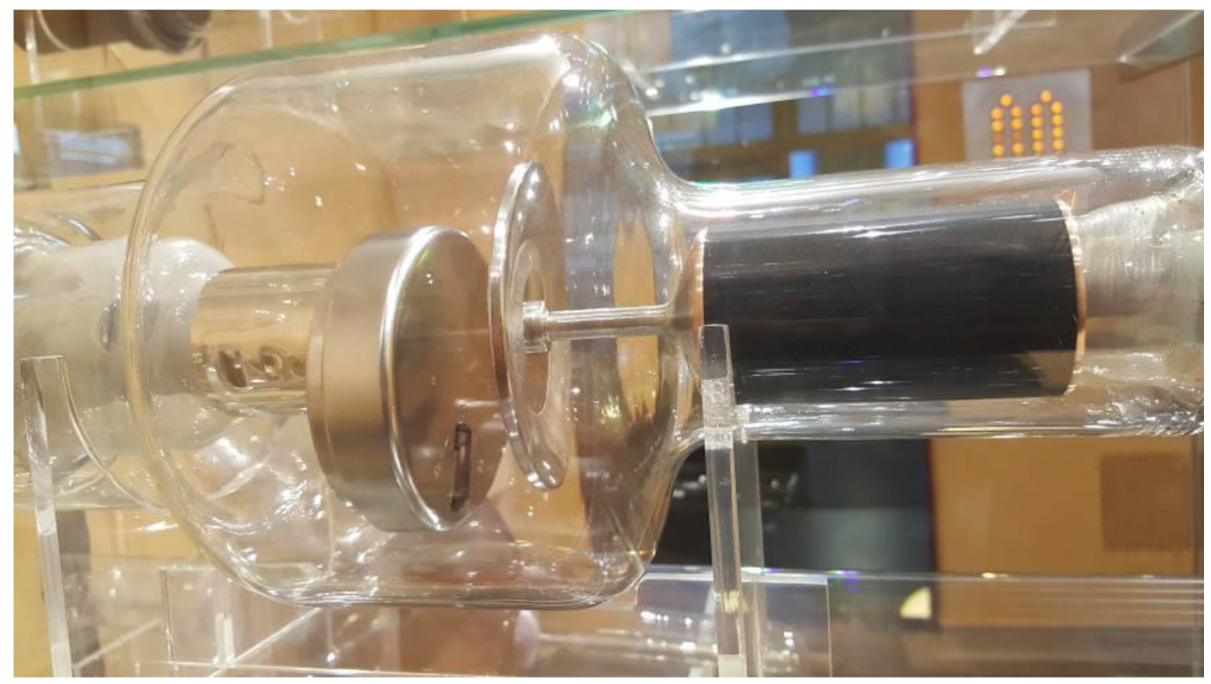

Fig. 37. Hidden cathode in a Philips tube from the production plant in Eindhoven, The Netherlands. (Picture taken at the Medizinhistorisches Museum Hamburg, Germany, UKE). 


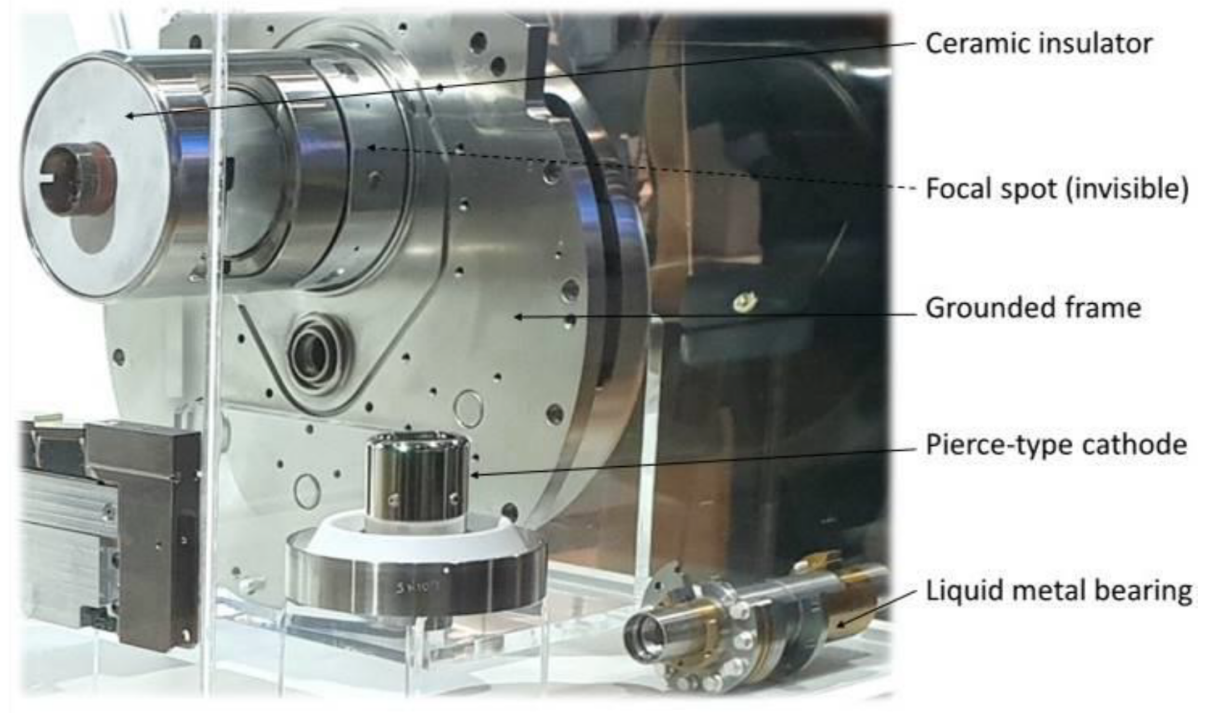

Fig. 39. GE Quantix $160^{\circledR}$ tube, launched 2018, with Pierce-type cathode for the spectral CT system GE Revolution Apex.

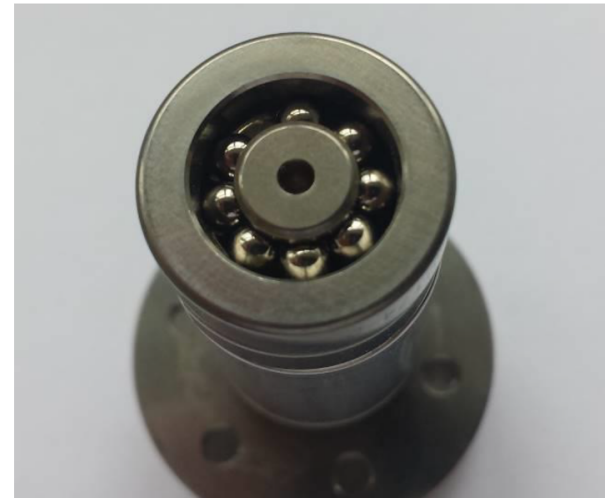

Fig. 40. Ball bearing system for Philips $\mathrm{SRO}^{\mathrm{TM}}$ tube series tube with $90 \mathrm{~mm}$ target diameter.

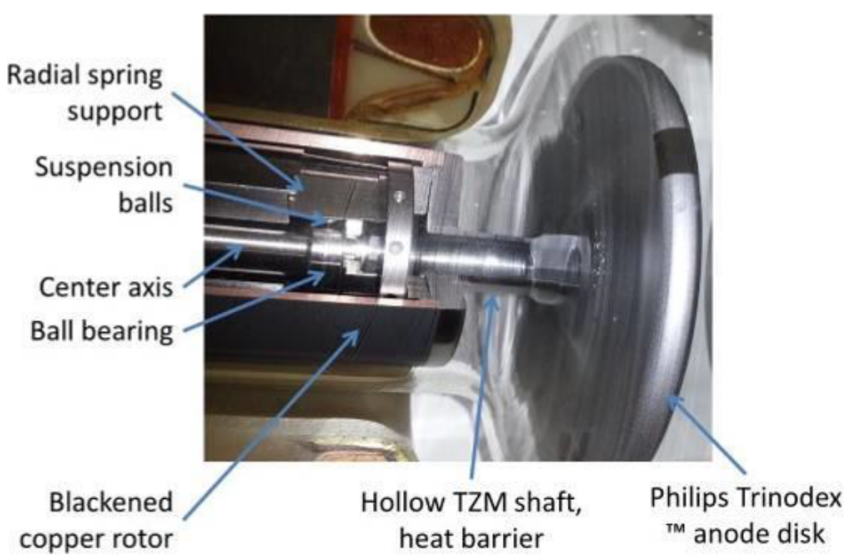

Fig. 41. Low noise radial spring supported ball bearing system in a Philips glass tube.

of the focusing cup, as in the tube from Mueller in Fig. 36. The rectangular focal spot can clearly be identified by the erosion pattern on the stationary anode. The classic form emerged by the introduction of larger focusing electrodes to improve the definition of the focal spot even when changing the tube current and tube voltage. Space charge effects, and focal spot "blooming" became apparent, when the anodes allowed for higher tube currents. Fig. 37 shows a tube from the Philips production plant in Eindhoven, The Netherlands. The cathode head was integrated in a large cathode plate, which shielded the glass insulator from bombardment by backscattered electrons.

Fig. 38 depicts a typical modern dual focal spot cathode for an $80 \mathrm{~kW}$ rotating anode tube for radiography. Coiled tungsten wires of $250 \mu \mathrm{m}$ diameter are mounted into a cathode head which forms the electric field in such a way that electrons are focused into the desired focal spot. The back of the edge of the anode disk can be seen blurred in the front of the picture. Space charge effects are electron-optically taken into account during design in a such way that the focal spot dimension would not substantially change with tube current and voltage. Other than with magnetic focusing, electron trajectories from electrostatic focusing are invariant of the applied tube voltage, when tube current and electronic space charge are negligible. But, due to the relatively high tube current density in high-power tubes, space charge effects cannot totally be avoided. Enhancing the emitter surface area and improving the starting conditions of electrons is therefore advised. In 1998 Siemens introduced a flat tungsten sheet emitter for the Pantix P40 tube for mammography, in 2003 for the Straton ${ }^{\mathrm{TM}}$ CT tube, see $[5,47]$, and in the Gigalix ${ }^{\mathrm{TM}}$ tube series in 2013, see Fig. 62. Philips introduced this technology for the iMRC ${ }^{\mathrm{TM}}$ CT tube in 2007.

In 2018 GE launched the latest major innovation in cathodes with the Quantix $160^{\circledR}$ X-ray tube for spectral CT, see Fig. 39. Other than with klystrons, for which the concept of Pierce-type cathodes had been employed for a long time before, analog fast control of the electron emission of X-ray tubes had been impossible so far. All prior X-ray cathodes have operated mainly in the saturation regime. The great majority of the available electrons are pulled to the anode. The tube current could only be switched digitally on and off in microseconds through application of biasing voltage between electron emitter and focusing electrodes, see Fig. 60. Or, it could be modulated by alternating the emitter temperature in dozens of milliseconds. Pierce-type cathodes produce an abundance of electrons internally. GE uses two flat emitters in parallel. A pull electrode, which generates a variable electric field at the emitter controls the share of freed electrons. Electronic space charge blocks electron emission to the anode at low pull field. Biasing the pull electrode controls the tube current in microseconds. GE uses this tube in the Revolution Apex ${ }^{\circledR}$ spectral CT system. The system is capable to quickly alter the tube voltage and measure X-ray attenuation of the object with different "colors" of the X-ray beam to produce spectral data. Tube current is about doubled in periods when the tube voltage and with it the X-ray conversion efficiency are low. Philips, instead, uses a dual layer detector for spectral differentiation. The tube 


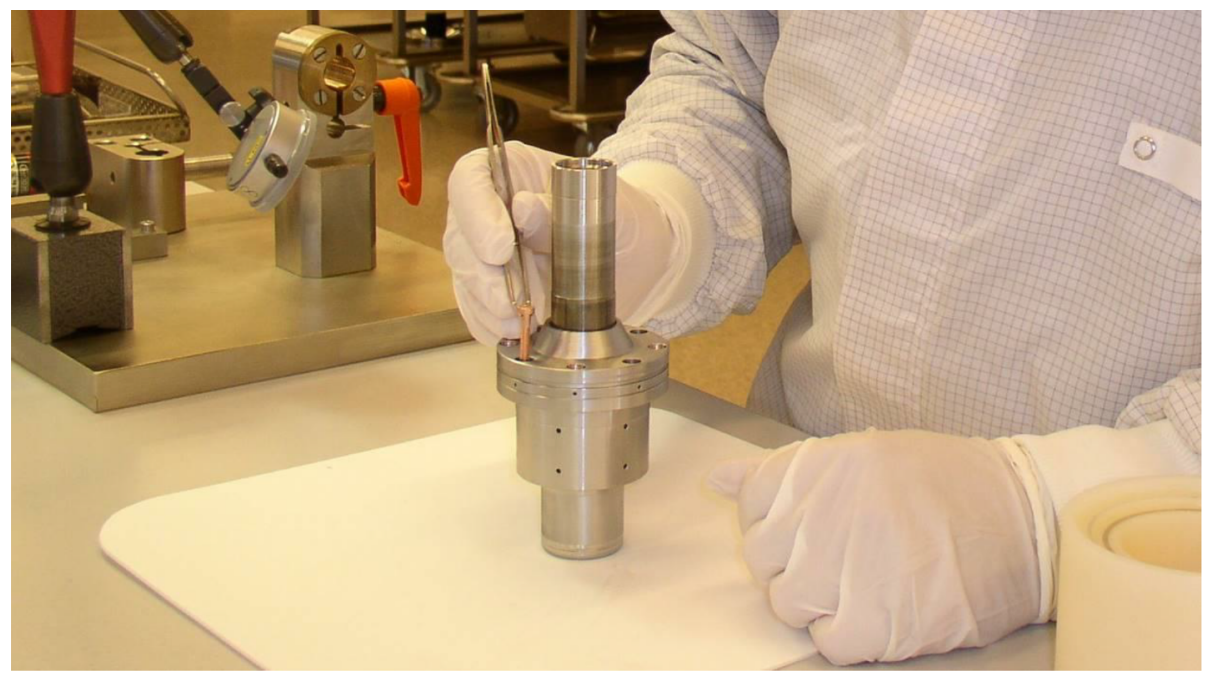

Fig. 42. Final assembly of a liquid metal bearing system for the Philips $\mathrm{MRC}^{\mathrm{TM}} 200$ angiography tube series. (Picture courtesy of Philips.)

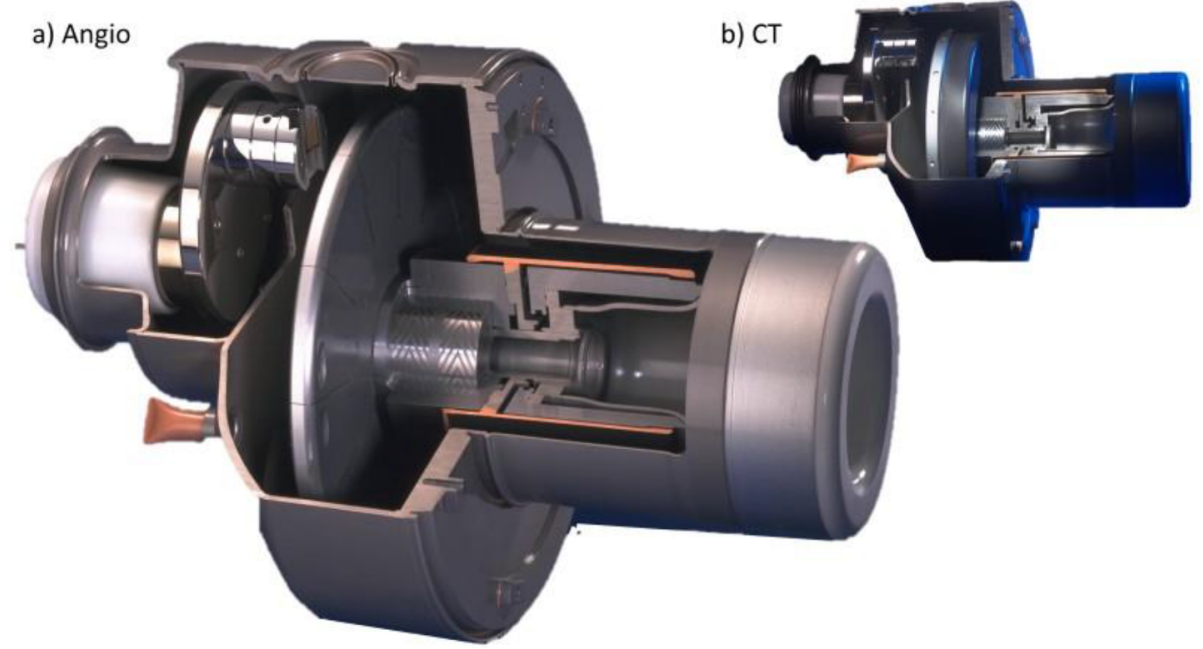

Fig. 43. (a) First rotating anode tube from 1989 with liquid bearing and, at that time, extreme $200 \mathrm{~mm}$ anode disk, Philips $\mathrm{MRC}^{\mathrm{TM}} 200$ series for cardiology and angiography. (b) CT version from 1993, still an active platform (Pictures courtesy of Philips).

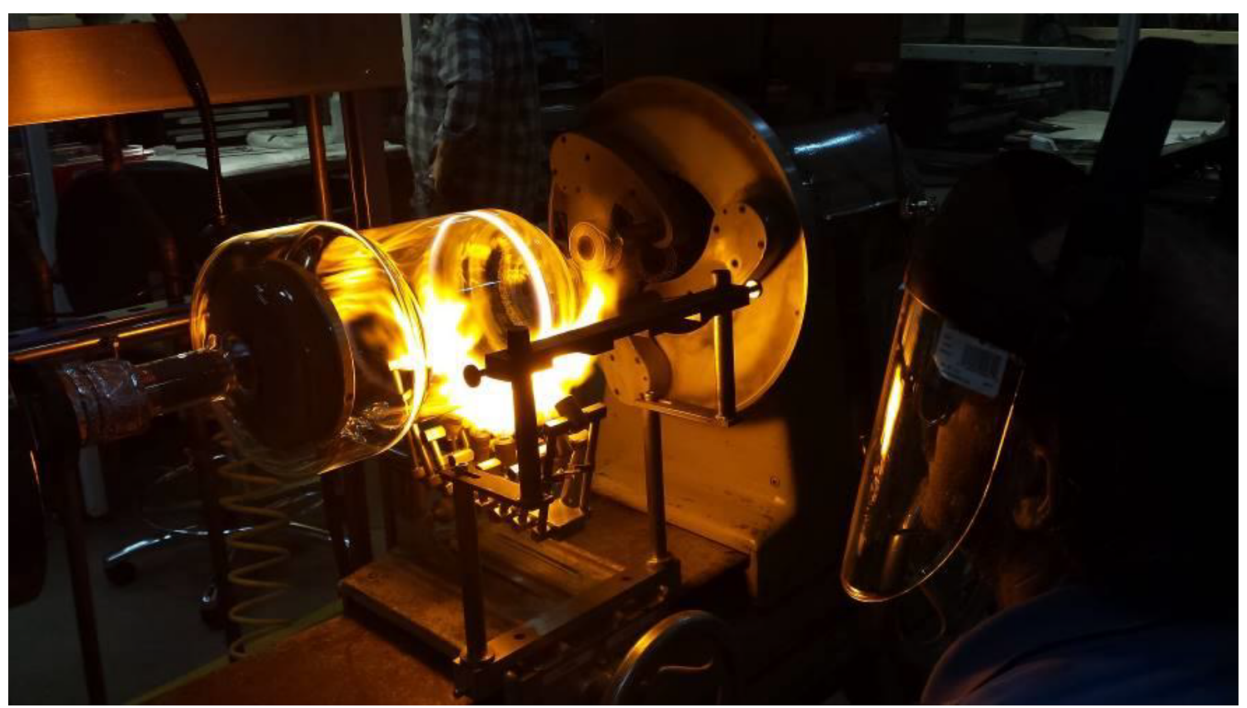

Fig. 44. Glass blower at Dunlee, Aurora IL, now Chronos. (Picture courtesy of Philips). 


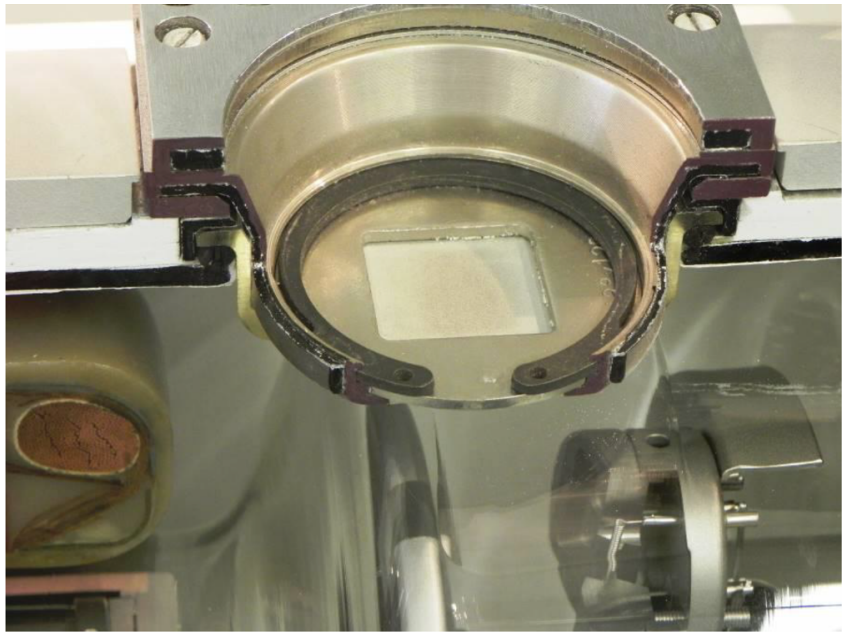

Fig. 45. Close-up view of the radiation port of a Philips tube housing assembly for radiography and angiography with exchangeable near focal spot aperture against off-focal radiation and intrinsic radiation filter.

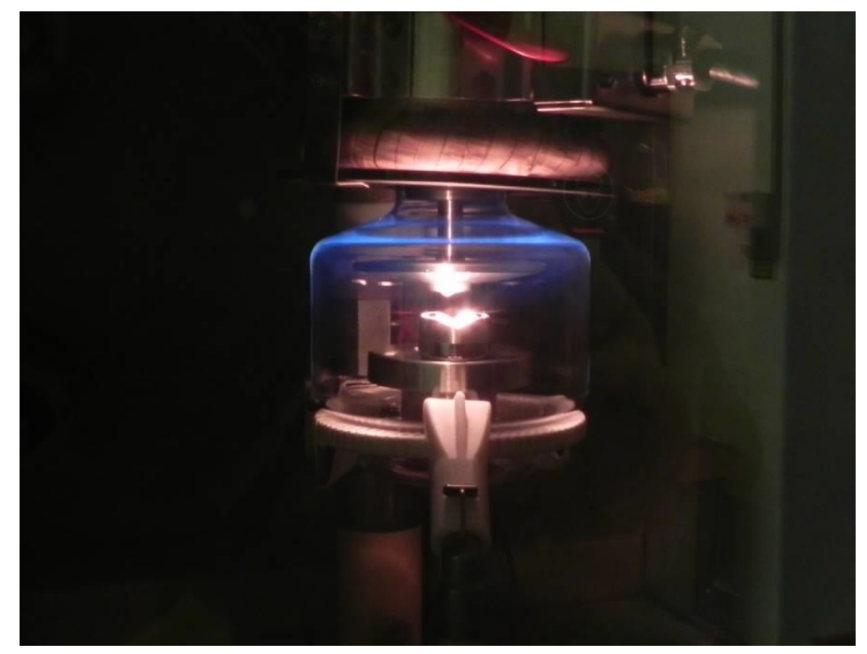

Fig. 46. Glass tube during the exhaust process with electron bombardment of the anode. The blue glow at the inner glass wall (top, about the cathode region) signals continued impact of backscattered electrons and ions on the glass.

is always at maximum emission. Siemens employs two spinning X-ray tube and detector pairs operated at different voltages in a dual-source system.

\subsection{Bearings and rotor systems}

Anode bearings have seen major improvements as well. Fig. 40 shows a ball bearing system for a standard radiographic X-ray tube like the Philips SRO 33100. Since the 1940 s, Philips has coated balls and raceways with lead, from 1980 on with silver for selected tube types. Initially until the middle of the $1990 \mathrm{~s}$, lead was rolled-in using a suspension of lead particulates in Vaseline ${ }^{\mathrm{TM}}$. Silver was coated galvanic since 1980 for the Super Rotalix Ceramic ${ }^{\mathrm{TM}}$ tube, SRC 120, see Fig. 59. In the $1990 \mathrm{~s}$ Varian, Salt Lake City, USA (now Varex), introduced ion coating, which has become the current standard coating technology.

Philips reduced rotor noise and vibration by implementing a radial spring suspension of one of the individual bearings, which enables the anode rotor to spin nearly force-free about its intrinsic axial axis of inertia, see Fig. 41. The same principle applied to the straddle-type bearing of the SRC tube is shown in Fig. 59. The center of gravity was suspended between two bearings to even-out the radial load. This

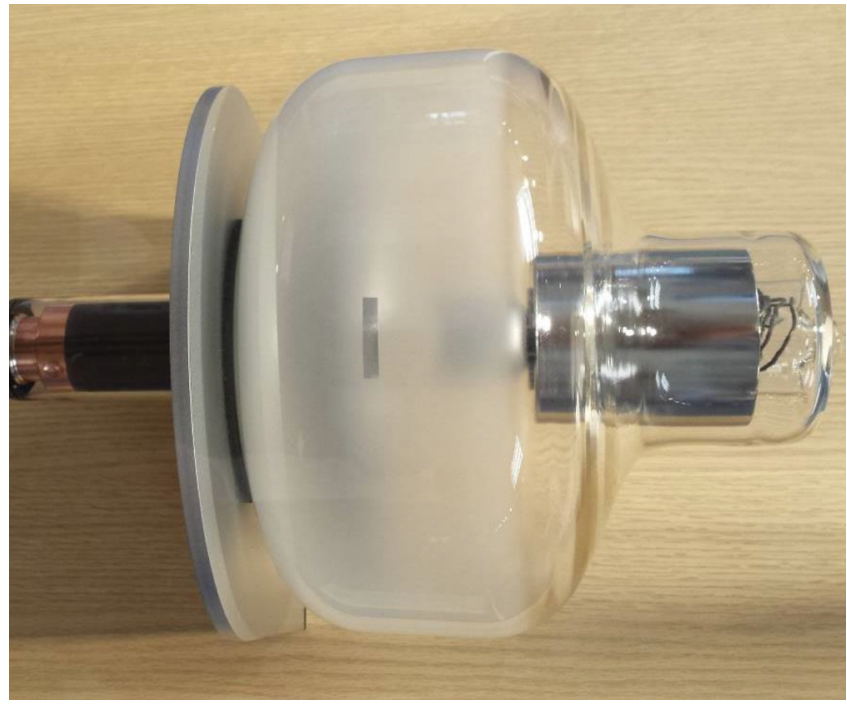

Fig. 47. Frosted glass wall of a tube from Dunlee, now Hamburg, Germany, to improve the electrical stability under bombardment by backscattered electrons.

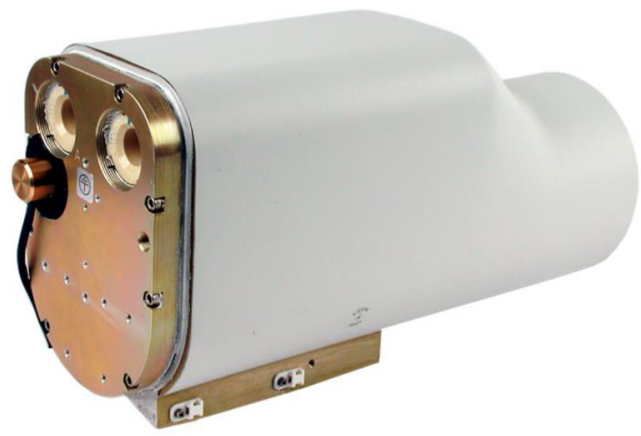

Fig. 48. Varex tube OR-III tube assembly with RAD-99 glass insert for surgical C-arm systems. (Picture courtesy of Varex).

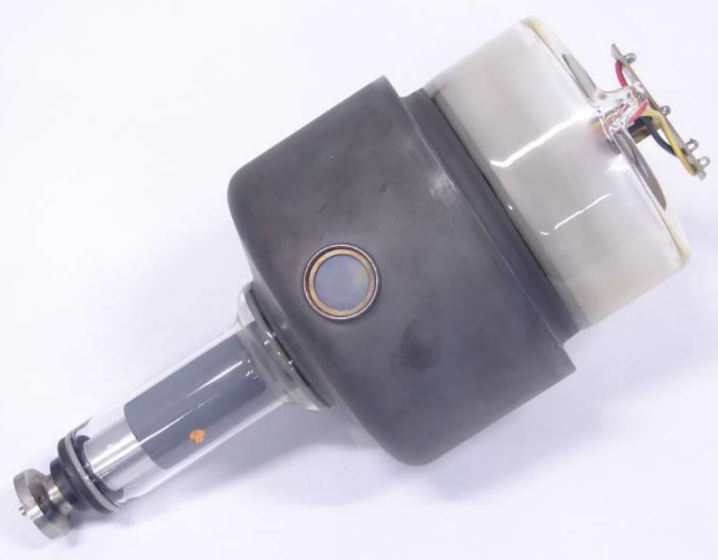

Fig. 49. GE MX-125 metal center section tube for the emerging angiography application, introduced in 1972. (Photo courtesy of GE.)

concept was later adapted by Siemens for the Akron ${ }^{\mathrm{TM}}$ tube series from Siemens in the 1990 s, by GE for the Performix ${ }^{\circledR}$ CT tube series and by Varian, now Varex, for the MCS 70xx CT tube series.

Still, the rotor life of ball bearing tubes is limited to several hundred hours rotation time. It is therefore essential to stop the rotation after each exposure. As aforementioned, Fig. 28 shows the focal spot track of a rotating anode with its typical erosion pattern from thermal cycling. 


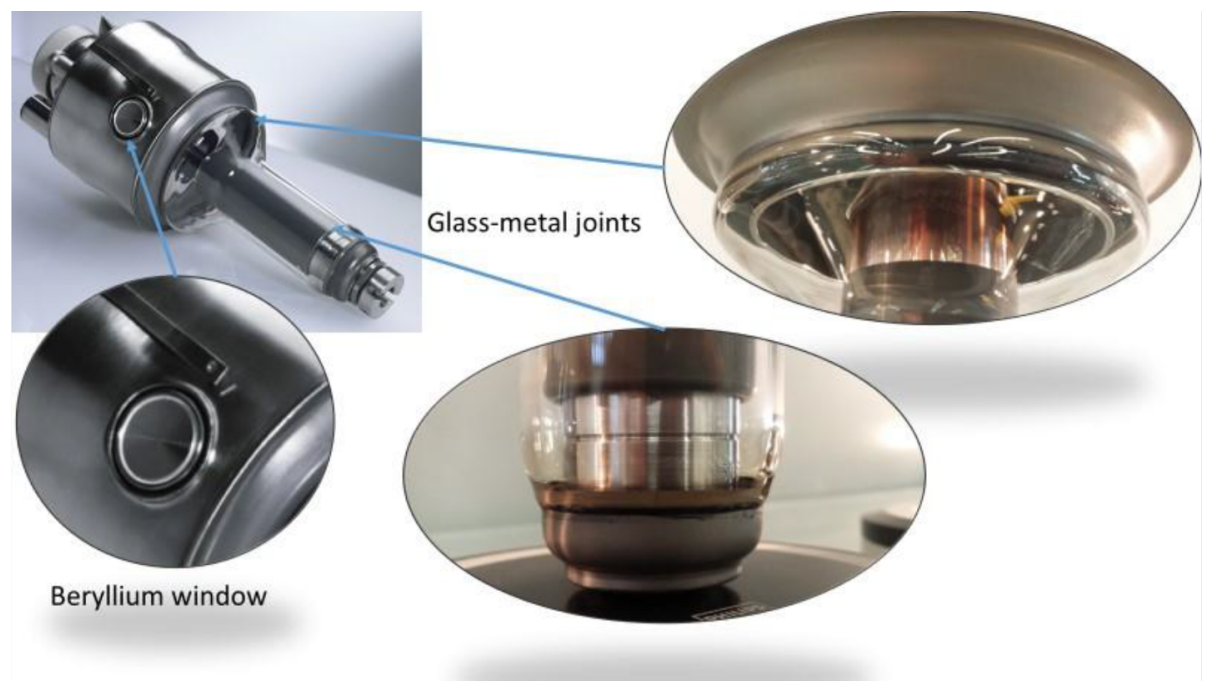

Fig. 50. Philips metal center section tube technology with steel frame, alumina coated beryllium X-ray window and glass-metal joints.

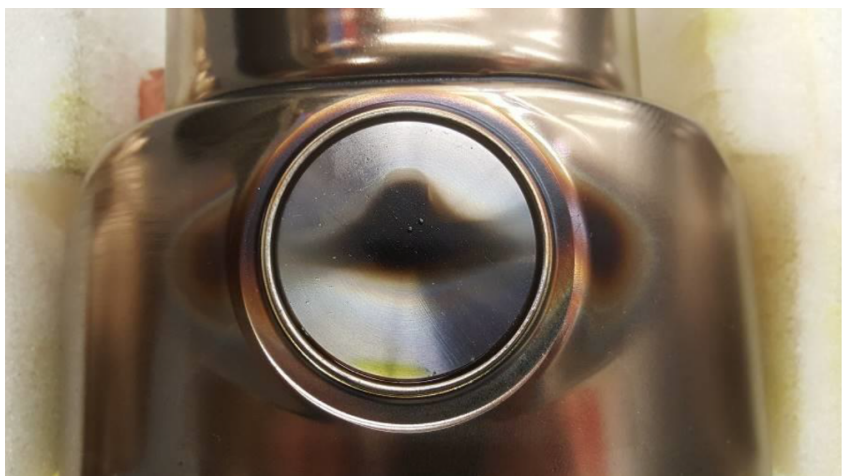

Fig. 51. Carbonized beryllium X-ray window after impact of electrons backscattered from the focal spot of a bi-polar angiography tube.
Two melting marks indicate that the tube was damaged by a failure of the rotation system. As an alternative, major vendors, Philips, Siemens, and GE tried magnetic bearings, but never commercialized it.

As already experienced by Bouwers from Philips during introduction of the first rotating anode tube, another challenge of all ball and magnetic bearing based concepts is the residual enthalpy, which remains in the anode when the temperature drops and the visible glow of the anode, as seen in Fig. 25, ceases after exposure. In 1989 Philips returned to the roots of Bouwers and introduced a gallium-indium-tin lubricated spiral groove bearing to keep the rotor cool. Rotating and stationary target tubes, so to speak, married again. The heat conducting liquid metal lubricant allows combining the benefits of great heat conduction of stationary anodes and its flat characteristics of heat dissipation, which is proportional to the temperature difference with ambient, and heat radiation. The invention of the liquid metal bearing

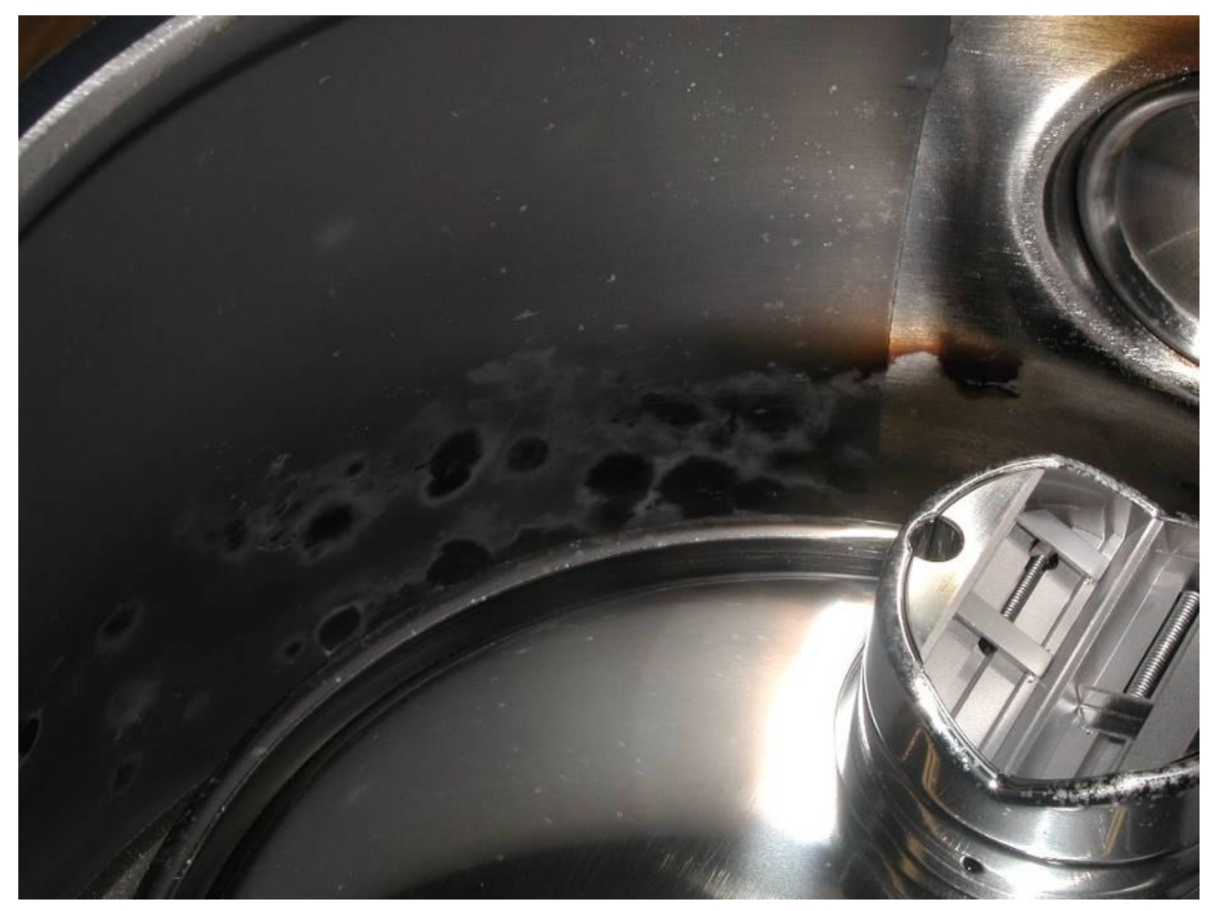

Fig. 52. Philips metal center section tube technology with steel frame, alumina coated beryllium X-ray window and glass-metal joints. 


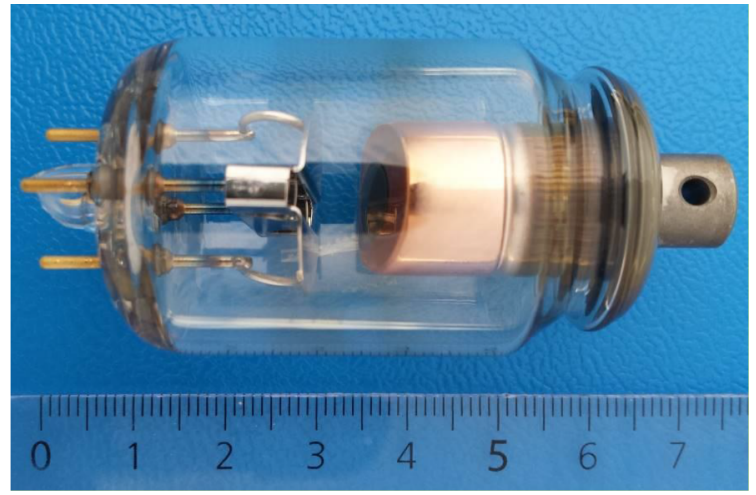

Fig. 53. Philips dental tube FO12 for the Oralix ${ }^{\mathrm{TM}}$ tube head, shown in Fig. 54, and centimeter ruler.

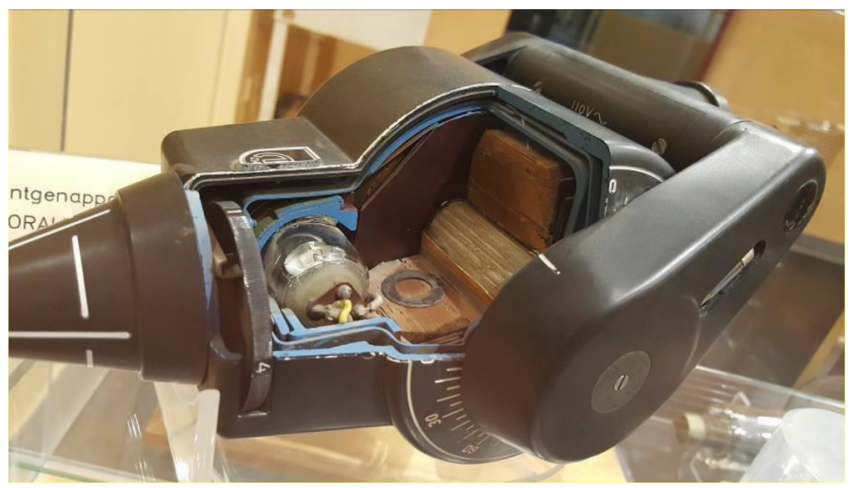

Fig. 54. Cut-out of a Philips Oralix ${ }^{\mathrm{TM}}$ dental tube head. Tube current and focal spot size were stabilized with a Wehnelt electrode and self-controlled resistive biasing. (Picture taken at the Medizinhistorisches Museum Hamburg, Germany, UKE).

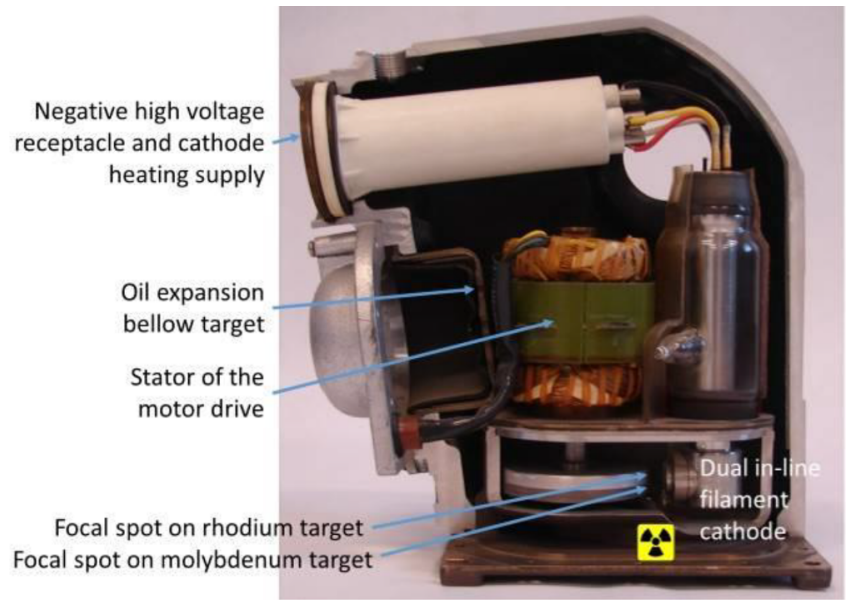

Fig. 56. GE DMR mammography tube assembly. X-ray focal spots on molybdenum and rhodium targets positioned at the perimeter of the anode. (Photo courtesy of GE).

angiography application benefitted first, before the platform concept has also been introduced for CT. Preparation times for the rotor to speed up could be skipped all together, as the liquid bearing has virtually infinite service life and spins noise-free all day. Its excellent heat conduction has simplified clinical workflow. Large anodes with high momentum of inertia can be used. Thus, X-ray output could be enhanced along with additional X-ray filtration to reduce patient dose. Fig. 43 is a cut-out picture of the first product. During development in the second half of the $1980 \mathrm{~s}$, when the author was project manager and R\&D manager of the Philips laboratory in Hamburg, Germany, the team was initially all frustrated. Testing of the first prototype tube turned out impossible. It produced a low-voltage Paschen discharge instead of Xrays. The nested liquid bearing was soaked with gas and spilled it into

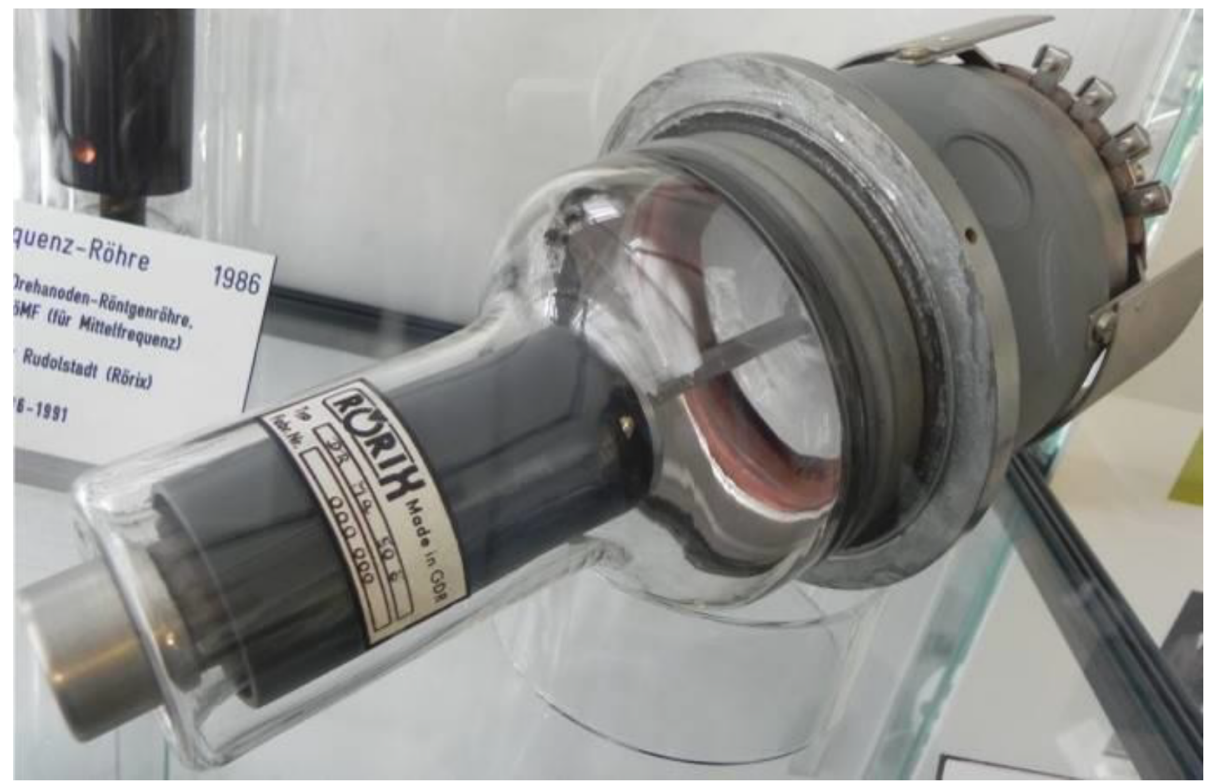

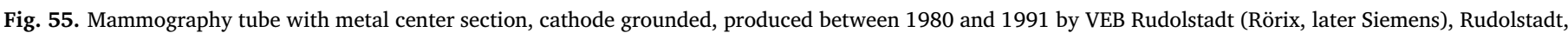
GDR. (Photo taken in the Siemens X-ray tube museum Rudolstadt, Germany).

for X-ray tubes dates to the $1970 \mathrm{~s}$ in the Philips Research laboratory in Eindhoven, The Netherlands. Its market introduction in the Maximus Rotalix Ceramic ${ }^{\mathrm{TM}}$ tube (MRC) in 1989 was a quantum leap, see [4] and has now been employed by the major tube manufacturers. Fig. 42 shows the assembly process of its bearing system. Cardiology and the tube envelope. Eventually, all such problems could be solved. The MRC ${ }^{\mathrm{TM}}$ platform has greatly improved durability and continues to be the basis of new developments. Toshiba (Canon), Siemens, GE and now Varex followed. 


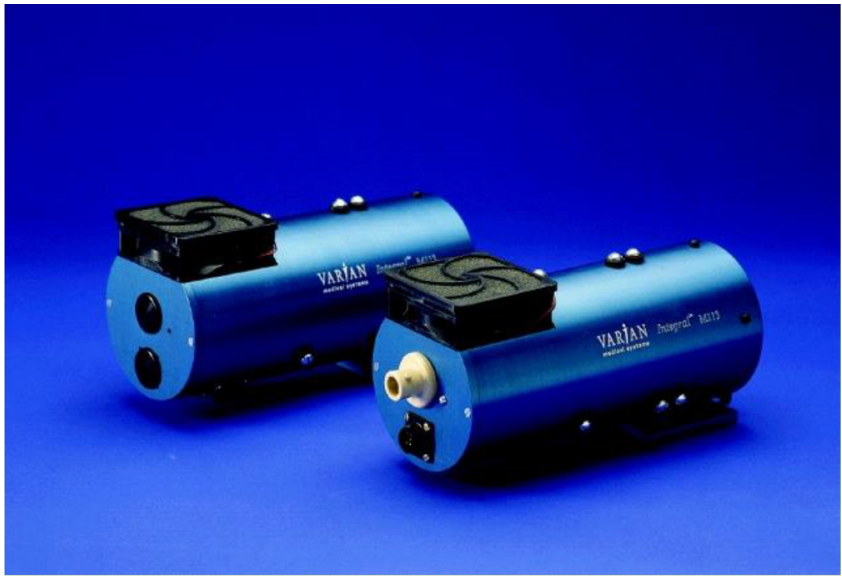

Fig. 57. The first tube produced by Varian, Salt Lake City, UT, USA (later Varex), the mammography tube B113 with metal center section, cathode grounded. (Picture courtesy of Varex).

\subsection{Tube frame}

\subsubsection{Glass}

Glass envelopes have remained standard for low and medium performance diagnostic tubes, see Fig. 44. Fig. 45 is a close-up picture of the X-ray window portion of a conventional glass tube for radiography and fluoroscopy. An aperture proximal to the focal spot prevents off focal radiation from entering the used beam. The X-ray window comprises the required beam filtering, as discussed in Chapter 1. Issues with glass insulation arise from the ill-controllable charging by electron and ion impact and from coating by metal from the thermionic cathode or from the anode. Fig. 46 illustrates the blue glow of the glass wall caused by electron and ion impact at the beginning of an exhaust procedure. Some vendors introduced roughened ("frosted") glass to hamper charge transfer. Fig. 47 shows a CT tube from Dunlee, a Philips subsidiary. A special assembly for surgery C-arm systems manufactured by Varian (now Varex), which comprises a glass tube, is shown in Fig. 48. a)

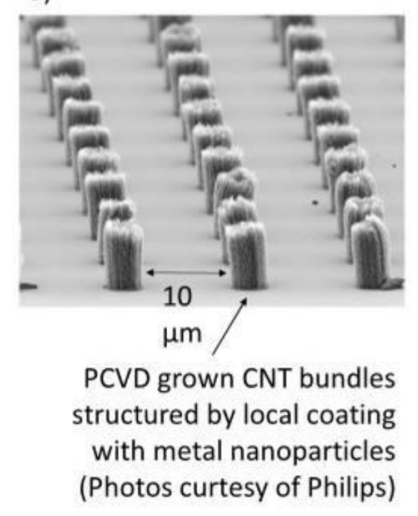

b)

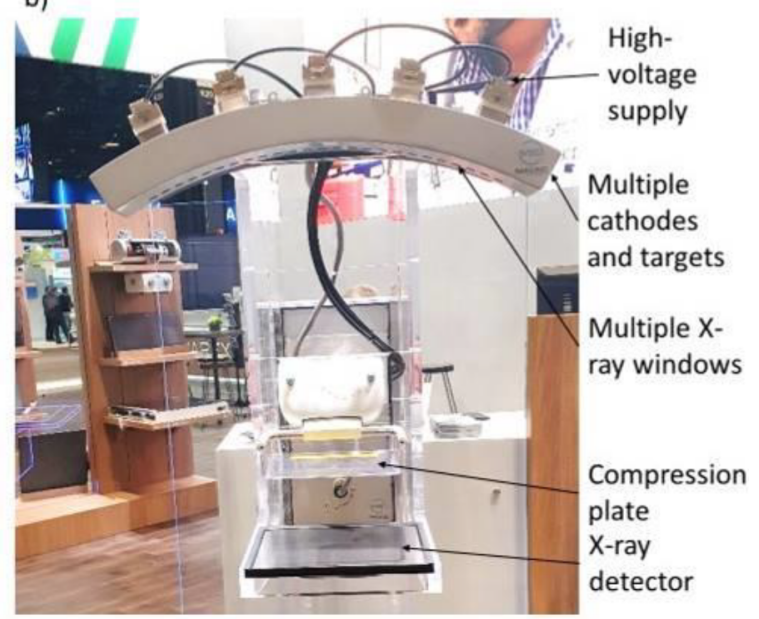

Fig. 58. (a) Bundles of carbon nano tubes as electron field emitters, grown by a catalytic CVD process (Photo courtesy of Philips). (b) Prototype of a tube with multiple field emitting cathodes and multiple anodes for tomosynthesis in mammography (VEC imaging).

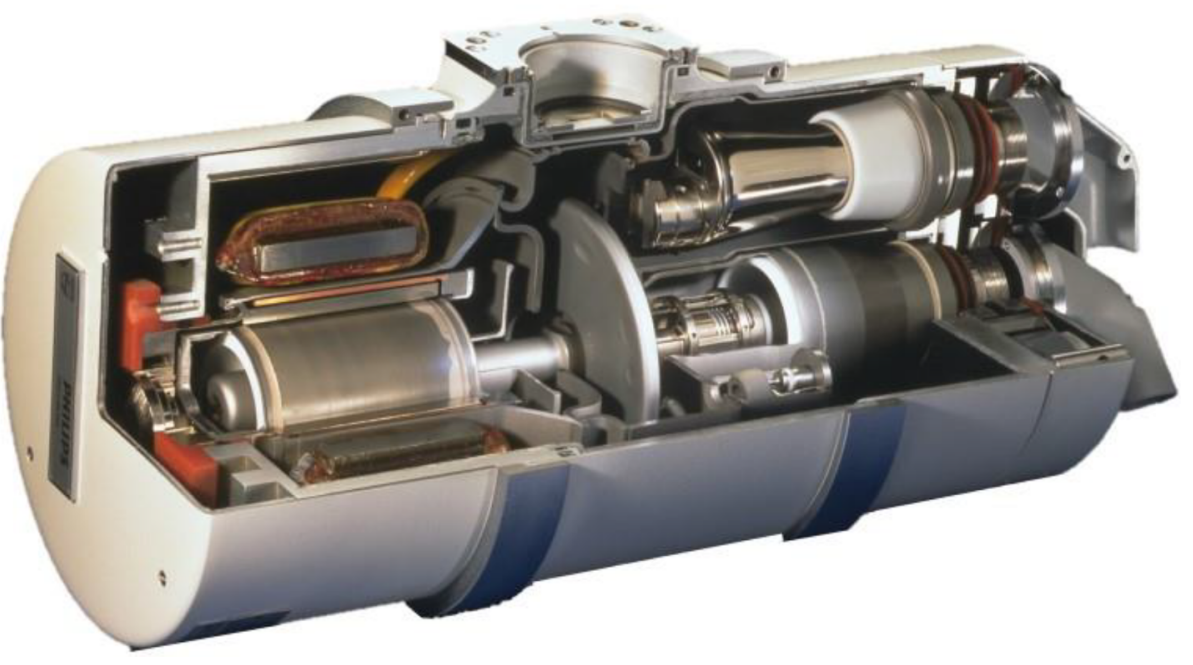

Fig. 59. First diagnostic all metal-ceramics rotating anode tube, introduced in 1980 by Philips, pioneering all later high performance tubes of major vendors. This $\mathrm{SRC}^{\mathrm{TM}}$ tube series featured a large high temperature Trinodex ${ }^{\mathrm{TM}}$ anode, very compact design, scattered electron trap, rotating anode insulator for minimal motor air-gap (short start-up time), silver-coated straddle ball bearing system with radial leaf spring suspension and axial spring pre-load for smooth operation. 
a)
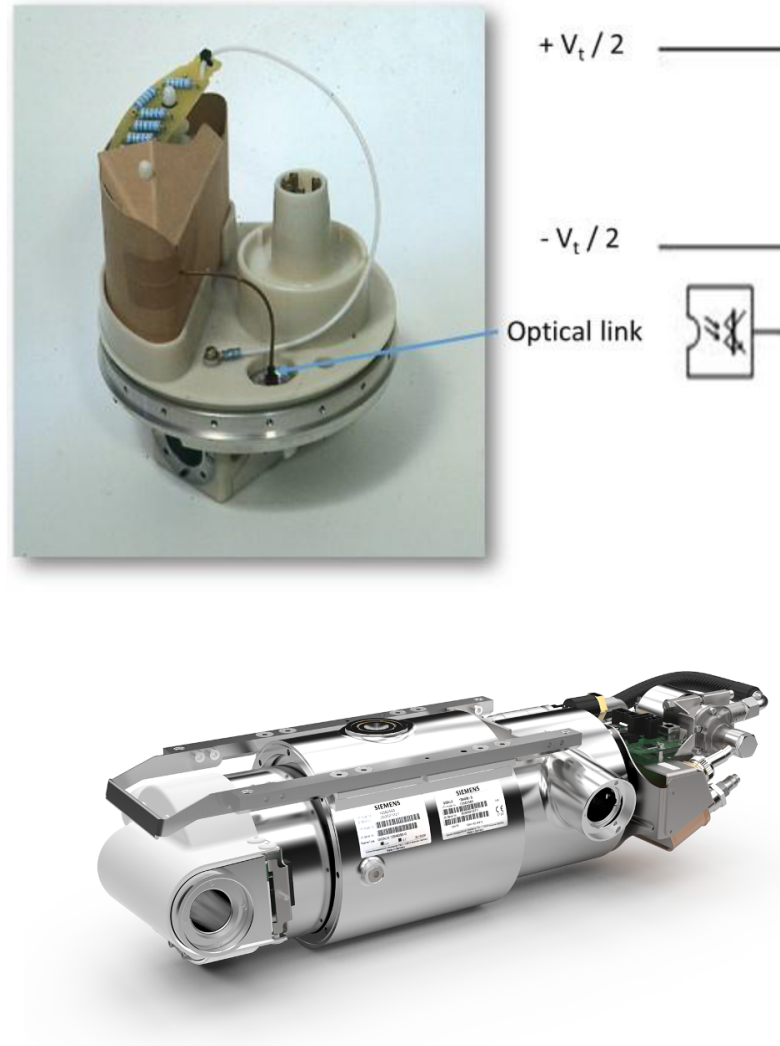

Fig. 61. Siemens angiography tube of the Gigalix ${ }^{\mathrm{TM}}$ series, launched 2013, with grid switchable flat electron emitter and liquid bearing. (Picture courtesy of Siemens-Healthineers, Gigalix, is a registered trademark of Siemens Healthcare $\mathrm{GmbH})$. (b)

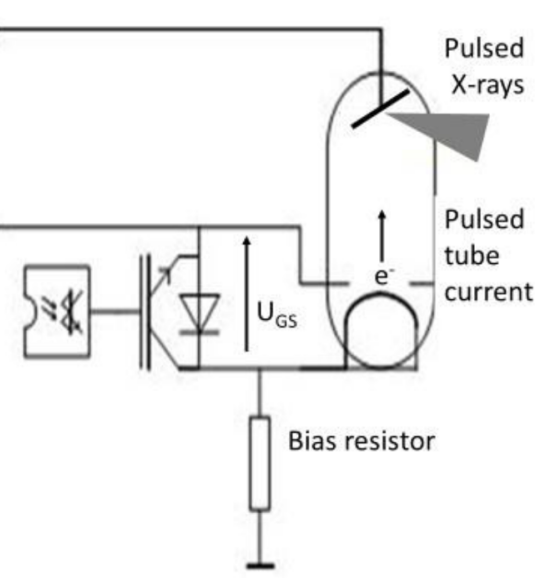

Fig. 60. (a) Grid switching electronics for Philips angiography tubes, integrated in the tube housing assembly of the MRC ${ }^{\mathrm{TM}}$ tube line, see Fig. 28. (b) Electric schematics: The tube voltage remains unchanged when, upon an optical signal, the tube current is stalled by applying a negative voltage $U_{\mathrm{GS}}$ of several kilovolts between isolated cathode head and tungsten emitter. As the spectrum does not change, this "gridding" avoids unwanted soft photons during pulsing of the X-ray flux. (a)
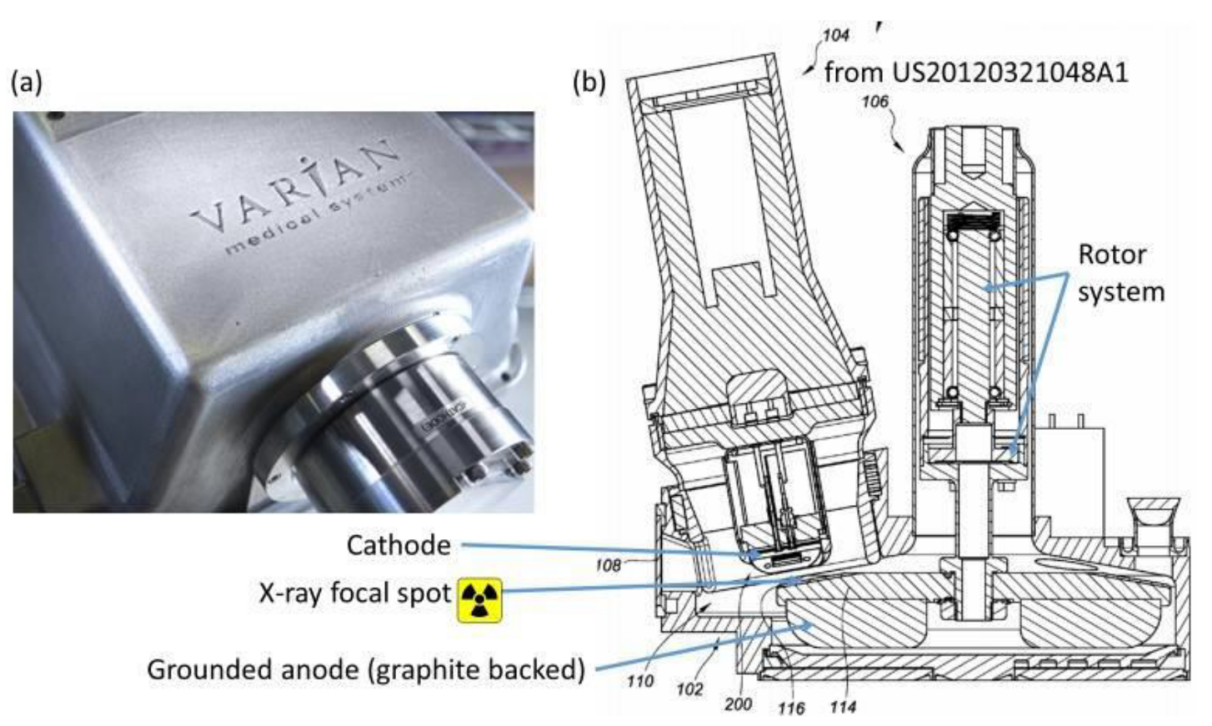

beryllium X-ray window of the Philips Super Rotalix Metal ${ }^{\mathrm{TM}}$ tube series, launched in the late $1970 \mathrm{~s}$. As the metal center section of a bipolar tube is bombarded by scattered electrons from the focal spot, thermal management of the X-ray window requires special attention. Fig. 51 depicts the thermal fingerprint at the X-ray port of bi-polar angiography tube. It shows layers of cracked oil where temperatures exceeded ca. $200{ }^{\circ} \mathrm{C}$ during operation.

In the $1950 \mathrm{~s}$, glass tubes for non-destructive testing had become available for tube voltages of more than $250 \mathrm{kV}$. Assemblies were bulky and immobile. Starting in the late 1970 s, Philips Hamburg, Germany succeeded replacing glass for high performance stationary anode tubes by compact metal frames with ceramics insulators, see [27]. A cut-out model of the first metal-ceramics tube on the market, the Philips Super Rotalix Ceramic SRC ${ }^{\mathrm{TM}} 120$ 0612, is shown in Fig. 59. Prototype tubes caused severe problems by surface flashover and puncture of the

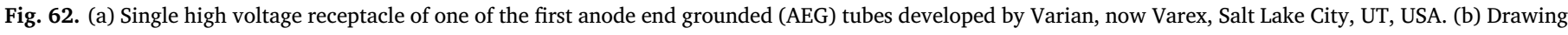
of an AEG tube from patent application US20120321048A1. (Picture (a) courtesy of Varex).

\subsubsection{Metal center section}

Bouwers from Philips had already implemented a metal center section in a stationary anode tube Metalix ${ }^{\mathrm{TM}}$ in the $1920 \mathrm{~s}$, and re-used this X-ray shielding and protection technology for the first rotating anode tube Rotalix ${ }^{\mathrm{TM}}$ in 1929, as discussed before, see Fig. 18 (d) and Fig. 18 (e) above. Fig. 49 shows a GE tube MX-125 for angiography from 1972; Fig. 50 illustrates the details of glass-metal joints and the ceramics insulators when high tube currents were applied, even at moderate high voltage. Vacuum ultraviolet radiation, X-rays, ions, and scattered electrons destabilized the insulation. Proper shielding of electrical triple points, improved processing and better ceramics solved these issues. Typical traces of tube arcing in a metal center section tube are visible in Fig. 52. Despite of these rough conditions the material survives. Eventually, a novel robust technology emerged, well received, 


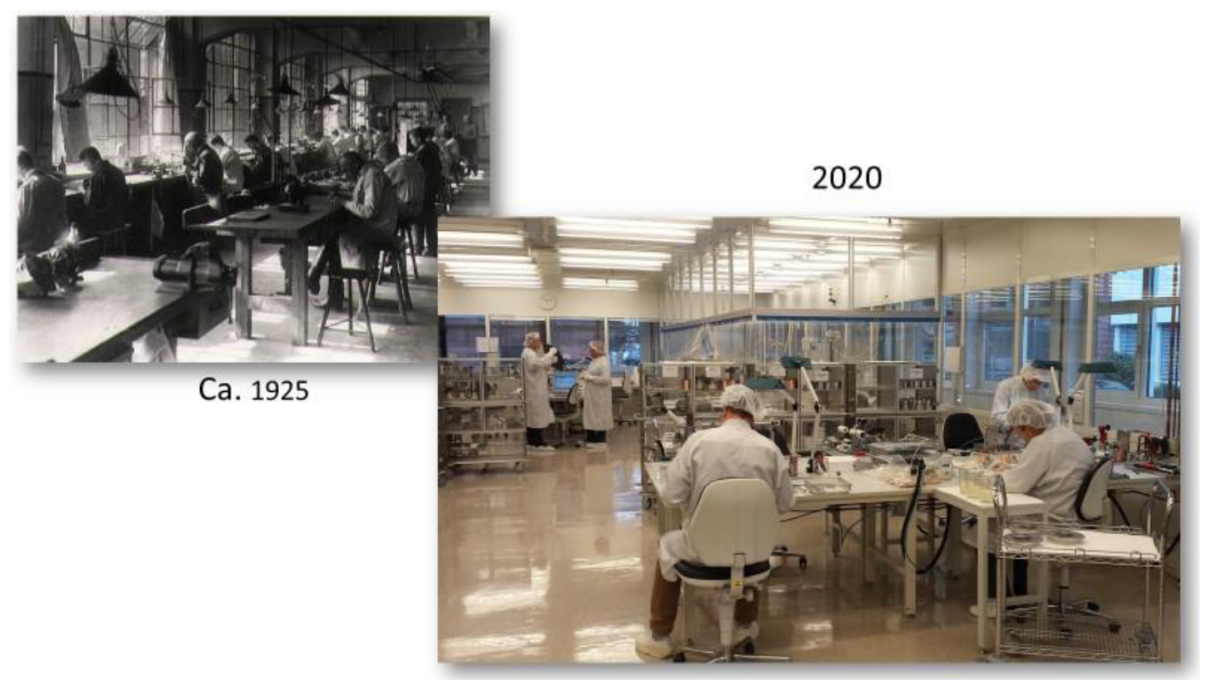

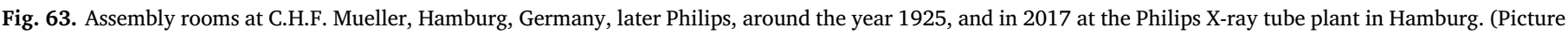
courtesy of Philips).

notably in the US market.

In addition to the tube housing, metal center section technology also enables a high degree of recycling of vacuum components. The SRC ${ }^{\mathrm{TM}}$ tube and its successors, notably the Philips $\mathrm{MRC}^{\mathrm{TM}}$ tube series with liquid bearing, see Fig. 43, can be disassembled and re-assembled multiple times, while worn-out components like cathodes are scrapped. The Philips SRC tube marked the beginning of recyclable metal ceramics technology in medical imaging, which has later been introduced by all major vendors of high-performance tubes.

\section{Special applications and features}

\subsection{Dental $X$-ray}

The short distance between source and image receiver allows for low tube voltages and low power ratings in single-shot dental application. Fig. 53 depicts a simple stationary tube for $50 \mathrm{kV}$ tube voltage. Fig. 54 shows a cut-off picture of a Philips Oralix ${ }^{\mathrm{TM}}$ dental tube housing assembly including high voltage transformer and rectifying circuitry. The tube comprised a kind of Wehnelt electrode, which consists of a cathode plate which is isolated from the electron emitter coil. Selfcontrolled resistive biasing stabilized tube current and focal spot size.

\subsection{Mammography}

The use of metal center sections and brazed-in X-ray windows from beryllium, helped reducing X-ray attenuation and filtration for the soft radiation required for mammography application. Beryllium, used in a similar way as early Lindemann glass (see Chapter 2), features great heat conduction and there is no risk of electrical puncture. Dust and oxides are poisonous, however. Thus, production and recycling must be well organized. Fig. 55 depicts a cathode-grounded mammography tube, produced between 1980 and 1991 by VEB Röhrenwerk, Rudolstadt (Rörix), GDR, now Siemens. Although glass technology served well from a thermal and high voltage perspective for tube voltages between $18 \mathrm{kV}$ and $50 \mathrm{kV}$, a standard glass frame causes undesired hard $\mathrm{X}$-ray filtration. In the beginning of mammography glass tubes were indeed in use. But it became clear very soon, that softer radiation was required for an optimal contrast-to-noise ratio in the images of soft tissue with potentially embedded tiny filaments of calcifications. First, $\mathrm{X}$-ray windows from beryllium were attached to the glass frame, and molybdenum or rhodium k-edge filters added. Fig. 55 visualizes an improvement. Except for the necessary insulation, the tube frame was metallic with a brazed-in beryllium window. Grounding of the cathode simplified "biasing" for focal spot width control. CGR, France, a GE company, introduced an anode grounded solution in 1992. Fig. 56 shows a cut-out model of the tube housing assembly with the Statorix 52.2 (DMR) tube. Two comparatively large focal tracks, coated with rhodium and molybdenum, positioned on the perimeter of the anode allowed for high tube currents. The concept helps minimizing off-focal radiation and allows for convenient patient positioning.

According to the records of Varex, Salt Lake City, UT, USA, mammography tubes were the first X-ray sources which the predecessor company Varian produced, see Fig. 57.

Fig. 58 (b) depicts the prototype of a mammography tomosynthesis system, disclosed in 2019 by VEC imaging in cooperation with Varex. Multiple X-ray sources are sequentially activated by switching field emitting cathodes. A similar system had been developed and clinically tested before by the company Xintek in cooperation with the University of North Carolina at Chapel Hill, USA, see [22,35,36]. Field emitters of this sample were structured by printing technique. Other than that, Fig. 58 (a) shows an example of bundles of carbon nano tubes grown at Philips by modern plasma enhanced chemical vapor deposition. The macro-structure is imprinted by a distribution of nanoparticles which act as catalyzer for the growth of carbon fibers in a plasma-enhanced chemical deposition process.

Field emission is extremely sensitive to the electric field at the emitter surface, see[16-17,40]. From an X-ray control standpoint, field emitting cathodes resemble low-pressure gas discharges as used in the early days of X-ray generation. To remedy the disadvantage of entanglement of contrast and brightness of an image, control grids in front of the emitters are essential to preserve the great achievement of Lilienfeld and Coolidge in 1913.

\subsection{Angiography/cardiology application}

Increasing fluoroscopy application in the $1970 \mathrm{~s}$, and the necessity to record sequences of images in cardiology and angiography work exceeded the capability of the available glass tubes. The introduction of a graphite target by GE, see Fig. 31, reduced the rotor starting time and improved the durability of the ball bearings during long runs of angiographic procedures.

Philips improved the situation by introducing the full metal ceramic tube Super Rotalix Ceramic ${ }^{\mathrm{TM}}$ tube SRC 120 0610, see Fig. 59. A relatively large anode was suspended on a radially spring supported straddle bearing system with a rotating ceramics insulator to maximize 
the efficiency of the motor. High patient and staff dose associated with angiographic diagnostics and therapy on site demanded for counter measures. Enhancing X-ray filtration narrows the spectrum and reduces harmful skin dose. A powerful tube like the $\mathrm{MRC}^{\mathrm{TM}}$ is required to benefit from hard filtration without introducing image noise or wait times for cooling.

Compared with previous high voltage switching and charging and discharging the cables for each pulse the introduction of a tube current switch was an improvement. Already in 1937, Siemens had introduced grid control of the electron emission, like the current modulation in radio tubes. Philips introduced grid switching for angiography and cardiology tubes of the MRC ${ }^{\mathrm{TM}}$ series in 1992, in 1996 with the MRM ${ }^{\mathrm{TM}}$ tube series and later also with $\mathrm{SRM}^{\mathrm{TM}}$ metal center section tubes in general radiography/fluoroscopy systems as grid-controlled fluoroscopy GCF ${ }^{\mathrm{TM}}$. Fig. 60 shows the grid switch electronics, which Philips has been integrating in similar form into the tube housing assembly of the MRC tube series for angiography and cardiology from 1993 onwards. Other manufacturers have at least temporarily realized this feature with bias supply from the high voltage generator, like Toshiba, and Siemens with early Megalix ${ }^{\mathrm{TM}}$ tubes and the latest angiography tube series Gigalix ${ }^{\mathrm{TM}}$. This tube, shown in Fig. 61, comes with "gridded" flat electron emitters and a liquid bearing.

\subsection{Compactness in radiography}

The quest for compactness, versatility and scalability has inspired Varex, Salt Lake City, UT, USA to offer a series of "anode end grounded" (AEG) tubes since 2010. Fig. 62 shows the drawing of a mammography AEG tube. Rotating anode and X-ray focal spot are on ground potential, positioned proximal to one end of the tube housing assembly. The cathode is charged negatively. A stationary electron trap collects backscattered electrons from the focal spot and reduces the power supplied to the rotating anode. The small insulating gap enhances the efficiency of the motor drive up. Its magnetic stator is positioned parallel with the cathode.

\section{Production}

Electrical stability and mechanical precision of X-ray tubes under high voltage of up to $150 \mathrm{kV}$ and temperatures of up to $3300{ }^{\circ} \mathrm{C}$ in the focal spot can only be maintained by well-controlled and clean production. Over decades, production yield at major manufacturers were in the range of $50 \%$ to $90 \%$. Meanwhile, stringent process improvement and high-quality material supply, rugged design, and high investment in production technology has typically cut scrap rates by at least an order of magnitude. Fig. 63 gives a glimpse of the evolution of production environment over nearly a century.

\section{Epilog}

This overview may end citing one of the eyewitnesses and pioneers of the early days of X-rays, who, as many others, sacrificed his life for it, Prof. Hermann Gocht, see [23], introduction, pg. 10 and 11:

"Perhaps some researchers started their first experiments under happier auspices in those days than we did; maybe the reader is also wondering why I am telling this so long and broad. I am happy to accept this reproachful question and answer: It is precisely this initial effort, this struggle with technical difficulties, this savoring of the simplest mistakes that have made us even more familiar with the devices and their proper use. ... Hard was that time, but beautiful.".

The development goes on.

\section{Declaration of Competing Interest}

The author declares that he has no known competing financial interests or personal relationships that could have appeared to influence the work reported in this paper.

\section{References}

[1] Albers-Schönberg. (1913). Die Röntgentechnik (The X-ray technology) (H.-E. Albers-Schönberg, B. Walter, F. Hauptmeyer, Drüner, \& F. M. Grödel (eds.); 4th ed.). Lucas Gräfe \& Sillem (Edmund Sillem).

[2] Assmus A. Early History of X Rays. Beam Line 1995;25(2):10-24.

[3] Behling R, Grüner F. Diagnostic X-ray sources-present and future. Nucl Instrum Methods Phys Res, Sect A 2018;878(11):50-7. https://doi.org/10.1016/j.nima. 2017.05.034.

[4] Behling Rolf. The MRC 200: A new high-output X-ray tube. MedicaMundi 1990;35(1).

[5] Behling Rolf. Modern Diagnostic X-Ray Sources - Technology-ManufacturingReliability. (1st ed.). CRC Press - Taylor and Francis Group LLC.; 2016.

[6] Behling Rolf. Performance and Pitfalls of Diagnostic X-Ray Sources : an Overview. Medical Physics International 2016;4(2):107-14.

[7] Behling, Rolf. (2018a). History of the X-Ray Tube. In P. Russo (Ed.), Handbook of XRay Imaging: Physics and Technology (1st ed., Vol. 1, pp. 139-154). CRC Press Taylor and Francis. https://www.crcpress.com/Handbook-of-X-ray-ImagingPhysics-and-Technology/Russo/p/book/9781498741521.

[8] Behling Rolf. X-ray tubes development. MPI Journal - Special Isssue - History of Medical Physics 2018;1:8-55.

[9] Behling Rolf. Modern Diagnostic X-Ray Sources - Technology-ManufacturingReliability (in print). 2nd ed. Taylor and Francis LLC: CRC Press; 2021.

[10] Bouwers, A. (Philips E. N. (1937). X-ray tube having a rotary anode (Patent No. 2081789). United States Patent Office.

[11] Breton JL. Rayons Cathodiques et Rayons X. Bernard et Cie: Librairie E; 1897.

[12] Clark, G. L. (1932). Applied X-rays (2nd ed.). McGraw-Hill book company, Inc.

[13] Clebsch. (1872). Zum Gedächtnis an Julius Plücker. (In commemoration of Julius Pluecker.). Abandlungen Der Königlichen Gesellschaft Der Wissenschaften in Göttingen, 16, 1-40.

[14] Doerfel, G. (2006). Julius Edgar Lilienfeld und William David Coolidge - Their X-ray tubes and their conflicts. [Julius Edgar Lilienfeld und William David Coolidge-Ihre Röntgenröhren und ihre Konflikte], in German. http://www.mpiwg-berlin.mpg.de/ Preprints/P315.PDF.

[15] Dyson, N. A. (1990). X-rays in Atomic and Nuclear Physics (2nd ed.). Cambridge University Press. https://doi.org/10.1017/CBO9780511470806.

[16] Forbes RG. Exact analysis of surface field reduction due to field-emitted vacuum space charge, in parallel-plane geometry, using simple dimensionless equations. J Appl Phys 2008;104(084303):1-10. https://doi.org/10.1063/1.2996005.

[17] Forbes RG. Field electron emissino theory for vacuum electronics. ITG International Vacuum. Electronics Workshop, September; 2018.

[18] Frühling S, Vogel H. Hamburg's X-ray pioneers (Die Röntgenpioniere Hamburgs), in German. Landsberg, Germany: Ecomed Verlagsgesellschft AG \& Co KG; 1995.

[19] Gaertner G. Historical development and future trends of vacuum electronics. Journal of Vacuum Science \& Technology B: Microelectronics and Nanometer Structures 2012;30(6):060801https://doi.org/10.1116/1.4747705.

[20] Gaertner, G. (2020). Modern Developments in Vacuum Electron Sources (in print) (G. Gaertner (ed.)). Springer International Publishing AG.

[21] Gaertner G, Koops HWP. Vacuum electron sources and their materials and technologies. Vacuum Electronics: Components and Devices 2008;429-481. https://doi. org/10.1007/978-3-540-71929-8 10.

[22] Gidcumb E, Gao B, Shan J, Inscoe C, Lu J, Zhou O. Carbon nanotube electron field emitters for x-ray imaging of human breast cancer. Nanotechnology 2014;25(24):245704https://doi.org/10.1088/0957-4484/25/24/245704.

[23] Gocht H. Handbuch der Röntgenlehre. (5th ed.). Ferdinand Enke; 1918.

[24] Gocht, Hermann. (1914). Die Gründung des chirurgischen Röntgeninstitutes am Allgemeinen Krankenhause Hamburg-Eppendorf (The establishment of the surgical X-ray institute at the General Hospital Hamburg-Eppendorf). In P. v. Bruhns (Ed.), Beiträge zur klinischen Chirurgie (92nd ed., pp. 776-783). Verlag der Laupp'schen Buchhandlung.

[25] Grigg ERN. The trail of the invisible light : from X-Strahlen to radio(bio)logy. Springfield: Charles C. Thomas; 1965. p. 1965.

[26] Gunderman RB. X-Ray vision: The evolution of medical imaging and its human implications. Oxford University Press; 2012.

[27] Hartl, W. (Philips), Peter, D. (Philips), \& Reiber, K. (Philips). (1983). A Metal Ceramic Diagnostic X-Ray Tube. Philips Tech. Rev., 41(4), 126-134.

[28] Hirsch, I. S. (1927). Robert H. Machlett. Radiology, 8(254).

[29] Hofman JAM. How Philips contributed to the evolution of medical X-ray technology over more than one hundred years. Eindhoven, The Netherlands: Philips Glo Koninklijke Philips Electronics N.V; 2010.

[30] Hofman JAM. The art of medical imaging: Philips and the evolution of medical Xray technology. MedicaMundi 2010;54(5).

[31] Kaye GWC. X rays. (3rd ed.). Co., London: Longmans, Green and; 1918.

[32] Kemerink GJ, Van Engelshoven JMA, Simon KJ. Early X-ray workers: an effort to assess their numbers, risk, and most common (skin) affliction. Insights Imaging 2016;7:275-82. https://doi.org/10.1007/s13244-015-0457-2.

[33] Kemerink GJ, Kütterer G, Kicken PJ, van Engelshoven JMA, Simon KJ, Wildberger JE. The skin dose of pelvic radiographs since 1896. Insights into. Imaging 2019;10(1). https://doi.org/10.1186/s13244-019-0710-1.

[34] Kiuntke F. On target with Roentgen - The Roentgen tube plant of the Siemens AG in Rudolstadt 1919-1939 [Mit Röntgen auf Kurs - Das Röntgenröhrenwerk der 
Siemens AG in Rudolstadt 1919-1939 in German; 2009.

[35] Koh AL, Gidcumb E, Zhou O, Sinclair R. Oxidation of Carbon Nanotubes in an Ionizing Environment. Nano Lett 2016;16(2):856-63. https://doi.org/10.1021/acs. nanolett.5b03035.

[36] Koh AL, Gidcumb E, Zhou O, Sinclair R. The dissipation of field emitting carbon nanotubes in an oxygen environment as revealed by in situ transmission electron microscopy. Nanoscale 2016. https://doi.org/10.1039/C6NR06231H.

[37] Kuetterer G. Oh, if there were means to make humans transparent like a jelly-fish! [Ach, wenn es doch ein Mittle gäbe, den Menschen durchsichtig zu machen wie eine Qualle!], in German. Books on demand GmbH; 2005.

[38] Kuetterer Gerhard. Lexikon der röntgenologischen Technik 1895 bis 1925 von Abdeckzunge bis Zylinderblende. (1st ed.). Books on Demand; 2017.

[39] Lenard P. Annalen der Physik und Chemie. Physik Und Chemie 1894;51(2):225-67. https://doi.org/10.1007/978-3-662-28327-1.

[40] Lepetit B. Electronic field emission models beyond the Fowler-Nordheim one Electronic field emission models beyond the Fowler-Nordheim one. J Appl Phys 2017;122(215105).

[41] Luis M, Nascimento F. Brief history of X-ray tube patents. World Patent Inf 2014;37:48-53. https://doi.org/10.1016/j.wpi.2014.02.008.

[42] Meggitt, G. (2010). Taming the rays: A history of radiation and protection. Lulu. com.

[43] Mould RF. X-rays in 1896-1897. Nowotwory Journal of Oncology - Histora Medicinae 2007;61(6):100-9.
[44] Pavlinsky GV. Fundamentals of X-Ray Physics. Cambridge, UK: Cambridge International Science Publishing Ltd; 2008.

[45] Plücker. (1858). Ueber die Einwirkung des Magneten auf die elektrischen Entladungen in verdünnten Gasen. (The influence of a magnet on the electrical discharges in diluted gases.). Annalen Der Physik, 179(1), 88-106. https://doi.org/ 10.1002/andp.18581790106.

[46] Roentgen, C. W. (1895). Über eine neue Art von Strahlen. In Sitzungsberichte der Würzburger Physik.-medic. Gesellschaft" 1895 and Annalen der Physik, Band 64, 1, 1898. https://doi.org/10.1007/978-3-662-00956-72 2.

[47] Schardt P, Deuringer J, Freudenberger J, Hell E, Knüpfer W, Mattern D, et al. New $\mathrm{x}$-ray tube performance in computed tomography by introducing the rotating envelope tube technology. Med Phys 2004;31(9):2699. https://doi.org/10.1118/1. 1783552.

[48] Stamer W. 100 years of X-ray tubes; from the simple X-ray tube to high performance rotating anode tubes. A recap of 100 years X-ray tube trechnology (100 Jahre Röntgenröhren, vom einfachen Röntgenrohr zur Hochleistungs-Drehanodenröhre Ein Rückblick auf 100 Jahre. Philips Medical Systems; 1995.

[49] W. Watson and Sons. Watson \& Sons, Ltd, L. (1916). W. Watson \& Sons, Ltd.: X-ray and electro-mechanical apparatus, price list no. 17 E (17 E (1916). W. Watson 6 Sons, Ltd.

[50] Walden TL. The first radiation accident in America: a centennial account of the $\mathrm{x}$ ray photograph made in 1890. Radiology 1991;181(3):635-9. https://doi.org/10. 1148/radiology.181.3.1947073. 